IZA DP No. 9958

Dynamic Effects of Educational Assortative Mating on Labor Supply

Rania Gihleb

Osnat Lifshitz

May 2016 


\title{
Dynamic Effects of Educational Assortative Mating on Labor Supply
}

\author{
Rania Gihleb \\ University of Pittsburgh \\ and IZA
}

Osnat Lifshitz

Academic College of Tel-Aviv Yafo
Discussion Paper No. 9958
May 2016

\author{
IZA \\ P.O. Box 7240 \\ 53072 Bonn \\ Germany \\ Phone: +49-228-3894-0 \\ Fax: +49-228-3894-180 \\ E-mail: iza@iza.org
}

\begin{abstract}
Any opinions expressed here are those of the author(s) and not those of IZA. Research published in this series may include views on policy, but the institute itself takes no institutional policy positions. The IZA research network is committed to the IZA Guiding Principles of Research Integrity.

The Institute for the Study of Labor (IZA) in Bonn is a local and virtual international research center and a place of communication between science, politics and business. IZA is an independent nonprofit organization supported by Deutsche Post Foundation. The center is associated with the University of Bonn and offers a stimulating research environment through its international network, workshops and conferences, data service, project support, research visits and doctoral program. IZA engages in (i) original and internationally competitive research in all fields of labor economics, (ii) development of policy concepts, and (iii) dissemination of research results and concepts to the interested public.
\end{abstract}

IZA Discussion Papers often represent preliminary work and are circulated to encourage discussion. Citation of such a paper should account for its provisional character. A revised version may be available directly from the author. 
IZA Discussion Paper No. 9958

May 2016

\section{ABSTRACT}

\section{Dynamic Effects of Educational Assortative Mating on Labor Supply*}

In $30 \%$ of young American couples the wife is more educated than the husband. Those women are characterized by a substantially higher employment (all else equal), which in turn amplifies income inequality across couples. Using NLSY79, we formulate and structurally estimate a dynamic life-cycle model of endogenous marriage and labor supply decisions in a collective framework. We establish that the education gap at the time of marriage, produces dynamic effects due to human capital accumulation and implied wage growth. Inequality between couples is largely driven by the persistence in labor supply choices and only slightly affected by assortative matching.

JEL Classification: J22, J12, J24, J31

Keywords: educational assortative mating, female labor supply, human capital, inequality

Corresponding author:

Rania Gihleb

Department of Economics

University of Pittsburgh

4901 Wesley W. Posvar Hall

230 South Bouquet Street

Pittsburgh, PA 15260

USA

E-mail: gihleb@pitt.edu

\footnotetext{
* We thank Claudia Olivetti, Zvi Eckstein, Laurence Kotlikoff, Kevin Lang, and Daniele Paserman for their support and advice. We are also grateful to Raquel Fernandez and Michael Keane and to all the participants and seminar attendees at the NYC EEA 2015 Meeting, 2014 Brucchi-Luchino Conference, 2013 NASM, 2012 EALE, 2012 ESPE, Ben-Gurion University, Hebrew University, IZA, University of Haifa, University of Oxford, University of Pittsburgh, Interdisciplinary Center Herzilia, for their helpful comments and suggestions.
} 


\section{Introduction}

The past six decades have witnessed some major transformations in the employment patterns of women. For example, the employment rate of married women roughly doubled between 1965 and 2000, and the gender education gap has reversed itself (Eckstein and Nagypal, 2004; Goldin et al., 2006). Interestingly, though not unexpectedly, the reversal of the gender education gap quickly translated into a reversal of the education gap within couples (see Figure 1) in favor of wives. This phenomenon has been somewhat overlooked in previous studies of educational assortative marriage trends, which focused more on homogamy (Schwartz and Mare, 2005; Mare, 1991). The dramatic increase in the proportion of couples in which the wife is more educated than the husband from $20 \%$ in the earlier cohorts to $30 \%$ in the more recent ones is of both demographic and economic interest. It has contributed to the increase in earnings inequality among couples. ${ }^{1}$

This paper examines how the spousal education gap, i.e., the wife's relative education to that of her husband, affects married women's labor supply behavior over the life-cycle. Thus, a husband's income is an important determinant of his wife's labor supply; but it alone is not enough to explain the variation in the observed employment rates of married women by spousal education gap. The model presented here highlights the role of labor supply and wage dynamics in explaining this variation. We argue that the matching decision in the marriage market sets in motion a process whose effect on women's labor participation decisions persists over the life-cycle, due to the accumulation of human capital and the expectation of higher future wages. Earnings are then the result of the joint endogenous marriage and labor supply decisions. We use a structurally estimated model to empirically examine the joint decisions of labor market participation and marriage and the extent to which path dependence effects can generate the observed difference in employment rates

\footnotetext{
1 It has precipitated the shift of the breadwinner role from men to women, which alongside changing economic (and social) conditions, may result in less career interruptions for women. Career interruptions that may limit professional advancement is one of the supply side explanations for why there are so few women at the top of the corporate ladder (Bertrand et al., 2010).
} 
between women whose husbands have a higher level of education than they do (who will be referred to throughout the paper as "married up") and those whose husbands have a lower level of education than they do (who will be referred to as "married down").

Understanding the dynamics of labor supply behavior and the matching decisions in the marriage market is important. Couples sorting on education (positive assortative mating) may amplify earnings inequality between couples (Fernandez and Rogerson, 2001; Kremer, 1997; Schwartz and Mare, 2005). However, the correlation in spouses earnings masks the fact that its also a result of the endogenous labor supply decision that depends on the match characteristics, particularly, the spousal education gap and the persistence effects that follow. Moreover, while there is an active literature on the tax and benefit policies designed to influence labor supply behavior, the joint decision of mating and labor supply has so far been under-explored. We highlight a heterogeneity dimension that points to a differential response by women to designed policy incentives. When examining labor supply behavior through the lens of the spousal education gap it is found that when a wife's education exceeds her husband's, she is significantly more likely to be employed relative to a wife whose education is equal to or less than her husband's, as can be seen in Figure 2. What is most striking is that the gap in employment is constant and stable during a period of increasing female labor force participation (LFP). This pattern is not surprising in light of the basic Becker/Gronau model of household specialization (Becker, 1973; Gronau, 1977), in which the efficient time allocation between market work and home production depends on the wage differential between the spouses. Put differently, the higher the husband's level of education, and therefore his income, the lower the likelihood of his wife being employed ceteris paribus.

Using data from the 1965-2011 March Current Population Survey (CPS), we show that even after controlling for husband's income, a wife who married down is significantly more likely to be employed (by up to 14.5 percentage points) than one who married up. The persistent association between husband's education and wife's labor supply indicates that it 
is not only the spouses' absolute incomes that play a role but also their relative incomes. A potential concern is that this finding is the result of selection bias. That is, women who marry up tend to have unobservable characteristics that are associated with low labor force participation rates. We address this concern using data on ability, attitudes, and expectations from the National Longitudinal Study of Youth 1979 and show that it is unlikely that selection bias can explain the patterns of employment by spousal education gap. ${ }^{2}$ Interestingly, however, we find that those with the relative lower (higher) ability within an education group are matching with those from a lower (higher) education group yet with the higher (lower) relative ability within their group. While this fails to explain the LFP pattern we observe, it is compelling because it resonates with positive assortative mating on ability.

We hypothesize that the persistent association between a wife's labor market participation and the spousal education gap can be explained by path dependence and "lock-in" effects. At the time of marriage, women act on rational expectations. Thus, a low (high) expected wage differential between the spouses, which is the case when a female marries down (up), leads to a higher (lower) likelihood of employment for the wife. The interaction between the husband's education/income and his wife's labor force participation decision produces dynamic effects due to the process of human capital accumulation and the related wage growth. Employment in the current period increases the wife's work experience and leads to higher future expected wages, thus reducing the incentive to leave the labor market even when the initial incentive to work is no longer relevant.

We present a dynamic model of endogenous marriage formation (and dissolution) and labor supply, with heterogeneous (female and male) agents. In each period, an individual chooses whether to get married/divorced and whether to work. Individuals face five forms of uncertainty: employment (whether or not they receive a job offer), wages, probability of meeting a potential partner, match quality, and fertility. The probability of a job offer in the current period depends on the individual's employment status in the previous period,

\footnotetext{
${ }^{2}$ See Appendix D for additional evidence and robustness checks.
} 
thus inducing persistence in employment status over time. In the model, returns to human capital accumulation/experience are endogenous. An individual's wage is determined by his/her observed human capital (schooling and experience), as well as by ability, which is observed by the potential partner but not by the researcher.

Gains from marriage stem from the joint consumption of a public good, from the quality of the match, and from children. In each period, there is an exogenous probability that a single individual will meet a potential partner. Once a potential partner is drawn, the potential couple then draws a match quality component of the partnership. The couple then decides whether to marry or remain single and continue to search. In order to describe the decision problem faced by the couple, we use the collective household model (Chiappori, 1988, 1992) in a dynamic framework with no commitment, as in Mazzocco et al. (2007). If the couple decides to get married, their match quality random component follows a Markov process during the course of their relationship.

We estimate the dynamic model and, for comparison, also its static version, using the simulated method of moments for a sample of white females taken from the National Longitudinal Survey of Youth 1979 (NLSY79) who at least completed high school. The estimated dynamic model provides a very good fit to the data, which is also much better than the fit of the static version, and the parameter values appear to be sensible. In particular, the dynamic model replicates the pattern of marital sorting by educational attainment and the large variation in labor supply across the different education groups observed in the data.

The comparison of correlation between spouses earnings from the dynamic model with the correlation from the static model gauges the role of the persistent (dynamic) effects on womens labor supply, and in turn on earnings inequality between couples. The correlation drops from 0.107 to 0.044 , suggesting that dynamics and persistence effects play an important role in earnings inequality. In addition, imposing random matching in the dynamic model drops the correlation slightly, from 0.107 to 0.083 . This points that assortative matching plays a relatively minor role in determining earnings inequality. 
In order to assess the importance of the dynamic labor supply effects, we also consider a counterfactual economy with no wage growth and the findings support our hypothesis. Notably, if returns to experience were zero, the gap in labor force participation between women who married up and women who married down would narrow by about 45 percent.

In a back-casting exercise, we provide validation for the model. Given the estimated benchmark model, when we replace the NLSY79 cohort's educational attainment distribution with that of a cohort twenty years older, the proportion of married-down women drops by 13 percentage points relative to the baseline model, while the proportion of marriedequal women remains largely unchanged. These model predictions are comparable to those observed historically. Remarkably, the resulting changes in marital sorting patterns alone are able to explain a large proportion - 36 percent - of the observed difference in married women's employment rates between these two cohorts.

The literature analyzing married women's labor supply decisions is voluminous, and we will not attempt to fully review it here (see Blundell and MaCurdy, 1999, for a comprehensive survey of the existing literature). There is also an extensive body of literature that examines female labor force participation dynamics (see for example Eckstein and Lifshitz, 2011). Dependencies between an individual's past and current labor supply decisions are well established and date back to Ben-Porath (1967). These can be generated by positive wage-based rewards for human capital accumulated via labor market experience (Eckstein and Wolpin, 1989; Altug and Miller, 1998; Olivetti, 2006), as well as by habit persistence (Altug and Miller, 1998). However, to the best of our knowledge this is the first paper estimating a dynamic model that considers the different employment profiles associated with the spousal education gap. We show that there are substantial dynamic labor supply effects produced by the spousal education gap, which work through the accumulation of labor market experience.

The paper also contributes to a growing empirical literature that estimates dynamic models of intra-household allocations and marital behavior using the collective framework. 
Estimating such models with endogenously evolving state variables is burdened by considerable computational complexity. Mazzocco et al. (2007) make an important contribution by extending the collective model with no commitment to an inter-temporal setting. ${ }^{3}$ However, the authors document how labor supply evolves during periods of transition in and out of marriage and make no distinction between individuals by education level. We focus on the life-cycle aspect of work decisions and on understanding the mechanism that leads to different outcomes and distinguish between individuals by education level.

We also relate to studies analyzing the extent to which assortative mating contributes to economic inequality between couples (Karoly and Burtless, 1995; Cancian and Reed, 1998; Burtless, 1999; Schwartz, 2010; Eika et al., 2014; Greenwood et al., 2014; Harmenberg, 2014; Pestel, 2014). The main approach taken in the literature is to build counterfactual earnings distributions in which couples would be matched randomly. A few studies focusing on inequality in the U.S. attempt to isolate the effects of assortative mating from the effects of labor supply (Greenwood et al., 2014; Hyslop, 2001). However, these studies do not deal with the endogeneity of labor supply with respect to the match characteristics and its dynamic effects over the life cycle. The structural model estimated in this paper considers the marriage and the labor supply as endogenous decisions.

The paper is organized as follows. Section 2 illustrates the main facts regarding the employment behavior of married white women and the association between that behavior and the spousal education gap. ${ }^{4}$ Section 3 develops the dynamic model. Section 4 presents the estimation methodology and section 5 presents the results. Section 6 provides counterfactual analysis and section 7 concludes.

\footnotetext{
${ }^{3}$ Gemici and Laufer (2011) build on Mazzocco and explicitly model non-marital cohabitation as an intermediate stage between marriage and singlehood. They estimate a dynamic model of household formation and dissolution as well as fertility and labor supply. Jacquemet and Robin (2011) estimate a search and matching model of the marriage market and household labor supply.

${ }^{4}$ For comparison, some evidence is also presented for white married males. Non-white and white marriage markets function differently. While studying the labor supply of black married women would present many other specific and interesting findings, it is beyond the scope of this paper.
} 


\section{Stylized Facts}

\subsection{Trends in Educational Assortative Mating}

From 1964 to 2011, the educational attainment of both men and women increased substantially. During that period, the proportions of men and women with college degrees grew from $12 \%$ and $8 \%$ respectively to $30 \%$ and $32 \% .^{5}$ Nevertheless, it is important to note that women's college graduation rates rose steadily throughout this period, whereas that of men began to level off in the early 80s and have remained constant since approximately 2000. In the mid-1980s women's educational attainment began to surpass that of men (Eckstein and Nagypal, 2004; Goldin et al., 2006). The reversal of the gender gap in education quickly translated into a reversal of the education gap between spouses.

The basic data is draw from the Current Population Survey (CPS). ${ }^{6}$ Figure 1(a) depicts the education distribution of married women relative to their husbands. Particularly noticeable is the fact that the drop in the proportion of women marrying up is closely mirrored by the rise in the percentage of those marrying down. ${ }^{7}$ Studies focusing on rates of homogamy (i.e., wife and husband have the same educational attainment) overlook the reversal of the gender education gap between spouses in recent decades. For recent cohorts, the proportion of married couples in which the wife is more educated than the husband has reached 30 percent. This demographic transition has important economic implications and has contributed to the shift of the breadwinner role from men toward women.

A cohort analysis (see Figure 1(b), reveals a similar trend of marrying down among women, starting from the birth cohort of 1910 and continuing until the 1986 cohort. $^{8}$

\footnotetext{
${ }^{5}$ An individual's educational attainment level is an ordinal variable that takes on one of five values: $1=$ High school dropouts (HSD); $2=$ High school graduates (HSG); $3=$ Some college education (SC); $4=$ College graduates $(\mathrm{CG})$; and $5=$ Post-college studies (PC).

${ }^{6} \mathrm{~A}$ full description of the data file can be found in Appendix C.1.

${ }^{7}$ The mean absolute value of the education gap (|Education_husband - Education_wife $\mid$ ) between spouses is also plotted in Figure 1 (to be read off the y axis on the right). It is seen to be stable from 1975 onwards.

${ }^{8}$ The turning points, as well as the crossing points, of the marrying down and marrying up lines coincide with the findings of Goldin et al. (2006) who examined the reversal of the college gender gap.
} 
Table 1 shows the distribution of wives by their husbands' level of education. It shows that women tend to marry a man within the same educational category or an adjacent one and therefore, the term marrying down (up) generally refers to an education gap of one category. Panels (2) and (3) compare the distributions of pre-WWII (1940-45) and postWWII (1960-65) cohorts. With the exception of female high school (HS) graduates, women from the late "baby boom" generation (Panel (3)) were more likely than the pre-WWII (Panel (2)) female cohorts to marry down.

\subsection{The Spousal Education Gap and Married Women's Employ- ment Rates}

The employment rates of married women aged 25-55 increased in all categories of educational attainment during the period 1965 to 2011 (Figure 2). The increase is particularly noticeable for women who were either high school graduates ${ }^{9}$ or had some college education, and relatively modest for the post-graduate group. While all married women are working more today, note that women marrying down or equal have higher employment rates than women marrying up, both historically and currently.

Table 2 presents women's employment rates according to wives' and husbands' educational attainment groups. Note the asymmetry between above the dioganal (women marrying down) and below the diagonal (women marrying up). ${ }^{10}$ The asymmetry is most pronounced among women who are college graduates and post-graduates. The employment rate for a post-graduate woman marrying a man with some college education is $80 \%$, compared to $66 \%$ if that woman marries a post-graduate male, a difference of 14 percentage points. For female college graduates, the employment rate is $24 \%$ lower for women marrying to a husband with post-graduate education, relative to women married to a husband who is only a HS graduate. For women with some college education, the employment rate is $62 \%$ if she is married to

\footnotetext{
${ }^{9}$ See Figure A1 in the Appendix.

${ }^{10}$ This phenomenon is not observed among husbands (see Table B1).
} 
a HS graduate compared to $44 \%$ if she is married to a post-graduate male, a difference of 18 percentage points. It is clear that the employment rate of women who married down is about 20 percentage points higher than that of of women who married up. The increase in the number of women who married down over the last fifty years thus explains a portion of the increase in female employment during that period.

Table 3 presents the marginal effects ${ }^{11}$ in a logit model of wives' employment as a function of standard controls and two indicator variables. The first indicator equals one if the wife is more educated than the husband, and the second is equals one if the husband is more educated than the wife, leaving the homogamous couples as the reference group. Estimates reported in column (1) are signed as expected and significant, indicating that employment probability increases with education and age. Compared to women in a homogamous marriage, being in a marriage where the wife is more educated is positively and significantly related to her probability of being employed, whereas the opposite is true for those marrying up. The marginal effects differ substantially ( -0.05 for married up versus 0.05 for married down), and their confidence intervals do not overlap. Rosenzweig and Wolpin (1980) argued that the fertility decision is endogenous and therefore we excluded the presence of children as a control in the first estimation. These controls were added in column (2) and the estimates for both married-up and married-down women are almost identical. The presence of children, and young children in particular, is associated with a lower likelihood of being employed.

The most straightforward explanation of the results is the correlation between education and income, which is discussed in the literature on the allocation of time between market and non-market work within the family (Becker, 1973, 1974, 1993; Gronau, 1977). The division of labor between spouses is based on their relative productivities in paid and unpaid work, with productivity effectively being measured by the wages each could obtain in the market.

\footnotetext{
${ }^{11}$ The marginal effects are obtained by calculating the average of the marginal effects for each individual in the sample. In assessing the individual marginal effects for each dummy variable, we compute the difference in the probability when the variable equals one and zero alternatively.
} 
Higher-educated husbands have higher market earnings, and therefore their wives will spend less time in paid work and more on home production. Table B2 in the Appendix re-shows the asymmetry phenomenon even for women married to husbands with annual earnings in the top $10 \%$, as well as for those married to husbands with median annual earnings (the results hold for other deciles as well; see Table B3 in the Appendix.). Thus, the husband's "income effect" appears unlikely to account for the wide variation in women's employment rates. $^{12}$ Therefore, in column (3) of Table 3, we include a set of dummy variables for the husband's annual income decile.The marginal effects fall to 3.6 percentage points for married women who married down and 2.9 percentage points for those who married up, but remain statistically significant in both cases. In other words, a wife who is more educated than her husband is associated with a remarkable 12 percent increase in the likelihood of her being employed with respect to the mean of the dependent variable.

Alternatively, since the data is cross sectional, one can argue that a husband's current income is likely to suffer from transitory measurement error or life cycle bias. Mincer (1962) in his classic paper postulated differential labor supply responses to permanent and transitory income. ${ }^{13}$ We therefore re-estimated the model after adding the husband's education ${ }^{14}$ as a long run determinant of the level of permanent income (it is less likely to suffer from bias than current income while being highly correlated with current income). From column (4) in Table 3, it appears that, the husband's education/potential income plays a role and is significantly associated with the likelihood of the wife being employed. Though the effects are not monotonic, note that the probability of the wife being employed decreases when the husband is a college graduate or post graduate, compared to when he only has some college education. Moreover, the married-up and married-down effects are similar to those displayed in column (3)(4.2 percentage points for married up and 2.5 percentage points for

\footnotetext{
${ }^{12}$ This is not an unexpected result since recent papers have shown that women's labor supply became less responsive to their husbands' wages over the sample period (Blau and Kahn, 2007).

${ }^{13}$ Mincer (1962) noted that a transitory reduction in income due to a husband's brief spell of unemployment has a stronger effect on his wife's labor supply than a permanent one.

${ }^{14}$ Four education group dummies; HS dropout is the omitted category.
} 
married down) and remain highly significant. In column (5), we include both the husband's current income decile and his education category and therefore current income is likely to pick up the effect of income shocks. The marginal effects for marrying up and down are again very similar, though slightly smaller (3.8 versus 4.2 percentage points for married up and 2.2 versus 2.5 percentage points for married down).

In column (6), we add metropolitan statistical area (MSA) specific intercept terms (fixed effects) to capture unobserved heterogeneity that remains constant over time. Results are practically identical and indicate that these differences are not driven by systematic MSA specific factors. ${ }^{15}$ The magnitude of the marginal effects in our preferred specification (column (6)) implies that being the more educated spouse (relative to being the less educated spouse) is associated with an increase of 12 percent in the wife's likelihood of being employed with relative to the mean of the dependent variable. ${ }^{16}$ The estimates are robust to a variety of specifications that address alternative explanations, as shown in Appendices D.1 and D.2.

Table 2 hinted that the effect may be stronger for the higher education levels. Therefore, we ran the logit model for female employment separately for each female education group (Table 4) and found that indeed the effects are by far the largest for women who are college graduates and post-graduates relative to women with only some college education, and furthermore the effect is trivial for HS graduates. For female college graduates, the marginal effect of marrying down is 8.5 percentage points and that of marrying up is 6.3 percentage points.

\footnotetext{
${ }^{15}$ Results remain similar when married black females are included.

${ }^{16}$ The wife's weekly work hours equation was estimated using a traditional selectivity bias correction analysis (Heckman, 1979). According to the results, marrying down (marrying up) is not associated with a significant effect on hours worked per week. The relative position of the female within the couple with respect of education seems to have an effect on the likelihood of being employed (extensive margin), but not on the intensity of work (intensive margin).
} 


\section{Model}

The findings presented thus far in general the explanatory power of the Becker/Gronau time allocation model to a fair extent. However, the persistence of the results associated with a wife's relative education point to a more complex structure. In particular, there are dynamic aspects to the Becker/Gronau predictions that arise out of inter-temporal dependence of actions that are likely to be missed by the static approach. The primary incentive to work early in the marriage may also be producing considerable long-term labor supply effects. The findings cannot be explained by selection in marriage or fertility patterns nor by differences in marital stability, as shown in Appendix D. Interestingly, while a positive selection on ability into marrying down within each education group would explain the higher employment rates of married-down women, we in fact find that the opposite is true (see Appendix D.4).

The evidence therefore seems to strongly suggest that lock-in effects are at work (induced by human capital accumulation/experience), resulting in a persistent employment status. Consider the case of a woman who married down. According to standard economic theory, a wife's labor supply early in marriage is a response to the husband's expected permanent income. In this respect and conditional on the husband's permanent potential income, the higher the wife's expected earnings are, the more likely she is to engage in paid work. The decision to work induces the accumulation of human capital, which translates into higher wages over time. This increases the opportunity cost of leaving the labor market and produces a positive lock-in effect. Therefore, these women have a lower propensity to leave the labor market. The opposite story unfolds for a woman marrying up, who decides to interrupt her labor market participation, based on her husband's permanent income.

In order to address these issues we formulate a model of marriage that includes labor supply decisions and builds on the approach taken by Mazzocco et al. (2007). In the model, agents make decisions regarding marital status (marriage or divorce) and employment in each period. Individuals start off with a schooling level, $S$, and an ability endowment, $\varphi_{1}$ (a 
random draw from a normal distribution). The model does not include educational choice, even though education is an important factor affecting other choices, whether endogenous or not. In the NLSY79 data, most women had completed schooling by the time of marriage. Among the women in our sample, 92\% reported "Not Enrolled" at the time of marriage and only $4 \%$ returned to school (and relatively late in the marriage). Therefore, in order to simplify matters and reduce the computational burden the initial sample is composed of representative single agents reflecting the distribution of education levels observed in the data. $^{17}$ We also treat the fertility process as exogenous. Since the data shows no evidence of differential fertility patterns by the husband's relative education once we condition on the wife's education (see Appendix D.4). However, we do estimate the probabilities of childbirth in order to reproduce the observed dynamics of family formation over the life cycle by education level. The price we pay for abstracting from education and fertility decisions is that they are treated as unchanged in counterfactuals, i.e., any policy experiment cannot work through changes in the incentives for educational attainment or fertility.

Given these limitations, and starting from the age at which formal education is completed, an individual maximizes the present value of her/his utility in each period over a finite horizon by choosing the following: (1) whether or not to work $(d \in\{0,1\})$, where each agent is endowed with one unit of time allocated to work, $d$, and amount of leisure, $l=1-d$; and (2) marital status $(m \in\{0,1\})$, i.e., whether to marry (if she/he meets a potential partner) or to continue searching for a spouse. When married, the individuals choose whether to stay married or divorce. We assume no search for a partner while married.

\subsection{Preferences}

Individual $j(j=H$ - Husband, $W$ - Wife $)$ in household $i$ has a period utility that depends on public good consumption, $x$, total number of children, $N$, and match quality (if

\footnotetext{
${ }^{17}$ High school graduates start at the age of 18 , those with some college education at 22 , college graduates at 23 , and those with post-graduate education at 25 .
} 
married), $Q$. The utility function is given by:

$$
U_{i t j}=\frac{\left(\frac{x_{i t}}{1+\xi}\right)^{\chi}}{\chi}+\alpha_{1 j} N_{i t}+m_{i t} Q_{i t}+\alpha_{2 j} m_{i t} N_{i t}
$$

where $\chi$ governs the intertemporal elasticity of substitution, and $\xi\left(m_{i t} ; N_{i t}\right)^{18}$ is the consumption deflator depending on marital status and the total number of children. Utility from children may differ if married $(m=1)$.

\subsection{Home Production Technology}

There is a public good, $x_{i t}$, that is produced using the domestic labor inputs of the spouses. The intra-household production technology is a function of the spouses' number of housework hours and the amount of goods purchased in the market for the production of the public good. In period $t$, the public good is produced according to the following technology:

$x_{i t}=\left(\left(1+\sum \gamma_{1 k} N_{i t}^{k}\right)\left(\delta_{j} l_{i t j}+\delta_{-j} l_{i t-j} m_{i t}\right)^{\varsigma}+\left(1+\sum \gamma_{2 k} N_{i t}^{k}\right)\left(\left(1-l_{i t j}\right) w_{i t j}+\left(1-l_{i t-j}\right) w_{i t-j} m_{i t}\right)^{\varsigma}\right)^{1 / \varsigma}$

where $\left(w_{i t j}+w_{i t-j} m_{i t}\right)$ is the amount of goods purchased in the market, which is equal to the individual's wage and his spouse's wage, if married. ${ }^{19}\left(\delta_{j} l_{i t j}+\delta_{-j} l_{i t-j} m_{i t}\right)$ are the effective housework hours, defined as a function of the individual's leisure (and his spouse's, if married). The productivity of labor $\left(l_{i t j}\right)$ in home production, $\delta_{j}$, is gender-specific. $\gamma_{1 k}$ and $\gamma_{2 k}$ govern the extent to which the number of children in each age group shifts the productivity of housework hours and of market goods, respectively. The home production function has constant elasticity of substitution and the parameter $\varsigma$ determines the elasticity of substitution between the housework time inputs and market good inputs in the production technology. This specification allows for concavity and some complementarity between the

\footnotetext{
${ }^{18} \xi\left(m_{i t} ; N_{i t}\right)=0.7 * m_{i t}+0.4 * N_{i t}$ where 0.7 is the weight to an adult, and 0.4 is that given to a child (OECD scale).

${ }^{19}$ We abstract from borrowing and savings decisions, so that in each period labor income is used to purchase goods, which are used as an input in home production (Eckstein and Lifshitz, 2011; Gemici and Laufer, 2011)
} 
two inputs, depending on the value of $\varsigma$.

\subsection{Fertility and Children}

The number of children in age group $k^{20}$ evolves according to:

$$
N_{i t}^{k}=N_{i t-1}^{k}+n_{i t}^{k}-o_{i t}^{k}
$$

where $n_{i t}^{k}=1$ if a child enters age group $k$ at time $t$ and zero otherwise and $o_{i t}^{k}=1$ if a child exits age group $k$ at time $t$ and zero otherwise. The probability of having another child is a function of the woman's marital status $\left(m_{i t}\right)$, her age and age squared interacted

non-linearly with her education $\left(S_{i W} A G E_{i t W}, S_{i W} A G E_{i t W}^{2}\right),{ }^{21}$ husband's education $\left(S_{i H}\right.$, if married), ${ }^{22}$ and the total current number of children $\left(N_{i t}\right)$. The probability of having an additional child is given by (as in Van der Klaauw (1996)):

$$
\begin{aligned}
\operatorname{Pr}\left(N_{t}=N_{t-1}+1\right)= & \Phi\left(\lambda_{1} m_{i t}+\sum_{S} \lambda_{2}^{S} S_{i W} A G E_{i t W}\right. \\
& \left.+\sum_{S} \lambda_{3}^{S} S_{i W} A G E_{i t W}^{2}+\lambda_{4} S_{i H}+\lambda_{5} N_{i t}\right)
\end{aligned}
$$

where $\Phi$ is the standard normal distribution function.

\subsection{The Labor Market}

We adopt the Mincerian/Ben-Porath wage function for each individual $j=\mathrm{H}$, W where experience is endogenously determined, such that:

$$
\ln w_{i t j}=\varphi_{i 1 j}+\varphi_{2 j} K_{i t-1 j}+\varphi_{3 j} K_{i t-1 j}^{2}+\sum_{S} \varphi_{4 j}^{S} S_{i j}+\epsilon_{i t j}
$$

\footnotetext{
${ }^{20}$ The age groups are $0-5$ and $6-18$.

${ }^{21} S_{i W} \in\{H S G, S C, C G, P C\}$

${ }^{22} S_{i H} \in\{H S, H S G, S C, C G, P C\}$
} 
where $K_{i t-1 j}$ is actual work experience accumulated by the individual. From the point in time at which formal education is completed, work experience evolves according to $K_{i t j}=$ $K_{i t-1 j}+d_{i t j} . S_{i j}$ denotes the individual's predetermined level of schooling. $\epsilon_{i t j}$ is a gender specific zero-mean, finite-variance and serially independent error, which is uncorrelated with

$K$ and $S, \epsilon_{j} \sim N\left(0, \sigma_{\epsilon_{j}}^{2}\right)$. The constant term, $\varphi_{i 1 j}$, denotes permanent individual ability endowment (similarly to a fixed effect) that is known to the individual and to his potential spouse. $^{23}$

The following frictions are introduced into the model: In each period $t$ the individual receives at most one job offer. The offer arrival rates follow a logistic distribution and depend on the labor market state variables (previous period employment, $d_{i t-1 j}$ and schooling , $S_{i j}$, as well as accumulated work experience, $\left.K_{i t-1 j}\right)$ :

$$
\operatorname{Prob}_{i t j}^{j o b \text { offer }}=\frac{\exp \left(\rho_{1 j} d_{i t-1 j}+\sum_{S} \rho_{2 j}^{S} S_{i j}+\rho_{3 j} K_{i t-1 j}\right)}{1+\exp \left(\rho_{1 j} d_{i t-1 j}+\sum_{S} \rho_{2 j}^{S} S_{i j}+\rho_{3 j} K_{i t-1 j}\right)}
$$

We implicitly assume that in each period the individual may lose his job with a probability that is negatively correlated with his accumulated experience and education. Since the employment rate of men is essentially close to 100 percent, we assume in the estimation that men always work, i.e., $\operatorname{Prob}_{i t H}^{j o b \text { offer }}=1$.

\subsection{The Marriage Market and Match Quality}

In each period, a single individual meets with probability $p$ a potential spouse who is characterized by a level of schooling, ability, and experience. Once a potential partner is drawn, the potential couple then draws a match quality for the marriage, denoted by $Q$. In particular, $Q$ consists of an education-level-specific measure of "compatibility", $\theta^{S}$, and a bliss shock, $Q^{b}$,

$$
Q=1\{\text { homogamous }\} \theta^{S}+Q^{b}
$$

\footnotetext{
${ }^{23}$ Ability is assumed to be a random draw from a normal distribution $\left(\varphi_{1 j} \sim N\left(0, \sigma_{\varphi_{1 j}}^{2}\right)\right)$.
} 
where $\theta^{S 24}$ is enjoyed by the couple when both have the same level of schooling; and $Q^{b} \sim N\left(0, \sigma_{Q}^{2}\right)$. The couple then decides whether to marry or remain single and continue searching. The problem facing the couple when making this decision is described in section 3.6. If they decide to marry, their match quality random component follows a Markov process during the course of their relationship, so that in each period they draw a new bliss component conditional on the component's value in the previous period. As in Brown and Flinn (2006), as well as Gemici and Laufer (2011), we define a finite number of bliss values $Q^{b} \in\left\{Q_{1}^{b}, \ldots, Q_{M}^{b}\right\} .^{25}$ The probability of $Q_{q}^{b}$ increasing to $Q_{q+1}^{b}$ in the next period is given by $P_{Q}^{+}$if $q<\mathrm{M}$ and the probability of it decreasing to $Q_{q-1}^{b}$ by $P_{Q}^{-}$if $q>1$.

The timing of events within a period is illustrated by the timeline in Figure 3.

\subsection{The Household's Problem}

The model describes a finite horizon problem. Agents stop making choices in period $T^{26}$ and in each period face five types of uncertainty: job offer arrival rates, wages, probability of finding a potential spouse (and her/his characteristics) if single, match quality, and fertility. At the beginning of each period $t$, once uncertainty is realized, we assume that marital status and labor decisions are endogenously and simultaneously made. An agent makes choices given a vector of underlying state variables $\Omega_{i t}$. The vector contains twelve state variables: couple's schooling, age ${ }^{27}$, accumulated experience, ability, previous work status, the number and age of the children, match quality, and the wife's Pareto weight (discussed below):

$$
\Omega_{i t}=\left[S_{H}, S_{W}, A G E_{i t W}, K_{i H t}, K_{i W t}, \varphi_{1 i H}, \varphi_{1 i W}, d_{i t-1 W}, N_{i t}, A G E_{i t}^{N}, Q_{i t}, \mu_{t W}\right]
$$

\footnotetext{
${ }^{24} S \in\{H S G, S C, C G, P C\}$

${ }^{25} \mathrm{~A}$ discrete approximation of the continuous distribution is performed and the values are governed by zero mean and $\sigma_{Q}^{2}$. We use a grid of five equally-spaced support points (see Brown and Flinn (2006) for further details).

${ }^{26}$ In the empirical estimation, the terminal period is set at $T=45$ since the evidence in the data shows that marriage, employment, and fertility profiles remain stable after the age of 45 .

${ }^{27}$ Since we assume that men always work, husband's age and experience are perfectly correlated. In the empirical estimation we will therefore consider only his experience in the state vector.
} 


\section{Single Households}

We now characterize the value of being single at time $t$. We solve the model backwards starting with the decision problem in period $T$ and $\Omega_{i T}$. The value of being single for individual $j$ in household $i$ is determined by the solution of the following problem:

$$
V_{i T}^{0 j}\left(\Omega_{i T}\right)=\max _{d_{i T j}} U_{i T j}\left(x_{i T}, l_{i T j}, N_{i T}^{k}\right)+\beta V_{i T+1}^{j}\left(\Omega_{i T+1} \mid \Omega_{i T}\right)
$$

s.t.

$$
\begin{gathered}
x_{i T}=\left(\left(1+\sum \gamma_{1 k} N_{i T}^{k}\right)\left(\delta_{j} l_{i T j}\right)^{\varsigma}+\left(1+\sum \gamma_{2 k} N_{i T}^{k}\right)\left(\left(1-l_{i T j}\right) w_{i T j}\right)^{\varsigma}\right)^{1 / \varsigma} \\
l_{i T j}+d_{i T j}=1, \quad j=W, H
\end{gathered}
$$

where $\beta$ is the discount factor and a linear approximation is used to estimate the terminal value function at the terminal period, $V_{i T+1}^{j} \cdot{ }^{28}$

Working recursively from the solution for period $T$, the single individual's problem in any period $t$ can be written as:

$$
V_{i t}^{0 j}\left(\Omega_{i t}\right)=\max _{d_{i t j}} U_{i t j}\left(x_{i t}, l_{i t j}, N_{i t}^{k}\right)+\beta \mathbb{E}\left[V_{i t+1}^{j}\left(\Omega_{i t+1} \mid \Omega_{i t}\right)\right]
$$

s.t.

$$
\begin{gathered}
x_{i t}=\left(\left(1+\sum \gamma_{1 k} N_{i t}^{k}\right)\left(\delta_{j} l_{i t j}\right)^{\varsigma}+\left(1+\sum \gamma_{2 k} N_{i t}^{k}\right)\left(\left(1-l_{i t j}\right) w_{i t j}\right)^{\varsigma}\right)^{1 / \varsigma} \\
l_{i t j}+d_{i t j}=1, \quad j=W, H
\end{gathered}
$$

where $\mathbb{E}$ is the expectations operator and $V_{i t+1}^{j}$ is the value function of agent $j$ in period

\footnotetext{
${ }^{28}$ The terminal value function for a single individual is given by:

$$
V_{i T+1}^{j}\left(\Omega_{i T+1}\right)=\tau_{1 j} S_{i j}+\tau_{2 j} K_{i T+1 j}+\tau_{3 j} d_{i T W}+\tau_{4 j} N_{i T+1}, \quad j=W, H
$$
}


$t+1$.

\section{Married Couples}

The couple maximizes the weighted sum of each spouse utility in marriage. The couple does not have access to commitment technology and therefore the problem can be characterized by a Pareto problem with participation constraints. In each period, the problem is given by:

$$
\begin{array}{ll}
\max _{\left\{d_{i t W}, d_{i t H}, m_{i t}\right\}} & \mu_{t W}\left\{U_{i t W}\left(x_{i t}, l_{i t W}, N_{i t}^{k}, Q_{i t}\right)+\beta \mathbb{E}\left[V_{i t+1}^{W}\left(\Omega_{i t+1} \mid \Omega_{i t}\right)\right]\right\} \\
& +\left(1-\mu_{t W}\right)\left\{U_{i t H}\left(x_{i t}, l_{i t H}, N_{i t}^{k}, Q_{i t}\right)+\beta \mathbb{E}\left[V_{i t+1}^{H}\left(\Omega_{i t+1} \mid \Omega_{i t}\right)\right]\right\}
\end{array}
$$

$$
\begin{gathered}
\text { s.t. } \\
x_{i t}=\left(\left(1+\sum \gamma_{1 k} N_{i t}^{k}\right)\left(\delta_{W} l_{i t W}+\delta_{H} l_{i t H}\right)^{\varsigma}+\left(1+\sum \gamma_{2 k} N_{i t}^{k}\right)\left(\left(1-l_{i t W}\right) w_{i t W}+\left(1-l_{i t H}\right) w_{i t H}\right)^{\varsigma}\right)^{1 / \varsigma} \\
U_{i t W}\left(x_{i t}, l_{i t W}, N_{i t}^{k}, Q_{i t}\right)+\beta \mathbb{E}\left[V_{i t+1}^{W}\left(\Omega_{i t+1} \mid \Omega_{i t}\right)\right] \geq V_{i t}^{0 W}\left(\Omega_{i t}\right) \\
U_{i t H}\left(x_{i t}, l_{i t H}, N_{i t}^{k}, Q_{i t}\right)+\beta \mathbb{E}\left[V_{i t+1}^{H}\left(\Omega_{i t+1} \mid \Omega_{i t}\right)\right] \geq V_{i t}^{0 H}\left(\Omega_{i t}\right) \\
l_{i t j}+d_{i t j}=1, \quad j=W, H
\end{gathered}
$$

where $V_{i t}^{1 j}\left(\Omega_{i t}\right) \equiv U_{i t j}\left(x_{i t}, l_{i t j}, N_{i t}^{k}, Q_{i t}\right)+\beta \mathbb{E}\left[V_{i t+1}^{j}\left(\Omega_{i t+1} \mid \Omega_{i t}\right)\right]$ is the value of being married for agent $j$ which is derived from the solution of the couple's problem in (9). Marriage is consensual and therefore, each spouse's value from marriage should be at least as high as the value from being single, $V_{i t}^{0 j}\left(\Omega_{i t}\right)$. Note that when $\beta=0$, individuals are not forward-looking and the model simplifies to a static structural model, with no explicit reference to the future consequences of current decisions.

The household problem does not have a closed form solution and is again solved numerically using backward induction. In order to compute agent $j$ 's value from being married, we solve the couple's problem in two steps: First, the time allocation problem is solved while ignoring the participation constraints and using the Pareto weight from the previous period, $\mu_{i t}$. When a couple first meets, the initial Pareto weight is determined by a Nash bargaining 
problem that assigns both partners equal bargaining weight. Hence, in the terminal period $T$ the planner solves the following problem:

$$
\begin{array}{ll}
\max _{\left\{d_{i T W}, d_{i T H}, m_{i T}\right\}} & \mu_{T W}\left(U_{i T W}\left(x_{i T}, l_{i T W}, N_{i T}^{k}, Q_{i T}\right)+\beta V_{i T+1}^{W}\left(\Omega_{i T+1} \mid \Omega_{i T}\right)\right) \\
& +\left(1-\mu_{T W}\right)\left(U_{i T H}\left(x_{i T}, l_{i T H}, N_{i T}^{k}, Q_{i T}\right)+\beta V_{i T+1}^{H}\left(\Omega_{i T+1} \mid \Omega_{i T}\right)\right)
\end{array}
$$

s.t.

$$
\begin{gathered}
x_{i T}=\left(\left(1+\sum \gamma_{1 k} N_{i T}^{k}\right)\left(\delta_{W} l_{i T W}+\delta_{H} l_{i T H}\right)^{\varsigma}+\left(1+\sum \gamma_{2 k} N_{i T}^{k}\right)\left(\left(1-l_{i T W}\right) w_{i T W}+\left(1-l_{i T H}\right) w_{i T H}\right)^{\varsigma}\right)^{1 / \varsigma} \\
l_{i T j}+d_{i T j}=1, \quad j=W, H
\end{gathered}
$$

where again a linear approximation is used to estimate the terminal value function in the terminal period, $V_{i T+1}^{j} \cdot{ }^{29}$ Given the current $\mu_{i T}$, from the solution of the above problem the value of a married agent $j, V_{i T}^{1 j}$, can be computed.

In the next step, we check whether the individual participation constraints are satisfied for the optimal time allocation. Three events are possible: (1) The participation constraints are satisfied for both partners, in which case they remain married or decide to marry and individual $j$ 's value is $V_{i T}^{1 j}$. (2) The participation constraints are binding or violated for both partners and it is optimal to divorce ${ }^{30}$ or not marry (if they are single). Partner $j$ 's value is then $V_{i T}^{0 j}$. (3) The participation constraint is violated for $j$ but satisfied for $-j$, i.e., the former is better off single and the latter married. In this case, the couple will renegotiate and the weight ${ }^{31}$ on the utility of the individual preferring to remain single, $\mu_{j}$, is increased

${ }^{29}$ The terminal value function for a married individual is given by:

$$
\begin{aligned}
V_{i T+1}^{j}\left(\Omega_{i T+1}\right)= & \tau_{1 j} S_{i j}+\tau_{2 j} K_{i T+1 j}+\tau_{3 j} d_{i T W}+\tau_{4 j} N_{i T+1}+\tau_{5 j} S_{i_{-j}} \\
& +\tau_{6 j} K_{i T+1-j}+\tau_{7 j} m_{i T+1}+\tau_{8 j} m_{i T+1} N_{i T+1}+\tau_{9 j} m_{i T+1} Q_{i T}, \quad j=W, H
\end{aligned}
$$

\footnotetext{
${ }^{30}$ In the event of divorce, women retain custody of their children and the husband does not pay any child support.

${ }^{31}$ For the Pareto weights, $\mu$, we use an equally-spaced grid of 11 points.
} 
to the point where he is indifferent between being single or married. At this new Pareto weight, if participation constraints are satisfied for both individuals, they remain married (or get married). Individual $j$ 's value is the new $V_{i T}^{1 j}$. Otherwise, the couple separates and the value for agent $j$ is $V_{i T}^{0 j}$.

Once the continuation values have been defined and in order to determine agent $j$ 's value from being married in an arbitrary period $t$, we solve the couple's problem recursively using the same two-step procedure described above.

\section{Estimation}

The model is estimated using the Simulated Method of Moments (SMM). The objective of the estimation is to find the parameter vector $\hat{\vartheta}$ that minimizes the quadratic distance between a set of empirical moments $\left(\Psi_{D}\right)$ and a set of simulated moments $(\Psi(\hat{\vartheta}))$. Formally, the SMM estimator $\hat{\vartheta}$ solves:

$$
\hat{\vartheta}=\arg \min _{\vartheta}\left[\Psi_{D}-\Psi(\hat{\vartheta})\right]^{\prime} W\left[\Psi_{D}-\Psi(\hat{\vartheta})\right]
$$

where $\vartheta$ is the vector of parameters of interest, $W$ is the weighting matrix and the weight assigned to each element of the vector $\left[\Psi_{D}-\Psi(\hat{\vartheta})\right]$ is the inverse estimated standard deviation of the particular data moment.

Given an individual's education, a potential spouse is drawn from a conditional distribution according to the actual distribution of the NLSY79 cohort (born during the period 1960-65). In particular, we use CPS data to generate the actual distribution of spouses' level of education and potential experience. ${ }^{32}$ Each individual can draw a potential spouse with an educational level no more that is no more than two levels above or below his or hers. This restriction is not essential but is based on the consideration of geographic proximity and that individuals search/meet potential spouses in similar social circles.

\footnotetext{
${ }^{32}$ We define years of potential experience as the difference between age and years of schooling.
} 
The model is estimated using the 1979-2008 waves of the NLSY79. In solving the dynamic programming problem, we focus on women with at least a high school degree. The details of the data construction are described in Appendix C.2. We solve the model for each agent in each period. In order to allow agents to follow a rich set of paths, we simulate 1000 agents for each level of schooling from the year schooling starting from the year they completed their education until they reach 45 years of age.

The following lists the set of empirical moments $\left(\Psi_{D}\right)$ that we seek to reproduce (see Table C2): average employment rates for women by age, education, marital status, and number of children; employment transition rates by age, marital status, and number of kids; wages by gender, education, and experience; wage variances by gender; the average probability of giving birth by age and education; the average number of children at the age of 40 by education; the percentage of married females by age and education; the distribution of marital matches by education; and transition rates between marital states by age and education. The number of targeted moments in the estimation is therefore 980 .

Following are the parameters $(\vartheta)$ to be estimated: the five parameters in the utility function $\left(\chi, \alpha_{1 j}, \alpha_{2 j}\right)$; the eleven parameters that determine the probability of having a child $\left(\lambda_{1}, \ldots, \lambda_{5}\right)$; the nine parameters governing the marriage market and match quality $\left(p, \theta^{S}, \mu_{Q}, \sigma_{Q}^{2}, P_{Q}^{+}, P_{Q}^{-}\right)$; the seven parameters of the household production function $\left(\gamma_{1 k}, \gamma_{2 k}, \delta_{-j}, \delta_{j}, \varsigma\right)$; the seventeen parameters that determine the wage process for women and men $\left(\varphi_{2 j}, \varphi_{3 j}, \varphi_{4 j}^{S}, \sigma_{\epsilon_{j}}^{2}, \sigma_{\varphi_{1 j}}^{2}\right)$; the thirteen parameters of the probability of receiving a job offer for women and for men $\left(\rho_{1 j}, \rho_{2 j}, \rho_{3 j}^{S}\right)$; and the parameters in the terminal utility function $\left(\tau_{1 j}, \ldots, \tau_{9 j}\right)$. In light of the simplifying assumptions made, some of these parameters will be normalized to zero rather than estimated. The discount factor $\beta$ is fixed at 0.97 . There are a total of 83 parameters to estimate. 


\subsection{Identification}

The identification of the parameters determining productivity, as well as the preferences for working and children (equation (1) and (2)), rely on the set of moments describing labor supply by family status and labor market transitions, both by education level.

The wage-related parameters (equation (5)) are identified from the wage profiles for the women in the sample and their husbands' earnings. Although we only observe the wages of those who work, the solution to the optimization problem provides the sample selection rules. A woman's job-offer arrival rate (equation (6)) is identified from data moments on transitions into and out of employment, again by education level.

The transition probabilities that define the dynamics of the match quality, $Q$, as well as the other match quality parameters (equation (7)), are identified from the profile of marriage rates according to age and also from the empirical transition matrix between marital statuses by education level. The fertility process (equation (4)) is identified from the data on the distribution of the number of children by mother's age.

\subsection{Parameter Estimates}

The parameter estimates and their standard errors are reported in Appendix C.2. A subset of the parameters are fundamental to understanding differences in employment profiles between the different marriage categories.

The estimated value of $\varsigma$ is 0.83 , a reasonable degree of substitution between market goods and housework inputs. A woman's preference for working depends on her family status. It is accounted for by the shifters to the marginal housework productivity. Mothers find it more costly to work, particularly if their children are young $\left(\gamma_{1,0-5}>\gamma_{1,6-18}>0\right)$. Younger and

older children have a similar effect on marginal market goods productivity, which can be seen from the fact that $\gamma_{2,0-5}$ and $\gamma_{2,6-18}$ are similar in magnitude.

The wage-related parameters exhibit familiar features: a college education carries a substantial wage premium compared to lower levels of education; an additional year of experience 
translates into a significant increase in wages of about 5 and 6 percent $^{33}$ for women and men, respectively; and men exhibit higher returns to education and work experience than women.

As expected, the arrival rate increases with education and is higher while on the job. Work experience has a positive though small effect on the job offer arrival rate. This is because the dynamics of work experience, which underly the dynamics of the job arrival rate, are loosely identified from the profile of employment according to age.

The match quality parameters suggest that the probability of a positive or negative match quality shock is 23 and 24 percent, respectively. Preference parameters for assortative mating, $\theta^{S}$, confirm that compatibility is valued and particularly so among the more educated. The parameters of the exogenous fertility processes have the predicted signs.

\section{Goodness of Fit}

We now turn to the within-sample fit of the model. The baseline dynamic model does a remarkable job of reproducing the profiles observed in the data. For comparison purposes we also examine the static version of the model (in which $\beta=0$, implying that the individual maximizes today's utility with no regard to the future and therefore, the model reduces to one of static discrete choice) and how well it reproduces some of the observed patterns. The same moments were used in the estimation of the static model ${ }^{34}$ and that of the dynamic baseline model.

Figure 4 presents the fit of the models to the marriage choice proportions by education group. Each of the profiles implied by the estimated models has the correct shape and closely matches the levels of the data. Table 5 shows that the dynamic framework has no trouble generating the assortative mating profiles at first marriage. The baseline model's prediction follows the data very closely. The static model, however, overpredicts the proportion of those marrying down. This is because agents in a static framework are short-sighted and do not

\footnotetext{
${ }^{33}$ Olivetti (2006) estimates the return to one additional year of full-time work at between 3 and 5 percent for women.

${ }^{34}$ The static model's estimated parameters together with their standard errors are available upon request.
} 
perceive the option value of waiting. Thus, marriage is consented to as soon as a single agent meets a partner, and marriage to that partner yields a higher current period utility (versus lifetime expected utility) than in the case of remaining single for both partners. Hence, marriage is more "random" than preferential and the sorting patterns more closely reflect the education distribution in the population. For example, in both frameworks a female college graduate is more likely to meet a man with less than a college degree than a man with a post-college degree. However, in the dynamic framework, the woman perceives the option value of waiting for a better match and in some cases chooses to continue her search.

The dynamic model accurately reproduces married women's employment age profiles for each education level (see Figure 5). The static model, however, fails to capture the hump in the data, which is most pronounced for women with some college education and college graduates, and tends to underpredict early in life and overpredict later in life systematically. This arises for the same reasons of "short-sightedness" seen earlier: In the static framework, individuals do not have a strong incentive to participate in the workforce when young in order to accumulate experience. The dip in employment reflects the impact of child-bearing on labor supply.

In particular, the dynamic model almost exactly replicates key empirical moments that were not directly targeted i.e. the large disparities between married women's labor supply, conditional on their educational attainment, and their relative educational position (Table 6), which helps validate the model. The dynamic model slightly underpredicts the employment rate for high school graduates who have married up or equal. Focusing on the group with the most remarkable employment gap, i.e. college graduates, in the data we observe a 20 percentage points gap (59\% vs. $79 \%$ ) between those who married up and those who married down. The dynamic model generates a gap of 19 percentage points (59\% vs. 78\%). The feature of the model that drives the higher labor market attachment of the married-down women is the return to experience. In contrast, the static model provides a poor fit. While the static model's predictions capture the general pattern of response to a husband's relative 
education, it underpredicts ${ }^{35}$ the employment rate gap between a married-up and marrieddown woman. For example, it predicts only a 3.7 percentage points difference $(71.5 \%$ vs. $75.2 \%)$ for college graduates.

Figures 6-7 present wage profiles by experience, gender, and education. For both men and women, the trends and levels are matched well by both estimated models.

Overall, the baseline dynamic model fits the data remarkably well, for the key moments, as well as providing a much better fit to the data than the static model. This is in contrast to previous estimations of dynamic models and their static versions (i.e., discount factor set to 0) that have provided similar in-sample fits.

Table 7 provides an additional assessment of the fit of the baseline model in various dimensions for the four education groups. First, the results show a good match in terms of fertility rates. The dynamic model also reproduces the differences in women's employment rates across marital status and the different fertility levels. Finally, because children significantly increase the value of home production, the degree of specialization in home production increases as a function of the number of children,

Table 8 confirms the evidence of selection on ability for women and men marrying up, down and equal presented in Appendix D.4, using the NLSY79. More specifically, we find that for both genders, conditional on educational attainment, those that married down (up) have lower (higher) average AFQT scores compared to those that married equal (see Tables D8 and D13). Especially interesting to note is the positive assortative mating on AFQT since those with the relative lower (higher) ability within an education group are matching with their "equals", i.e., those from a lower (higher) education group yet with the higher (lower) relative ability within their group. While these moments were not targeted in the estimation, the model generates ability moments that provide additional checks of robustness. Table 8 reports average ability by education and by relative position in education for women and men in Panels A and B, respectively. Although we cannot compare these ability moments to

\footnotetext{
${ }^{35}$ Except for the HS graduates.
} 
AFQT moments from the data, it is reassuring that the mechanism in the model duplicates what is observed in the data.

Moreover, the comparison of correlation between spouses earnings from the dynamic model with the correlation from the static model gauges the role of the persistent (dynamic) effects on women's labor supply, and in turn on earnings inequality between couples. The correlation drops from 0.107 to 0.044 , suggesting that dynamics and persistence effects due to the endogenous labor supply with respect to the match characteristics have a major influence on earnings inequality.

The estimated dynamic model fully accounts for the endogeneity of labor supply decisions with respect to the match characteristics and therefore allows the assessment of assortative mating on earnings inequality between married couples. Imposing random matching ${ }^{36}$ in the model drops the correlation only slightly, from 0.107 to 0.083 . This points that assortative matching plays a relatively minor role in determining earnings inequality.

\section{Counterfactuals}

\subsection{Returns to Experience}

As discussed earlier, we consider wage returns to experience and its dynamic effects to be strong candidates to explain the differences in labor supply observed among married women across the three categories of relative spousal education. We now turn to assessing the magnitude of the effects of wage growth (wage returns to experience). While this is difficult using reduced form techniques, our model makes it possible to construct counterfactual profiles by comparing profiles with and without returns to experience for women (in the latter case, a woman's life-cycle wage profile would be flat, conditional on her educational level). We compare outcomes from the simulation, assuming that experience does not lead to any wage growth for females, i.e., $\varphi_{2 W}=\varphi_{3 W}=0$, with the baseline outcomes predicted

\footnotetext{
${ }^{36}$ When an individual meets a potential partner, a union is formed.
} 
from the dynamic model given the estimated parameters. The differences in behavioral outcomes should can therefore be attributed to the lack of returns to experience.

The simulation results are reported in Figure C1, Figure 8 and Tables 9-10. Without the prospect of wage growth, the marriage market is affected: It takes longer for women from all education groups to marry (Figure $\mathrm{C} 1$ ). The effects of this on the rate of marriage by the age of 45 is minor, except for women with a post-graduate degree. The model explains this by means of a higher rejection rate on the part of men. Because lifetime expected value from working is lower and women are less attached to the labor force, more men opt to wait for a woman with a higher lifetime value gained from work experience. Accordingly, the model predicts higher rates of marrying down, especially among college and post-college graduate females (Table 9), and particularly the latter: Holding everything else constant, with a lower value from working, women are less "attractive" to men from their own education group, yet are still desired by men with less than a post-graduate degree, thus, the marriage rate will be lower and more women will marry down.

The employment profiles in Figure 8 reflect the lower labor market attachment among women arising due to lack of incentive, in the absence of wage growth, to invest in human capital when young. We also note that less-educated women are more sensitive to the returns to experience. Since they are more likely to be on the margin of the employment decision than high-skilled workers, and therefore are more responsive to changes in the incentive to work. ${ }^{37}$

The effect of experience is also important in understanding the employment rate differences between the three marriage categories within the same education group. The model without wage growth still predicts an employment gap between the married-up group and the married-down group, though a more modest one $(5.2 \%$ vs. $12.6 \%$ for some college education, $6.9 \%$ vs. $18.9 \%$ for college graduates, and $1.2 \%$ vs. $13.3 \%$ for post-graduates; see

\footnotetext{
${ }^{37}$ These predictions are in line with the results in Juhn et al. (1991, 2002). They provide estimates of the elasticity of LS by skill group and confirm that low-skilled LS is much more elastic than that of high-skilled workers.
} 
Table 10). The return to experience explains $44 \%$ of the gap between the married-up and the married-down group. Married-down women have an incentive to work more given their lower-earning husbands. Everything else being equal, there is a smaller wage differential between a woman who has married down and her husband, so that she is more likely to work than a woman who has married up. However, given the flat wage profile, the opportunity cost of not participating or leaving the job market is much lower. Therefore, when the husband of a married-down woman experiences a positive wage shock, she is more likely to decide not to participate in the labor force since she does not perceive higher forgone earnings compared to if she were to participate and accumulate experience.

\subsection{Divorce}

Divorce is known to affect a variety of labor market outcomes. Fernandez and Wong (2011) find that the higher probability of divorce faced by younger cohorts of women is able to explain a large proportion of the observed increase in female labor force participation, relative to older cohorts. ${ }^{38}$ In order to assess the importance of divorce as a factor explaining female labor force participation, we perform a counterfactual simulation assuming that no divorce $^{39}$ is possible and compare the predictions with the baseline results.

Due to the higher "spousal insurance" married women experience would benefit from the absence of divorce, their incentive to work and accumulate experience as a form of selfinsurance is lessened. Indeed, as expected, Figure 9 displays lower employment rates over the whole life-cycle. The decrease in employment for the less educated (HS graduates and some college education) is more pronounced than in the case of college and post-college graduates. This reflects the fact that the more-educated groups have lower divorce rates than the less-educated ones (see Table D5) and therefore would be less affected by changes in divorce risk. With respect to employment rates, the counterfactual predicts a significantly

\footnotetext{
${ }^{38}$ See also Stevenson (2008) and Voena (2011) for the relationship between divorce and female labor force participation.

${ }^{39}$ One should approach this exercise with caution since when divorce is not allowed, bargaining weight within the couple remains constant over the course of marriage and is not re-negotiated.
} 
lower overall difference between women who marry up and women who marry down: The mean difference in employment rates under "no divorce" is 11.5 percentage points, compared to 5.5 percentage points in the baseline model. The results therefore suggest that divorce plays a role in explaining the employment rate gap observed between women married up and women who married down.

\subsection{Schooling Distribution}

The model is estimated based on data for the 1965 cohort in the NLSY79. One of the key forces driving the decision to marry is the education distribution of potential wives and that of husbands, which are determined outside the model. We now substitute the schooling distributions for the 1965 cohort with that for the 1945 cohort, keeping all parameters fixed at the estimated values. Any differences in behavioral outcomes are therefore attributable to this modification.

Table 11 presents the prediction of the sorting profile. Since the education gender gap is larger for the 1945 cohort, women are overall less likely to marry down (the probability falls from 37 percent to 24 percent) while the homogamy rate is largely unaffected. The data exhibits the same pattern (see Figure 1). Note that the employment profiles for women married up, equal, and down are largely unchanged (see Table 12). The striking difference in labor supply behavior along with the lower proportion of married-down women translates into lower employment profiles relative to the baseline cohort (see Figure 10). In other words, the changes in the education distribution predict a 13 percentage points increase in the proportion of married-down women (from $24 \%$ to $37 \%$ ) while homogamy rates are predicted to remain constant, and employment rates for married women aged 30-40 are predicted to increase by 5.7 percentage points. In the data, the employment rate increased by roughly 10 percentage points for that age group between the 1945 and 1965 cohorts. Furthermore, the associated change in the proportion of women marrying down on its own is able to account for 3.8 percentage points out of the 5.7 percentage point difference. Marriage sorting patterns 
have life-cycle consequences and are critical to the understanding of the female labor supply.

\section{Conclusion}

We have shown that a woman's education relative to her husband's produces dynamic effects on her labor supply. The reduced form results suggest that if a woman is more educated than her husband, the likelihood of her being employed is up to 14.5 percentage points higher than for a woman less educated than her husband.

We constructed a dynamic model of endogenous marriage and labor supply decisions in a collective framework and both the dynamic and static versions of the model were structurally estimated using data from the NLSY79. The results indicate that there are substantial dynamic effects. While the dynamic model captures the key profiles of labor supply, and marriage decisions displayed by the data reasonably well, the static model provide a poor fit. The estimates were then used to gauge the importance of wage growth on the labor supply behavior of women in the three marriage categories (marrying up, equal, or down). In particular, we find that when wage returns to experience are omitted from the estimated model and everything else is kept equal, the predicted employment gap between who married up and women who married down narrows substantially. Returns to experience on their own account for 44 percent of the employment gap.

Our estimated model fully accounts for the endogeneity of labor supply decisions with respect to the match characteristics and therefore allows the assessment of assortative mating on earnings inequality between married couples. We impose random matching on the estimated model and find that it plays a minor role compared with persistence effects due to the endogenous labor supply with respect to the marital match characteristics at the time of marriage.

The findings from an exercise that replaced the 1965 cohort with the 1945 cohort suggest that changes in assortative mating patterns over time are an important factor in explaining 
the increase in married women's LFP. Not taking this into account may lead to overestimation of the importance of other factors that determine women's labor supply, such as the changing wage structure (see Jones, Manuelli and McGrattan, 2003), the improvement in home technology (see Greenwood, Guner, Kocharkov and Santos, 2012), and cultural changes (see Fernandez, 2007).

In conclusion, while previous research on the labor supply of women have emphasized the importance of returns to experience, we have found that a husband's education relative to that of his wife and wage returns to experience can account for dynamic labor supply effects to a large extent. One possible extension of the model would be to examine savings and asset accumulation dynamics in a framework under various income tax policies. Another direction that has appeared in recent models emphasizes that investment in education generates returns in the marriage market (Chiappori et al., 2009; Ge, 2011). Finally, it may be worthwhile to endogenize the education decision. 


\section{References}

Altug, Sumru, and Robert Miller (1998) 'The effect of work experience on female wages and labour supply.' Review of Economic Studies 65(1), 45-85

Beck, Audrey, and Carlos González-Sancho (2009) 'Educational assortative mating and children's school readiness.' Center for Research on Child Wellbeing Working Paper

Becker, Gary S. (1973) 'A theory of marriage: Part I.' Journal of Political Economy 81(4), 813-846

_ (1974) 'A theory of marriage: Part II.' Journal of Political Economy 82(2), S11-S26

_ (1993) A Treatise on the Family. Enlarged Edition (Cambridge, MA: Harvard University Press)

Becker, Gary S., Elisabeth M. Landes, and Robert T. Michael (1977) 'An economic analysis of marital instability.' Journal of Political Economy 85(6), 1141-1187

Ben-Porath, Yoram (1967) 'The production of human capital and the life cycle of earnings.' The Journal of Political Economy 75(4), 352-365

Bertrand, Marianne, Claudia Goldin, and Lawrence F Katz (2010) 'Dynamics of the gender gap for young professionals in the financial and corporate sectors.' American Economic Journal: Applied Economics pp. 228-255

Blau, Francine D., and Lawrence M. Kahn (2007) 'Changes in the labor supply behavior of married women: 1980-2000.' Journal of Labor Economics 25(3), 393-438

Blundell, Richard, and Thomas MaCurdy (1999) 'Labor supply: A review of alternative approaches, in O. Ashenfelter and D. Card (eds.).' Handbook of Labor Economics. Elsevier Science, Amsterdam

Brown, M., and C. Flinn (2006) 'Investment in child quality over marital states.' Manuscript 
Burtless, Gary (1999) 'Effects of growing wage disparities and changing family composition on the us income distribution.' European Economic Review 43(4), 853-865

Cancian, Maria, and Deborah Reed (1998) 'Assessing the effects of wives' earnings on family income inequality.' Review of Economics and Statistics 80(1), 73-79

Chiappori, Pierre-André (1988) 'Rational household labor supply.' Econometrica: Journal of the Econometric Society pp. 63-90

Chiappori, Pierre-Andre (1992) 'Collective labor supply and welfare.' Journal of Political Economy pp. 437-467

Chiappori, Pierre-Andre, Murat Iyigun, and Yoram Weiss (2009) 'Investment in schooling and the marriage market.' The American Economic Review pp. 1689-1713

Cullen, Julie Berry, and Jonathan Gruber (2000) 'Does unemployment insurance crowd out spousal labor supply?' Journal of Labor Economics 18, 546-71

Eckstein, Zvi, and Eva Nagypal (2004) 'The evolution of U.S. earnings inequality: 19612002.' Federal Reserve Bank of Minneapolis Quarterly Review 28(2), 10-29

Eckstein, Zvi, and Kenneth Wolpin (1989) 'Dynamic labour force participation of married women and endogenous work experience.' The Review of Economic Studies 56(3), 375-390

Eckstein, Zvi, and Osnat Lifshitz (2011) 'Dynamic female labor supply.' Econometrica $79(6), 1675-1726$

Eika, Lasse, Magne Mogstad, and Basit Zafar (2014) 'Educational assortative mating and household income inequality.' Technical Report, National Bureau of Economic Research

Fernandez, Raquel (2007) 'Culture as learning: The evolution of female labor force participation over a century.' NBER Working Paper 
Fernandez, Raquel, and Joyce Cheng Wong (2011) 'The disappearing gender gap: The impact of divorce, wages, and preferences on education choices and women's work.' NBER Working Paper

Fernandez, Raquel, and Richard Rogerson (2001) 'The determinants of public education expenditures: Longer-run evidence from the states.' Journal of Education Finance $27(1), 567-583$

Ge, Suqin (2011) 'Women's college decisions: How much does marriage matter?' Journal of Labor Economics 29(4), 773-818

Gemici, Ahu, and Steve Laufer (2011) 'Marriage and cohabitation.' mimeo. New York University

Goldin, Claudia (1990) Understanding the gender gap: An economic history of American women (New York: Oxford University Press)

Goldin, Claudia, Lawrence F. Katz, and Ilyana Kuziemko (2006) 'The homecoming of american college women: A reversal of the college gender gap.' Journal of Economic Perspectives 20(4), 133-156

Gray, Jeffry S. (1997) 'The fall in men's return to marriage: Declining productivity effects or changing selection?' Journal of Human Resources 32, 481-504

Greenwood, Jeremy, Nezih Guner, Georgi Kocharkov, and Cezar Santos (2012) 'Technology and the changing family.' NBER Working Paper

- (2014) 'Marry your like: Assortative mating and income inequality.' American Economic Review 104(5), 348-53

Gronau, Reuben (1977) 'Leisure, home production and work: The theory of the allocation of time revisited.' Journal of Political Economy 85, 1099-1123 
Harmenberg, Karl (2014) 'A note: The effect of assortative mating on income inequality.' Instituto de Estudios Econmómicos Internacionales-Universidad de Estocolmo

Heaton, T.B. (2002) 'Factors contributing to increasing marital stability in the united states.' Journal of Family Issues 23, 392-409

Heckman, James (1979) 'Sample selection bias as a specification error.' Econometrica $47(1), 153-161$

Heckman, James, and Thomas MaCurdy (1980) 'A life cycle model of female labor supply.' Review of Economic Studies 47, 47-74

Hyslop, Dean R (2001) 'Rising us earnings inequality and family labor supply: The covariance structure of intrafamily earnings.' American Economic Review pp. 755-777

Jacquemet, Nicolas, and Jean-Marc Robin (2011) 'Marriage with labor supply.' Manuscript, SciencePo (Paris)

Jones, Larry E, Rodolfo E Manuelli, and Ellen R McGrattan (2003) 'Why are married women working so much?' Technical Report, Federal Reserve Bank of Minneapolis

Juhn, Chinhui, Kevin M Murphy, and Robert H Topel (2002) 'Current unemployment, historically contemplated.' Brookings Papers on Economic Activity 2002(1), 79-116

Juhn, Chinhui, Kevin M Murphy, Robert H Topel, Janet L Yellen, and Martin Neil Baily (1991) 'Why has the natural rate of unemployment increased over time?' Brookings Papers on Economic Activity 1991(2), 75-142

Karoly, Lynn A, and Gary Burtless (1995) 'Demographic change, rising earnings inequality, and the distribution of personal well-being, 1959-1989.' Demography 32(3), 379-405

Kremer, Michael (1997) 'How much does sorting increase inequality?' The Quarterly Journal of Economics 112(1), 115-139 
Lundberg, Shelly (1985) 'The added worker effect.' Journal of Labor Economics 3, 11-37

Mare, Robert (1991) 'Five decades of educational assortative mating.' American Sociological Review 56, 15-32

Mazzocco, Maurizio, Claudia Ruiz, and Shintaro Yamaguchi (2007) 'Labor supply, wealth dynamics and marriage decisions.' mimeo

Mincer, Jacob (1962) 'Labor force participation of married women: A study of labor supply.' Aspects of Labor Economics pp. 63-97

Olivetti, Claudia (2006) 'Changes in women's hours of market work: The role of returns to experience.' Review of Economic Dynamics 9(4), 557-587

Pencavel, John (1998) 'Assortative mating by schooling and the work behavior of wives and husbands.' American Economic Review 88(2), 326-329

Pestel, Nico (2014) 'Beyond inequality accounting: Marital sorting and couple labor supply'

Rosenzweig, Mark, and Kenneth Wolpin (1980) 'Life-cycle labor supply and fertility: Causal inference from household models.' The Journal of Political Economy 88(2), 328-348

Rotz, Dana (2011) 'Why have divorce rates fallen? The role of women's age at marriage.' Unpublished manuscript, Harvard University

Schwartz, Christine, and Robert Mare (2005) 'Trends in educational assortative marriage from 1940 to 2003.' Demography 42(4), 621-646

Schwartz, Christine R (2010) 'Earnings inequality and the changing association between spouses? earnings.' AJS; American journal of sociology 115(5), 1524

Stevenson, Betsey (2008) 'Divorce law and women's labor supply.' Journal of Empirical Legal Studies 5(4), 853-873 
Stevenson, Betsey, and Justin Wolfers (2007) 'Marriage and divorce: Changes and their driving forces.' Journal of Economic Perspectives 21(2), 27-52

Teachman, Jay (2002) 'Stability across cohorts in divorce risk factors.' Demography $39(2), 331-351$

Van der Klaauw, Wilbert (1996) 'Female labour supply and marital status decision: A lifecycle model.' Review of Economic Studies 63(2), 199-235

Voena, Alessandra (2011) 'Yours, mine and ours: Do divorce laws affect the intertemporal behavior of married couples?' Technical Report, Stanford Institute for Economic Policy Research 


\section{Figure 1: Marriage Patterns}

(a) Cross Sectional

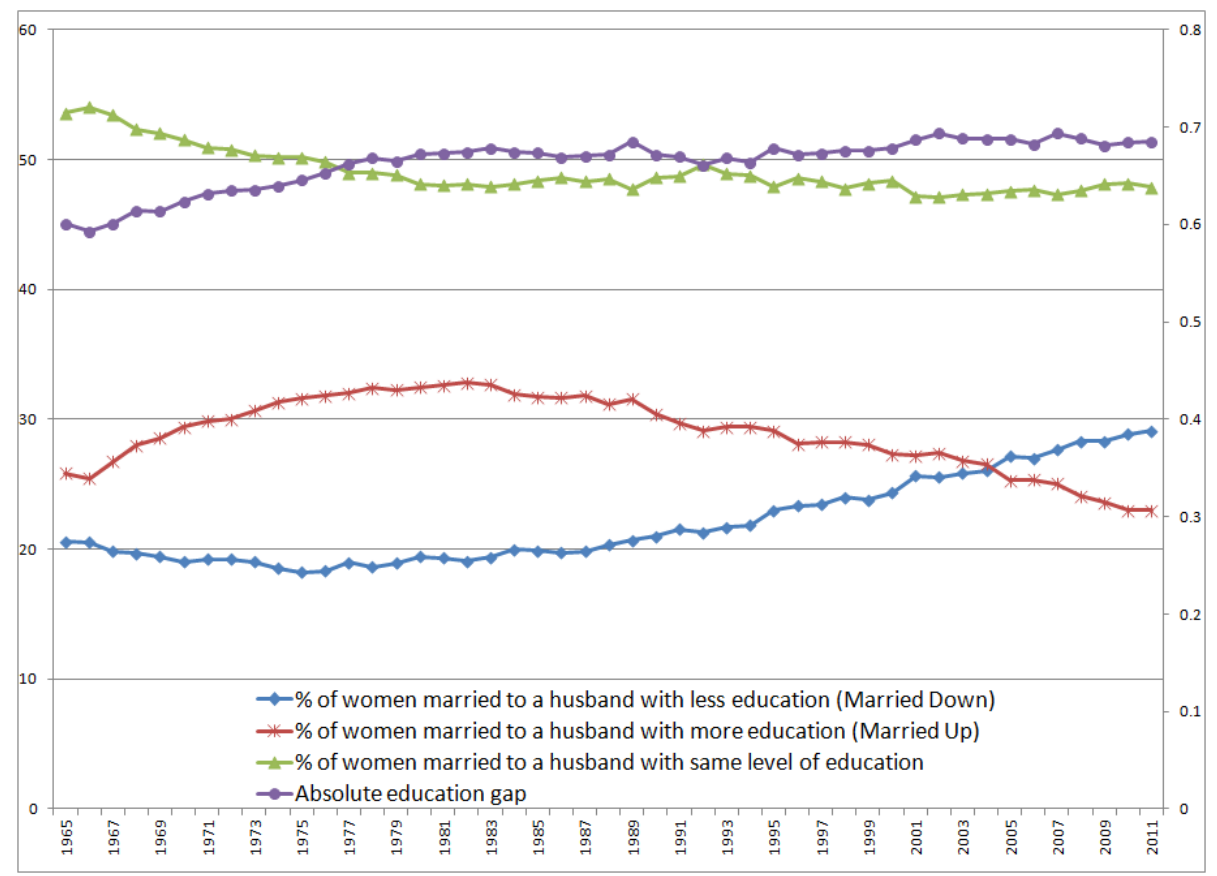

(b) Birth Cohorts

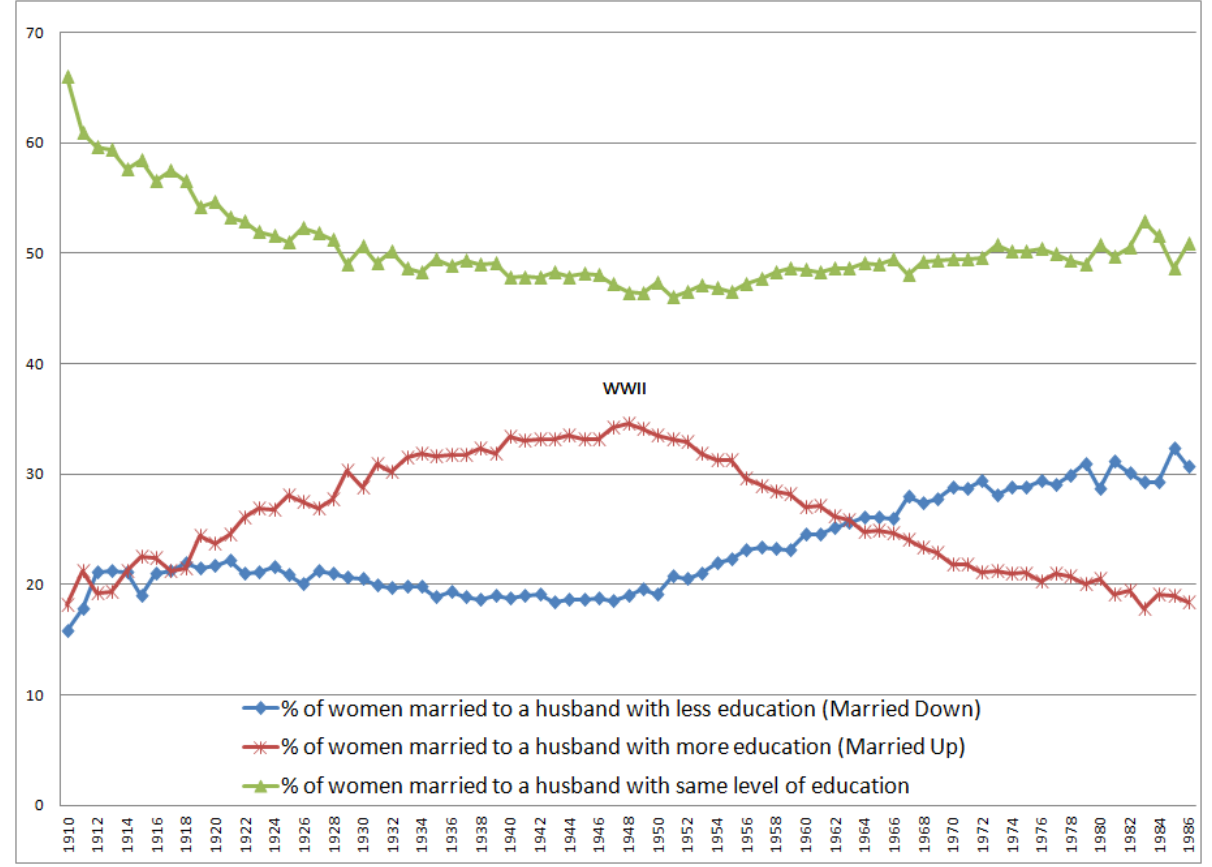

Source - March CPS 1965 - 2011.

Notes - Married white women, ages 25 - 55 . 
Figure 2: Employment Rate by Wives' Education and Match

(a) Some College

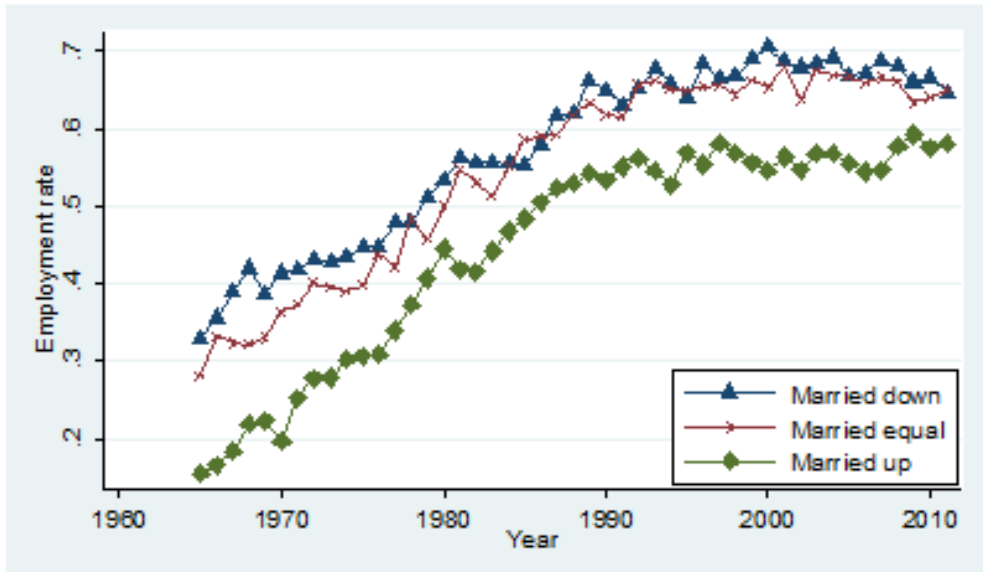

(b) College Graduate

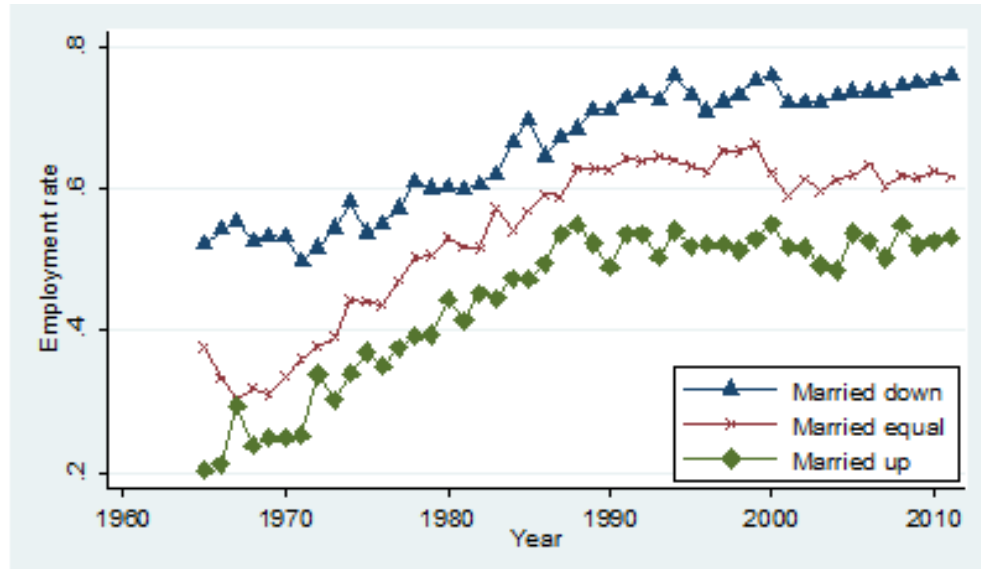

(c) Post-Graduate

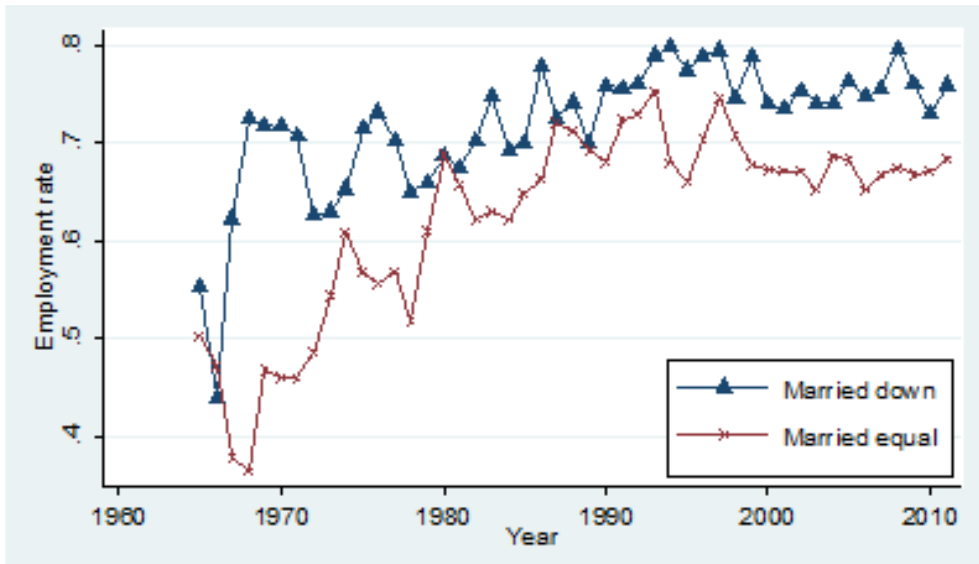

Source - March CPS 1965 - 2011.

Notes - Married white women, ages 25 - 55. Proportion working at least 20 weekly hours. 
Figure 3: Timing of Shocks and Decisions

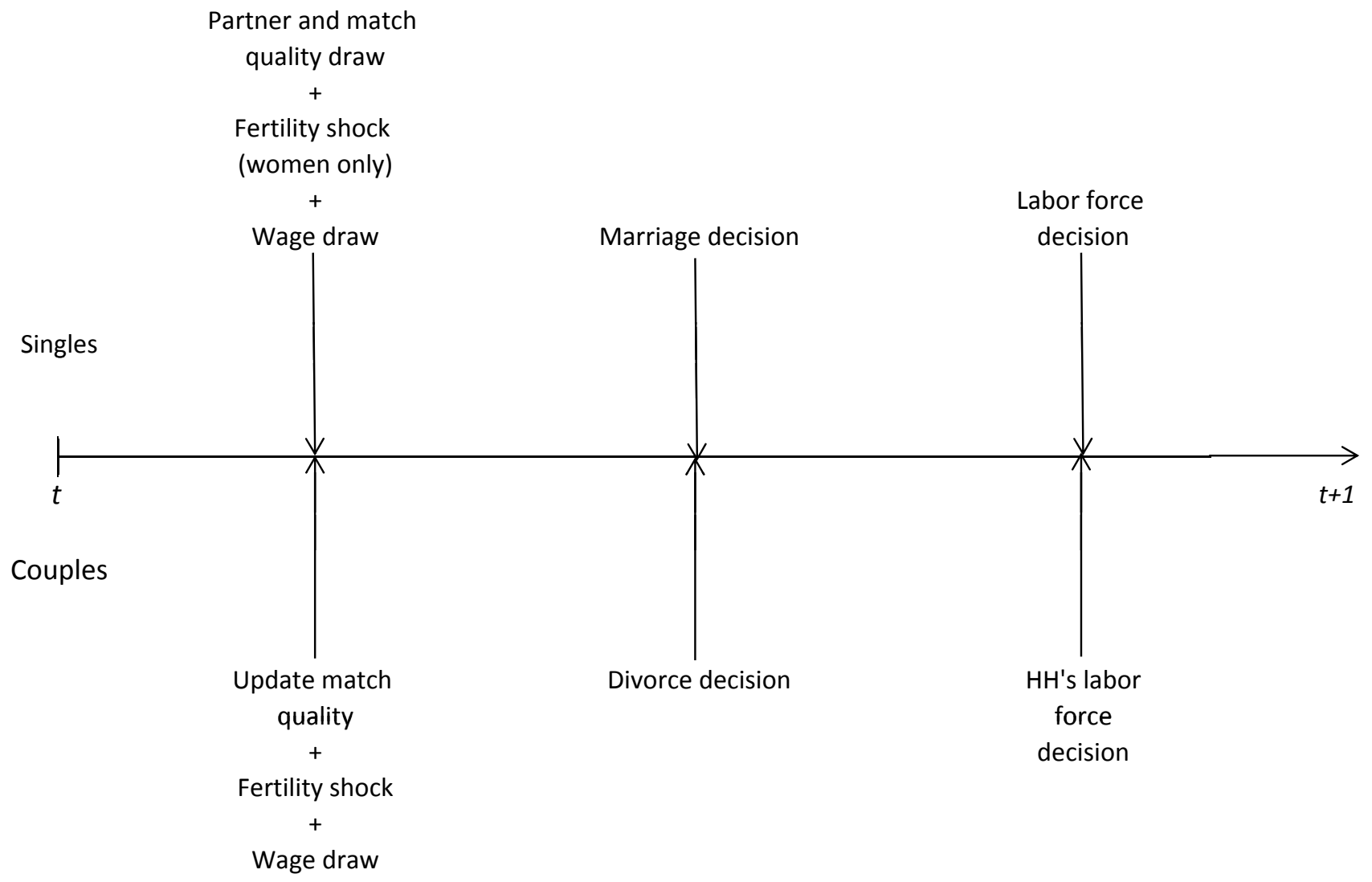

Notes - 

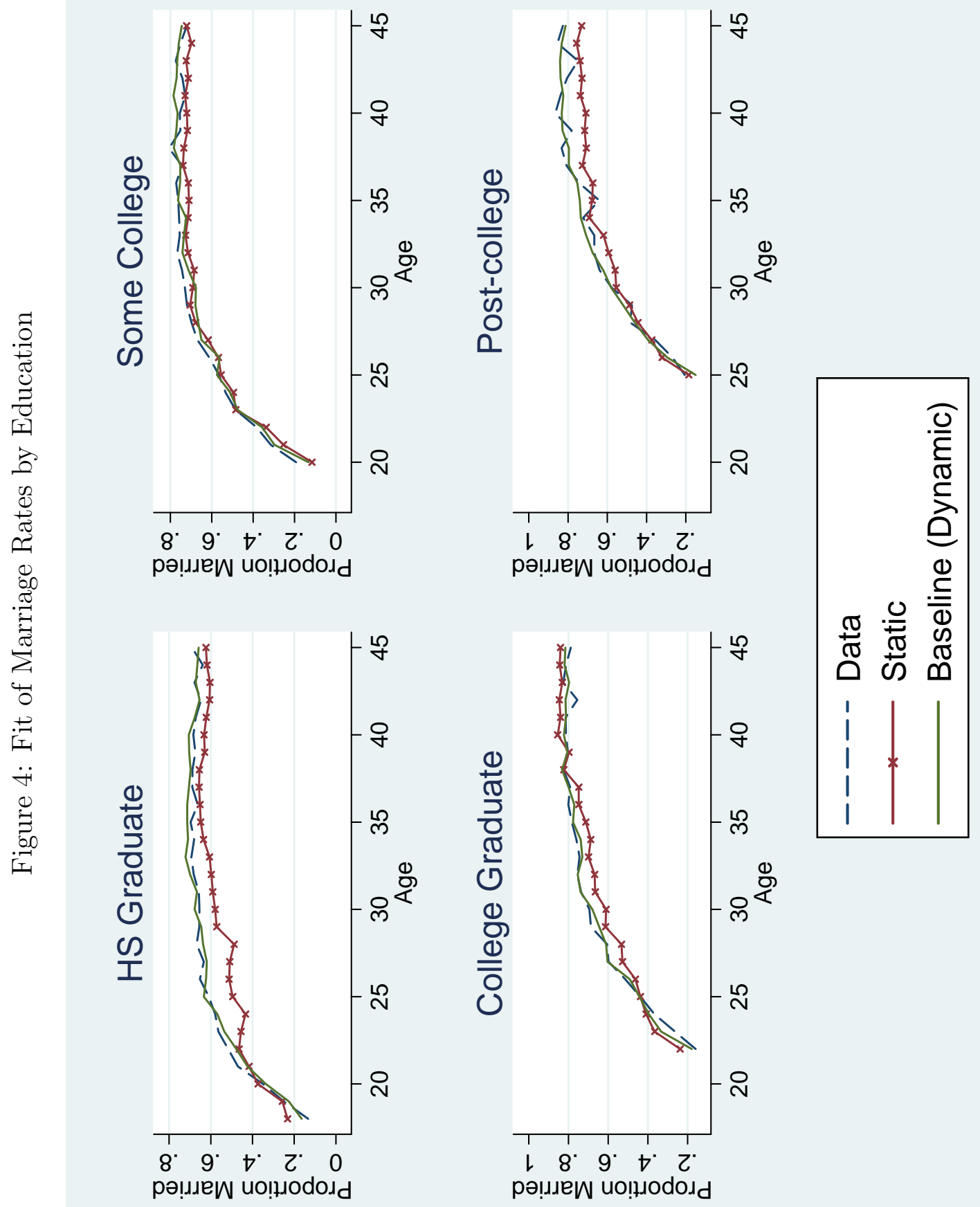


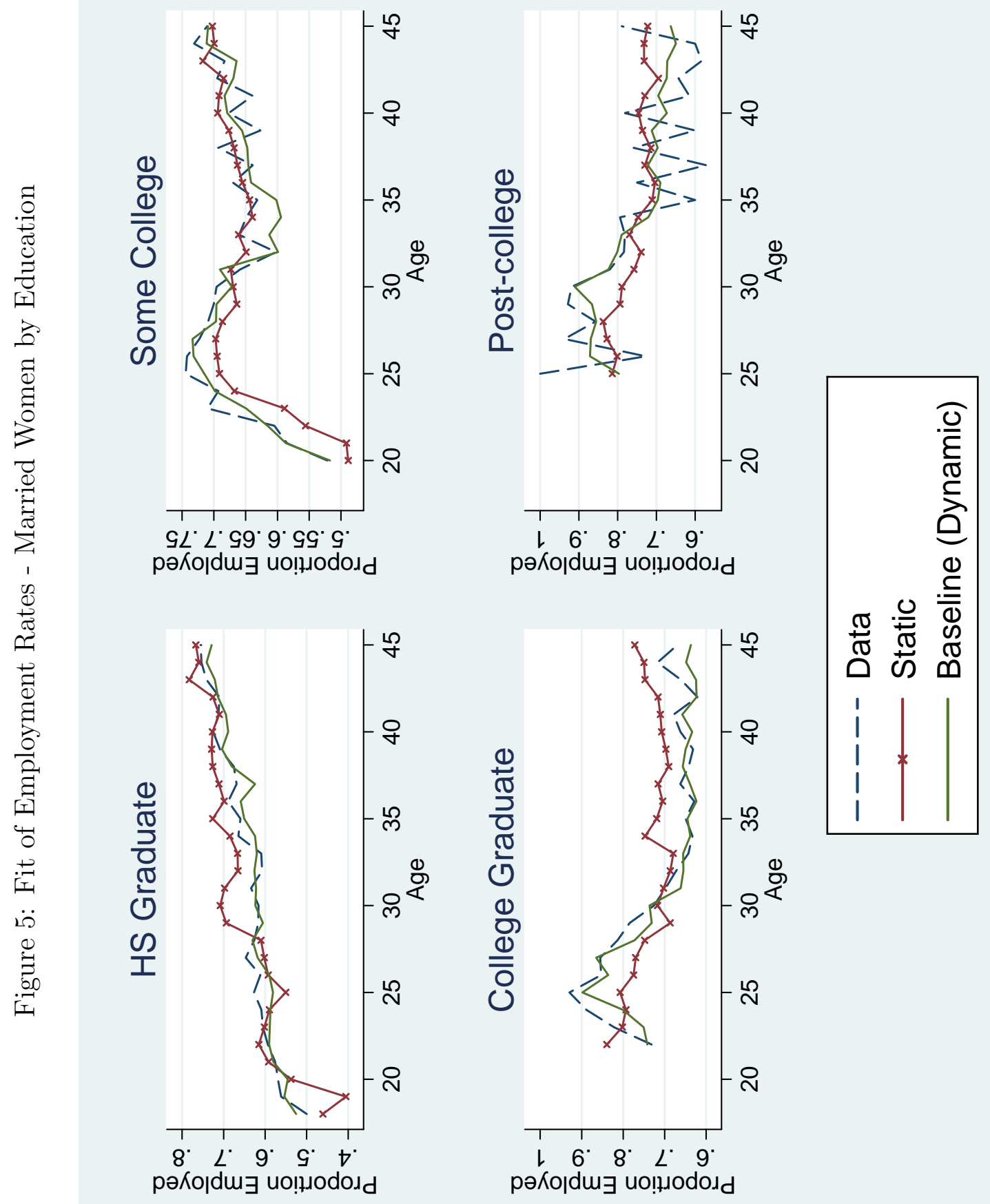



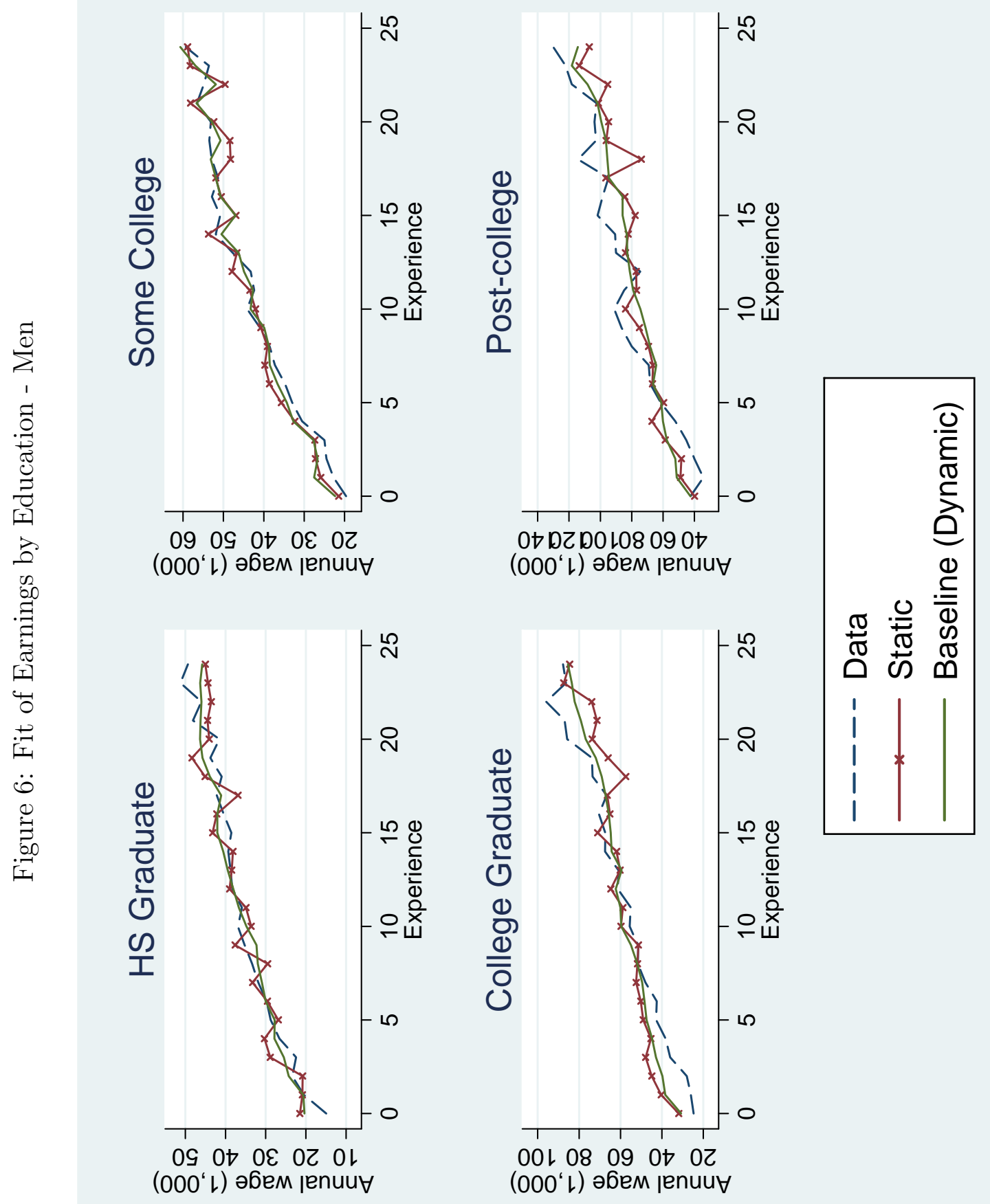

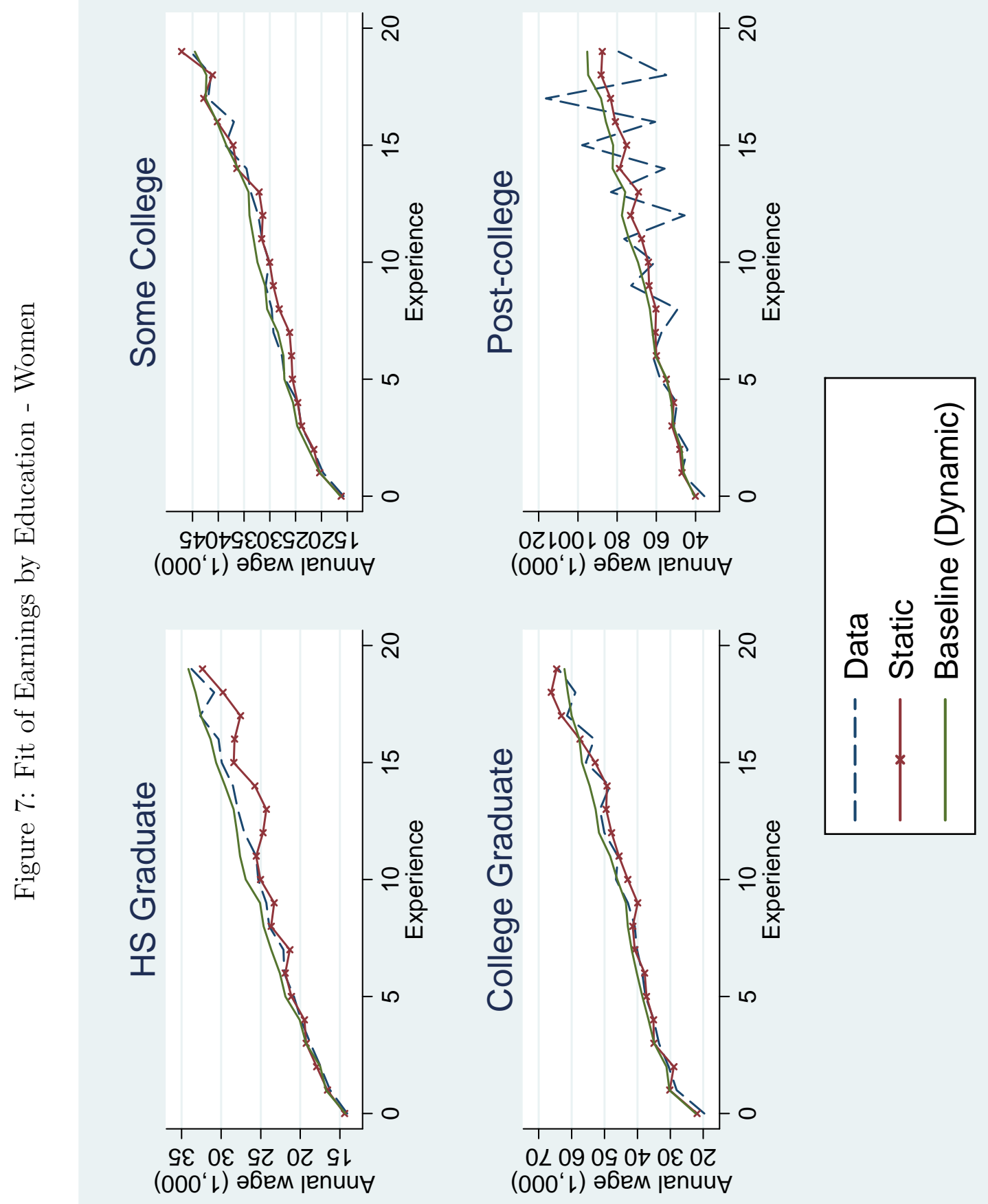


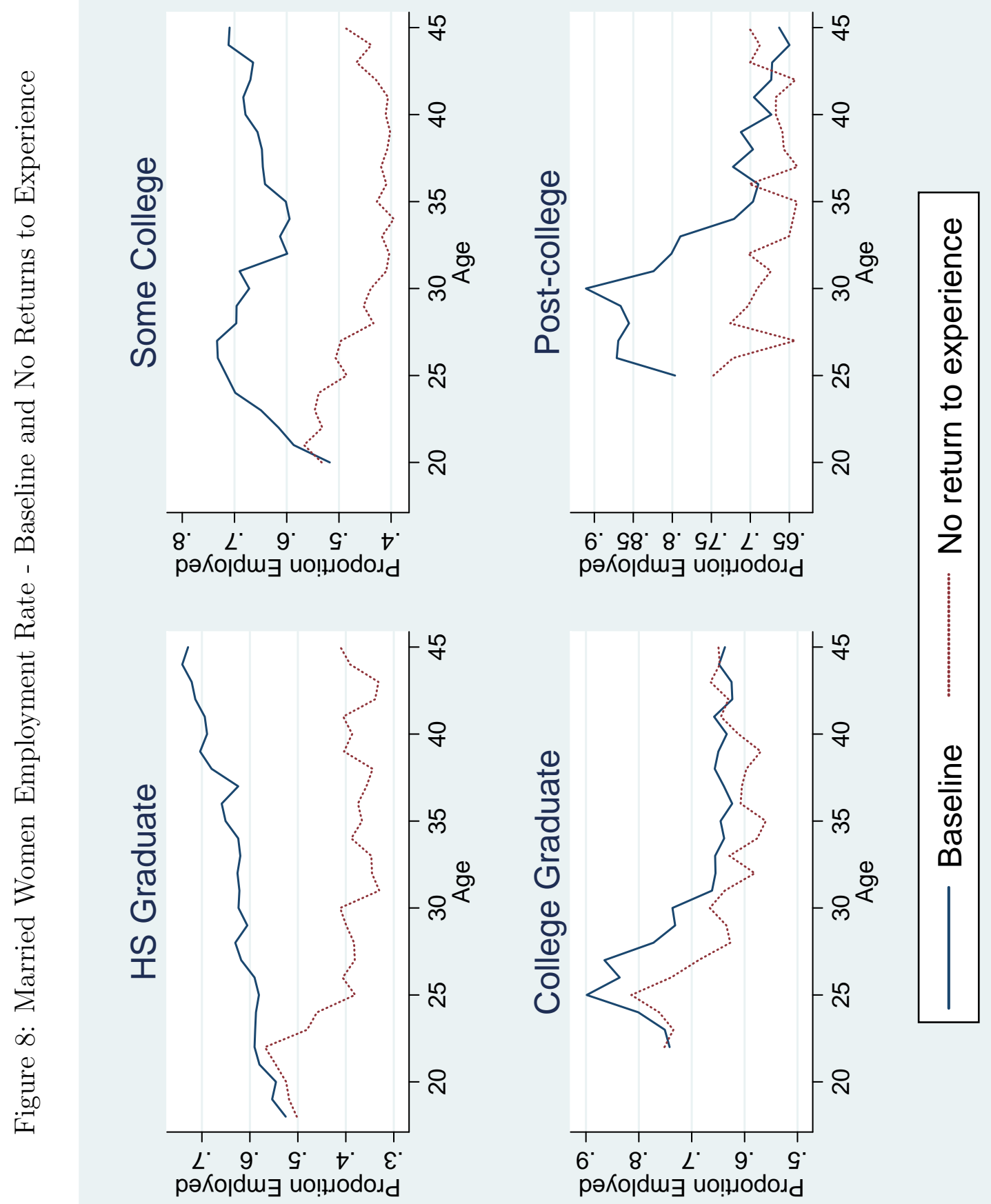




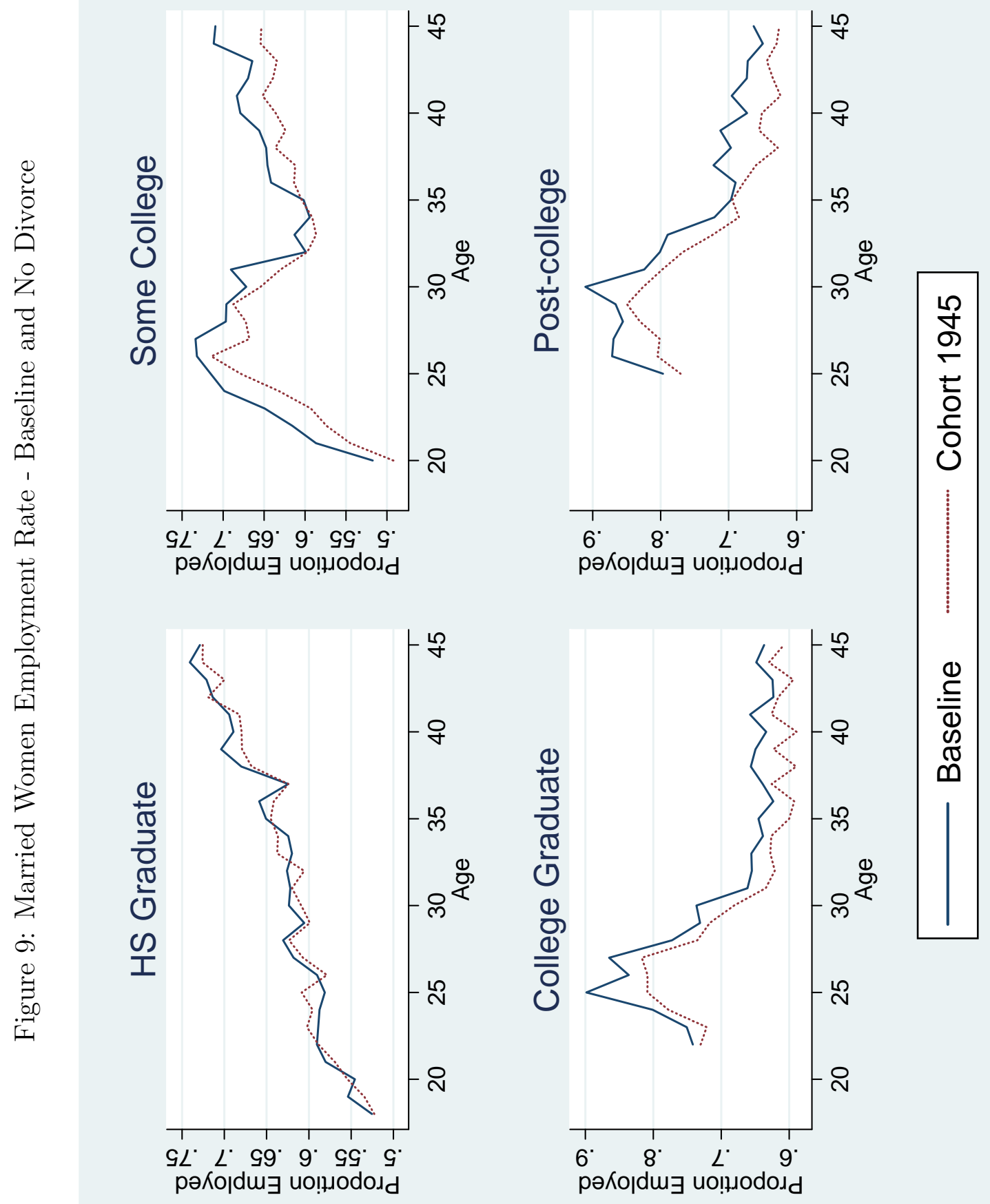




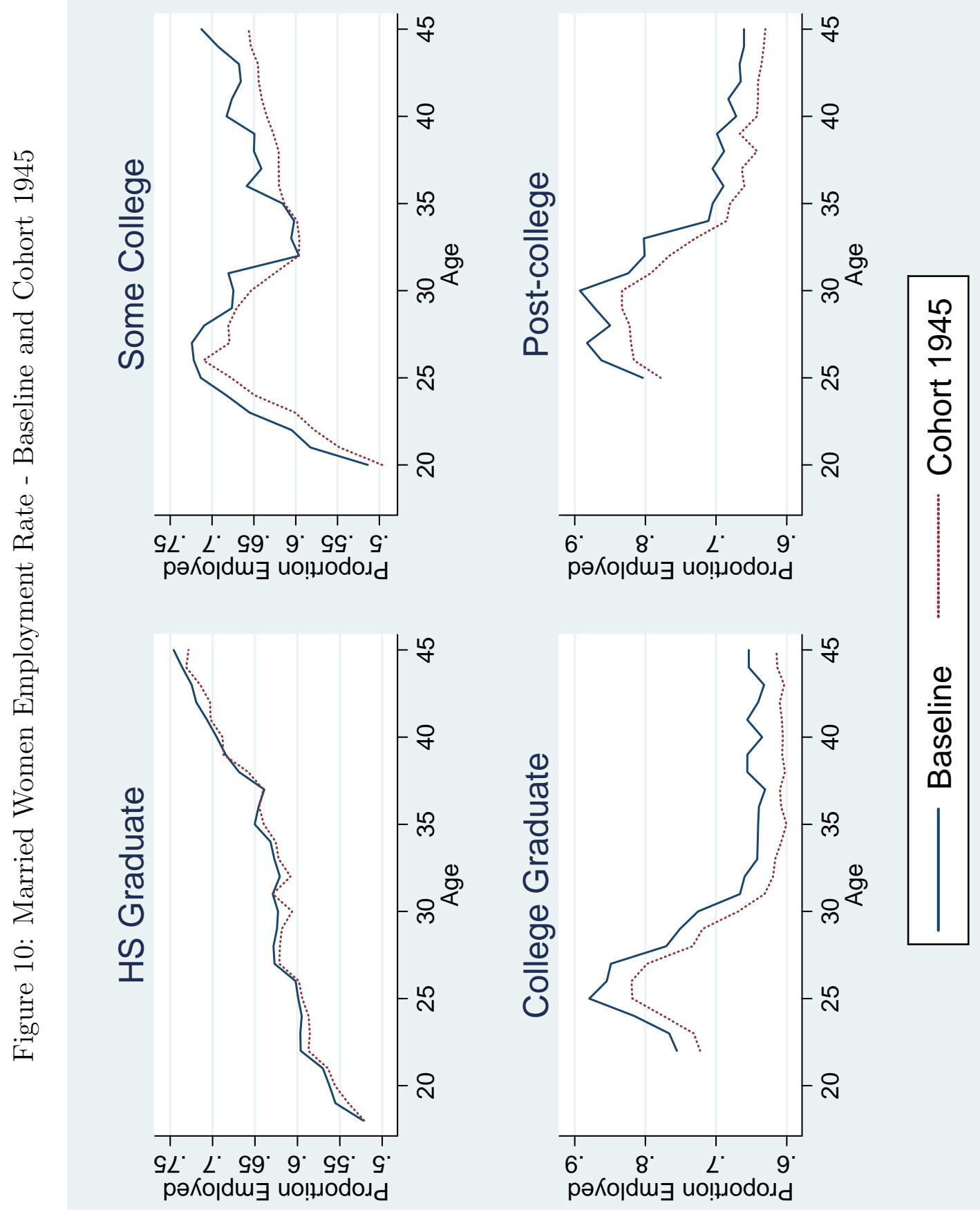


Table 1: Husbands' Education Distribution by Wive's Educational Attainment

\begin{tabular}{|c|c|c|c|c|c|}
\hline \multirow{4}{*}{ Husband Education Group } & \multicolumn{5}{|c|}{$(1)$} \\
\hline & \multicolumn{5}{|c|}{ All sample } \\
\hline & \multicolumn{5}{|c|}{ Wife Education Group } \\
\hline & HSD & HSG & $\mathrm{SC}$ & $\mathrm{CG}$ & $\mathrm{PC}$ \\
\hline High School Dropout (HSD) & 65.32 & 17.27 & 5.9 & 1.87 & 1.05 \\
\hline High School Graduate (HS) & 25.49 & 50.36 & 25.57 & 12.15 & 7.82 \\
\hline Some College (SC) & 7.13 & 20.43 & 38.27 & 19.36 & 13.85 \\
\hline College Graduate (CG) & 1.64 & 9.2 & 21.38 & 43.57 & 29.29 \\
\hline Post College Degree (PC) & 0.42 & 2.74 & 8.88 & 23.05 & 48 \\
\hline \multirow[t]{2}{*}{$\%$ Wives Married Down } & 0 & 17.27 & 31.47 & 33.38 & 52 \\
\hline & \multicolumn{5}{|c|}{$\begin{array}{c}40-45 \text { cohorts } \\
\text { Wife Education Group }\end{array}$} \\
\hline Husband Education Group & HSD & HSG & $\mathrm{SC}$ & CG & $\mathrm{PC}$ \\
\hline High School Dropout (HSD) & 59.87 & 17.82 & 5.98 & 1.91 & 1.45 \\
\hline High School Graduate (HS) & 30.57 & 50.1 & 23.48 & 9.9 & 6.31 \\
\hline Some College (SC) & 7.58 & 20.1 & 33.33 & 14.62 & 11.84 \\
\hline College Graduate (CG) & 1.59 & 9.1 & 24.61 & 41.88 & 21.38 \\
\hline Post College Degree (PC) & 0.38 & 2.88 & 12.59 & 31.69 & 59.03 \\
\hline$\%$ Wives Married Down & 0 & 17.82 & 29.46 & 26.43 & 40.97 \\
\hline
\end{tabular}

(3)

60-65 cohorts

Husband Education Group

Wife Education Group

\begin{tabular}{lllccc} 
& HSD & HSG & SC & CG & PC \\
\cline { 2 - 6 } High School Dropout (HSD) & 59.53 & 11.44 & 4.85 & 1.42 & 0.74
\end{tabular}

$\begin{array}{llllll}\text { High School Graduate (HS) } & 28.6 & 56.05 & 28.56 & 13.42 & 8.67\end{array}$

$\begin{array}{llllll}\text { Some College (SC) } & 9.15 & 21.64 & 41 & 20.78 & 14.82\end{array}$

$\begin{array}{llllll}\text { College Graduate (CG) } & 2.29 & 8.76 & 18.99 & 44.54 & 31.22\end{array}$

\begin{tabular}{llllll} 
Post College Degree (PC) & 0.43 & 2.11 & 6.6 & 19.84 & 44.55 \\
\hline
\end{tabular}

$\begin{array}{llllll}\text { \% Wives Married Down } & 0 & 11.44 & 33.41 & 35.62 & 55.45\end{array}$

Source - March CPS 1965 - 2011.

Notes - Married white women, ages 25 - 55. 
Table 2: Women's Employment Rate by Wives' and Husband's Educational Attainment

\begin{tabular}{lcccc}
\hline \hline & \multicolumn{4}{c}{ Women Education Group } \\
Men Education Group & HSG & SC & CG & PC \\
\cline { 2 - 6 } & & & & \\
High School Dropout (HSD) & $\mathbf{4 9}$ & $\mathbf{5 7 . 4 7}$ & $\mathbf{6 8 . 0 7}$ & $\mathbf{7 1 . 2 4}$ \\
High School Graduate (HS) & 51.92 & $\mathbf{6 2 . 1 8}$ & $\mathbf{7 1 . 5 8}$ & $\mathbf{8 0 . 4 7}$ \\
Some College (SC) & 51.47 & 60.23 & $\mathbf{6 8 . 3 9}$ & $\mathbf{7 9 . 9 7}$ \\
College Graduate (CG) & 44.87 & 49.74 & 57.78 & $\mathbf{7 1 . 6 1}$ \\
Post College Degree (PC) & 41.17 & 44.38 & 47.76 & 66.31 \\
& & & & \\
\hline \hline
\end{tabular}

Source - March CPS 1965 - 2011.

Notes - Married white women, ages 25 - 55. Proportion working at least 20 weekly hours. * - small sample size. In bold: women marrying down. 
Table 3: Estimated Effects on Wife's Employment

\begin{tabular}{|c|c|c|c|c|c|c|}
\hline VARIABLES & $(1)$ & $(2)$ & $(3)$ & $(4)$ & $(5)$ & $(6)$ \\
\hline Female married down $(\mathrm{d})$ & $\begin{array}{c}0.050^{* * *} \\
(0.001)\end{array}$ & $\begin{array}{c}0.049 * * * \\
(0.001)\end{array}$ & $\begin{array}{c}0.036 * * * \\
(0.002)\end{array}$ & $\begin{array}{c}0.042^{* * *} \\
(0.002)\end{array}$ & $\begin{array}{c}0.038^{* * * *} \\
(0.003)\end{array}$ & $\begin{array}{c}0.037 * * * \\
(0.003)\end{array}$ \\
\hline Female married up (d) & $\begin{array}{c}-0.049 * * * \\
(0.001)\end{array}$ & $\begin{array}{c}-0.047 * * * \\
(0.001)\end{array}$ & $\begin{array}{c}-0.029 * * * \\
(0.001)\end{array}$ & $\begin{array}{c}-0.025 * * * \\
(0.002)\end{array}$ & $\begin{array}{c}-0.022 * * * \\
(0.002)\end{array}$ & $\begin{array}{c}-0.023 * * * \\
(0.003)\end{array}$ \\
\hline Female post graduate $(\mathrm{d})$ & $\begin{array}{c}0.254^{* * * *} \\
(0.002)\end{array}$ & $\begin{array}{c}0.249 * * * \\
(0.002)\end{array}$ & $\begin{array}{c}0.299^{* * *} \\
(0.002)\end{array}$ & $\begin{array}{c}0.278^{* * *} \\
(0.005)\end{array}$ & $\begin{array}{c}0.306^{* * *} \\
(0.005)\end{array}$ & $\begin{array}{c}0.293^{* * *} \\
(0.006)\end{array}$ \\
\hline Female college graduate $(\mathrm{d})$ & $\begin{array}{c}0.191^{* * *} \\
(0.002)\end{array}$ & $\begin{array}{c}0.182^{* * *} \\
(0.002)\end{array}$ & $\begin{array}{l}0.230^{* * *} \\
(0.002)\end{array}$ & $\begin{array}{c}0.195^{* * *} \\
(0.005)\end{array}$ & $\begin{array}{l}0.225^{* * *} \\
(0.005)\end{array}$ & $\begin{array}{l}0.204^{* * *} \\
(0.006)\end{array}$ \\
\hline Female some college $(\mathrm{d})$ & $\begin{array}{l}0.181^{* * *} \\
(0.002)\end{array}$ & $\begin{array}{c}0.165^{* * *} \\
(0.002)\end{array}$ & $\begin{array}{l}0.201^{* * *} \\
(0.002)\end{array}$ & $\begin{array}{c}0.152^{* * *} \\
(0.004)\end{array}$ & $\begin{array}{c}0.177^{* * *} \\
(0.004)\end{array}$ & $\begin{array}{c}0.162^{* * *} \\
(0.005)\end{array}$ \\
\hline Female high school graduate $(\mathrm{d})$ & $\begin{array}{c}0.145^{* * *} \\
(0.002)\end{array}$ & $\begin{array}{c}0.123^{* * *} \\
(0.002)\end{array}$ & $\begin{array}{c}0.145^{* * *} \\
(0.002)\end{array}$ & $\begin{array}{c}0.102^{* * *} \\
(0.003)\end{array}$ & $\begin{array}{c}0.120 * * * \\
(0.003)\end{array}$ & $\begin{array}{c}0.111^{* * *} \\
(0.004)\end{array}$ \\
\hline Age & $\begin{array}{c}0.003^{* * *} \\
(0.000)\end{array}$ & $\begin{array}{c}-0.004^{* * *} \\
(0.000)\end{array}$ & $\begin{array}{c}-0.003^{* * *} \\
(0.000)\end{array}$ & $\begin{array}{c}-0.004^{* * * *} \\
(0.000)\end{array}$ & $\begin{array}{c}-0.003^{* * *} \\
(0.000)\end{array}$ & $\begin{array}{r}-0.003^{*} \\
(0.002)\end{array}$ \\
\hline Age gap & $\begin{array}{c}-0.001^{* * *} \\
(0.000)\end{array}$ & $\begin{array}{c}-0.002^{* * *} \\
(0.000)\end{array}$ & $\begin{array}{c}-0.001^{* * * *} \\
(0.000)\end{array}$ & $\begin{array}{c}-0.002^{* * * *} \\
(0.000)\end{array}$ & $\begin{array}{c}-0.001^{* * * *} \\
(0.000)\end{array}$ & $\begin{array}{l}-0.001 \\
(0.000)\end{array}$ \\
\hline Number of children in the $\mathrm{HH}$ & & $\begin{array}{c}-0.043^{* * *} \\
(0.000)\end{array}$ & $\begin{array}{c}-0.041^{* * * *} \\
(0.000)\end{array}$ & $\begin{array}{c}-0.042^{* * * *} \\
(0.000)\end{array}$ & $\begin{array}{c}-0.038^{* * * *} \\
(0.000)\end{array}$ & $\begin{array}{c}-0.043^{*} \\
(0.025)\end{array}$ \\
\hline Presence of a child $0-6$ & & $\begin{array}{c}-0.221^{* * *} \\
(0.001)\end{array}$ & $\begin{array}{c}-0.224^{* * *} \\
(0.001)\end{array}$ & $\begin{array}{c}-0.221^{* * *} \\
(0.001)\end{array}$ & $\begin{array}{c}-0.226^{* * *} \\
(0.001)\end{array}$ & $\begin{array}{c}-0.233^{* * *} \\
(0.002)\end{array}$ \\
\hline Male post graduate (d) & & & & $\begin{array}{c}-0.038^{* * *} \\
(0.007)\end{array}$ & $\begin{array}{c}0.029^{* * *} \\
(0.007)\end{array}$ & $\begin{array}{c}0.029^{* * *} \\
(0.008)\end{array}$ \\
\hline Male college graduate $(\mathrm{d})$ & & & & $\begin{array}{l}0.010^{*} \\
(0.005)\end{array}$ & $\begin{array}{c}0.062^{* * *} \\
(0.005)\end{array}$ & $\begin{array}{c}0.059^{* * *} \\
(0.006)\end{array}$ \\
\hline Male some college $(\mathrm{d})$ & & & & $\begin{array}{c}0.076^{* * *} \\
(0.004)\end{array}$ & $\begin{array}{c}0.098^{* * *} \\
(0.004)\end{array}$ & $\begin{array}{c}0.096^{* * *} \\
(0.005)\end{array}$ \\
\hline Male high school graduate $(\mathrm{d})$ & & & & $\begin{array}{c}0.051^{* * *} \\
(0.003)\end{array}$ & $\begin{array}{c}0.061^{* * *} \\
(0.003)\end{array}$ & $\begin{array}{c}0.059^{* * *} \\
(0.004)\end{array}$ \\
\hline $\begin{array}{l}\text { Dummies for the deciles of } \\
\text { Husband's annual income }\end{array}$ & NO & NO & YES & $\mathrm{NO}$ & YES & YES \\
\hline Time dummies & YES & YES & YES & YES & YES & YES \\
\hline MSA fixed effects & $\mathrm{NO}$ & $\mathrm{NO}$ & NO & $\mathrm{NO}$ & $\mathrm{NO}$ & YES \\
\hline Mean employment (dependent variable) & 0.519 & 0.519 & 0.519 & 0.519 & 0.519 & 0.512 \\
\hline Observations & 972,821 & 972,821 & 972,821 & 972,821 & 972,821 & 681,503 \\
\hline
\end{tabular}

Notes - Married white women, ages 25 - 55. Employment indicator is one when working at least 20 weekly hours. Marginal effects (instead of logit coefficients) are reported. ${ }^{* * *} \mathrm{p}<0.01,{ }^{* *} \mathrm{p}<0.05,{ }^{*} \mathrm{p}<0.1$. (d) for dummy variable. Reference education group: HSD. 
Table 4: Estimated Effects by Education Group (Dependent Variable: Employment)

\begin{tabular}{|c|c|c|c|c|}
\hline VARIABLES & $\begin{array}{c}(1) \\
\text { High School } \\
\text { Graduate }\end{array}$ & $\begin{array}{c}(2) \\
\text { Some } \\
\text { Graduate }\end{array}$ & $\begin{array}{c}(3) \\
\text { College } \\
\text { Graduate }\end{array}$ & $\begin{array}{c}(4) \\
\text { Post- } \\
\text { Graduate }\end{array}$ \\
\hline Female married down $(\mathrm{d})$ & $\begin{array}{c}-0.032^{* * *} \\
(0.004)\end{array}$ & $\begin{array}{c}0.009^{* * *} \\
(0.004)\end{array}$ & $\begin{array}{c}0.085^{* * *} \\
(0.004)\end{array}$ & $\begin{array}{c}0.059^{* * *} \\
(0.005)\end{array}$ \\
\hline Female married up (d) & $\begin{array}{c}-0.005^{* *} \\
(0.002)\end{array}$ & $\begin{array}{c}-0.075^{* * *} \\
(0.003)\end{array}$ & $\begin{array}{c}-0.063^{* * *} \\
(0.004)\end{array}$ & \\
\hline $\begin{array}{l}\text { Dummies for the deciles of } \\
\text { Husband's annual income }\end{array}$ & YES & YES & YES & YES \\
\hline Time dummies & YES & YES & YES & YES \\
\hline MSA fixed effects & YES & YES & YES & YES \\
\hline Mean employment (dependent variable) & 0.477 & 0.574 & 0.594 & 0.691 \\
\hline Observations & 324,168 & 147,670 & 112,336 & 52,429 \\
\hline
\end{tabular}

Notes - Married white women, ages 25 - 55. Employment indicator is one when working at least 20 weekly hours. Marginal effects (instead of logit coefficients) are reported. All models include own age, age gap, number of children in the HH and an indicator for the presence of a child $0-6$. $* * * \mathrm{p}<0.01,{ }^{* *} \mathrm{p}<0.05, * \mathrm{p}<0.1$.

Table 5: Assortative mating at First Marriage - Data, Baseline and Static Model

\begin{tabular}{cccc}
\hline \hline & & $\begin{array}{c}\text { Baseline } \\
\text { Dynamic } \\
\text { Model }\end{array}$ & $\begin{array}{c}\text { Static } \\
\text { Model }\end{array}$ \\
Woman's Education & Data & & \\
\hline HS Graduate & & & \\
Up & 0.264 & 0.244 & 0.232 \\
Equal & 0.586 & 0.585 & 0.533 \\
Down & 0.150 & 0.171 & 0.236 \\
Up & & & \\
Equal & 0.277 & 0.234 & 0.177 \\
Down & 0.288 & 0.292 & 0.309 \\
College & 0.434 & 0.474 & 0.514 \\
Equal & & & \\
Down & 0.168 & 0.155 & 0.075 \\
Up & 0.465 & 0.449 & 0.362 \\
Equal & 0.367 & 0.396 & 0.563 \\
Down & & & \\
& - & - & - \\
& 0.407 & 0.417 & 0.279 \\
\hline \hline
\end{tabular}


Table 6: Married Women's Employment by Relative Position in Education - Data, Baseline and Static Model

\begin{tabular}{cccc}
\hline \hline & & $\begin{array}{c}\text { Baseline } \\
\text { Dynamic } \\
\text { Model }\end{array}$ & $\begin{array}{c}\text { Static } \\
\text { Model }\end{array}$ \\
Woman's Education & Data & & \\
\hline HS Graduate & & & \\
Up & 0.636 & 0.624 & 0.645 \\
Equal & 0.640 & 0.630 & 0.640 \\
Down & 0.660 & 0.653 & 0.651 \\
Some College & & & \\
Up & 0.609 & 0.604 & 0.658 \\
Equal & 0.672 & 0.677 & 0.716 \\
Down & 0.732 & 0.730 & 0.729 \\
College Graduate & & & \\
Up & 0.590 & 0.591 & 0.715 \\
Equal & 0.738 & 0.749 & 0.780 \\
Down & 0.795 & 0.780 & 0.752 \\
Post-college & & & \\
Up & - & - & - \\
Equal & 0.678 & 0.673 & 0.722 \\
Down & 0.813 & 0.807 & 0.796 \\
& & & \\
\hline \hline
\end{tabular}

Table 7: Selected Moments - Data and Baseline Model

\begin{tabular}{|c|c|c|c|c|c|c|c|c|}
\hline & \multicolumn{4}{|c|}{ Data } & \multicolumn{4}{|c|}{ Baseline Model } \\
\hline & $\begin{array}{c}\text { HS } \\
\text { Graduate }\end{array}$ & $\begin{array}{l}\text { Some } \\
\text { College }\end{array}$ & $\begin{array}{c}\text { College } \\
\text { Graduate }\end{array}$ & $\begin{array}{l}\text { Post } \\
\text { College }\end{array}$ & $\begin{array}{c}\text { HS } \\
\text { Graduate }\end{array}$ & $\begin{array}{l}\text { Some } \\
\text { College }\end{array}$ & $\begin{array}{c}\text { College } \\
\text { Graduate }\end{array}$ & $\begin{array}{c}\text { Post } \\
\text { College }\end{array}$ \\
\hline No. of kids by 40 & 1.90 & 1.82 & 1.73 & 1.42 & 2.07 & 1.86 & 1.48 & 1.53 \\
\hline \multicolumn{9}{|l|}{ Married with } \\
\hline 0 children & 0.82 & 0.83 & 0.91 & 0.89 & 0.80 & 0.86 & 0.87 & 0.87 \\
\hline 1 child & 0.64 & 0.68 & 0.77 & 0.75 & 0.65 & 0.71 & 0.78 & 0.76 \\
\hline 2 children & 0.58 & 0.61 & 0.60 & 0.61 & 0.61 & 0.61 & 0.60 & 0.60 \\
\hline 3 children & 0.47 & 0.57 & 0.49 & 0.48 & 0.49 & 0.52 & 0.52 & 0.56 \\
\hline $4+$ children & 0.46 & 0.36 & 0.35 & 0.47 & 0.45 & 0.44 & 0.45 & 0.44 \\
\hline \multicolumn{9}{|l|}{ Single with } \\
\hline No child & 0.80 & 0.80 & 0.88 & 0.87 & 0.81 & 0.79 & 0.91 & 0.88 \\
\hline Child & 0.64 & 0.77 & 0.90 & 1.00 & 0.72 & 0.84 & 0.89 & 0.98 \\
\hline
\end{tabular}

Notes - Due to the small sample size of single women, we assumed that the fertility effect can be adequately captured by the presence of any children. 
Table 8: Ability and Match Quality by Match

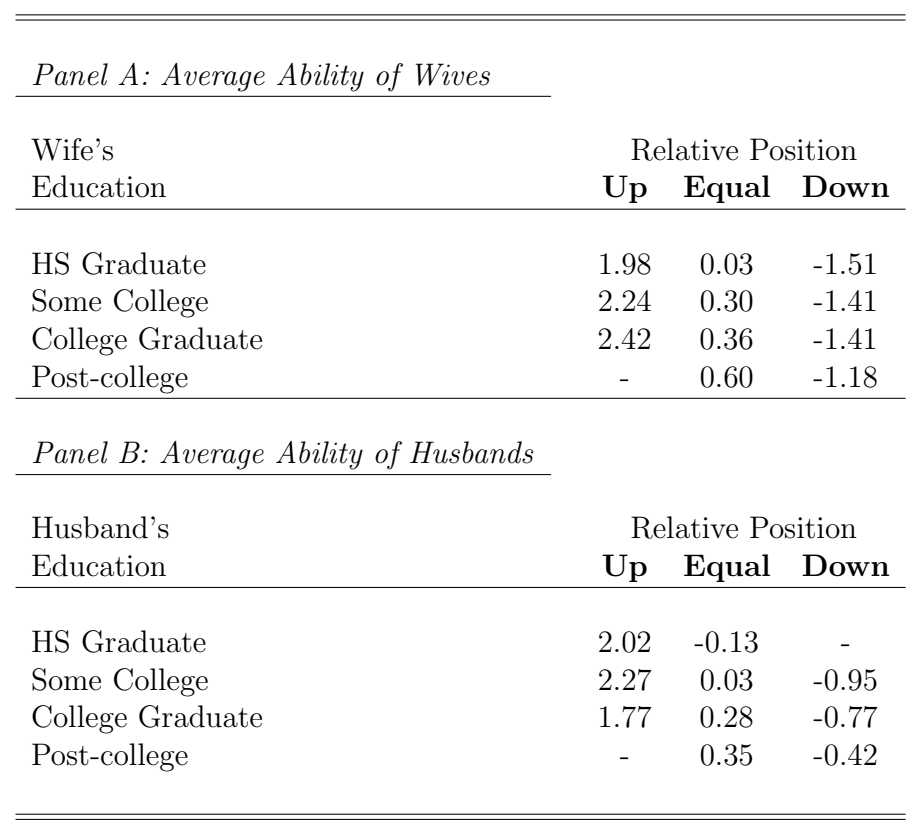

Table 9: Assortative mating at the First Marriage - Baseline and No Return to Experience

\begin{tabular}{ccc}
\hline \hline & $\begin{array}{c}\text { Baseline } \\
\text { Dynamic } \\
\text { Model }\end{array}$ & $\begin{array}{c}\text { No Return } \\
\text { to Experience }\end{array}$ \\
Woman's Education & & \\
HS Graduate & 0.244 & 0.253 \\
Up & 0.585 & 0.563 \\
Equal & 0.171 & 0.184 \\
Down & & \\
Some College & 0.234 & 0.216 \\
Up & 0.292 & 0.310 \\
Equal & 0.474 & 0.473 \\
Down & & \\
College Graduate & 0.155 & 0.132 \\
Up & 0.449 & 0.396 \\
Equal & 0.396 & 0.472 \\
Down & & - \\
Up & - & 0.249 \\
Equal & 0.417 & 0.751 \\
Down & 0.583 & \\
& & \\
\hline \hline
\end{tabular}


Table 10: Married Women's Employment by Relative Position in Education - Baseline and No Return to Experience

\begin{tabular}{ccc}
\hline \hline & $\begin{array}{c}\text { Baseline } \\
\text { Dynamic } \\
\text { Model }\end{array}$ & $\begin{array}{c}\text { No Return } \\
\text { to Experience }\end{array}$ \\
Woman's Education & & \\
HS Graduate & 0.624 & 0.368 \\
Up & 0.630 & 0.411 \\
Equal & 0.653 & 0.412 \\
Down & & \\
Some College & 0.604 & 0.418 \\
Up & 0.677 & 0.454 \\
Equal & 0.730 & 0.470 \\
Down & & \\
College Graduate & 0.591 & 0.555 \\
Up & 0.749 & 0.611 \\
Equal & 0.780 & 0.624 \\
Down & & \\
Post-college & - & - \\
Up & 0.673 & 0.669 \\
Equal & 0.807 & 0.681 \\
Down & & \\
& & \\
\hline \hline
\end{tabular}

Table 11: Assortative mating at the First Marriage - Baseline and Cohort 1945

\begin{tabular}{ccc}
\hline Woman's Education & $\begin{array}{c}\text { Baseline } \\
\text { Dynamic } \\
\text { Model }\end{array}$ & $\begin{array}{c}\text { Cohort } \\
\mathbf{1 9 4 5}\end{array}$ \\
HS Graduate & & \\
Up & & \\
Equal & 0.244 & 0.336 \\
Down & 0.585 & 0.551 \\
Some College & 0.171 & 0.113 \\
Up & & \\
Equal & 0.234 & 0.278 \\
Down & 0.292 & 0.318 \\
College Graduate & 0.474 & 0.404 \\
Up & & \\
Equal & 0.155 & 0.255 \\
Down & 0.449 & 0.484 \\
Post-college & 0.396 & 0.261 \\
Equal & & \\
Down & - & - \\
& 0.417 & 0.496 \\
\hline \hline
\end{tabular}


Table 12: Married Women's Employment by Relative Position in Education - Baseline and Cohort 1945

\begin{tabular}{ccc}
\hline \hline & $\begin{array}{c}\text { Baseline } \\
\text { Dynamic } \\
\text { Model }\end{array}$ & $\begin{array}{c}\text { Cohort } \\
\mathbf{1 9 4 5}\end{array}$ \\
Woman's Education & & \\
\hline HS Graduate & & \\
Up & 0.624 & 0.622 \\
Equal & 0.630 & 0.620 \\
Down & 0.653 & 0.655 \\
Some College & & \\
Up & 0.604 & 0.620 \\
Equal & 0.677 & 0.651 \\
Down & 0.730 & 0.746 \\
College Graduate & & \\
Eq & 0.591 & 0.640 \\
Down & 0.749 & 0.717 \\
Post-college & 0.780 & 0.801 \\
Up & & \\
Equal & - & \\
Down & 0.673 & 0.722 \\
& 0.807 & 0.820 \\
\hline \hline
\end{tabular}




\section{Appendix A}

Figure A1: Married HS Graduate Female's Employment Rate by Match

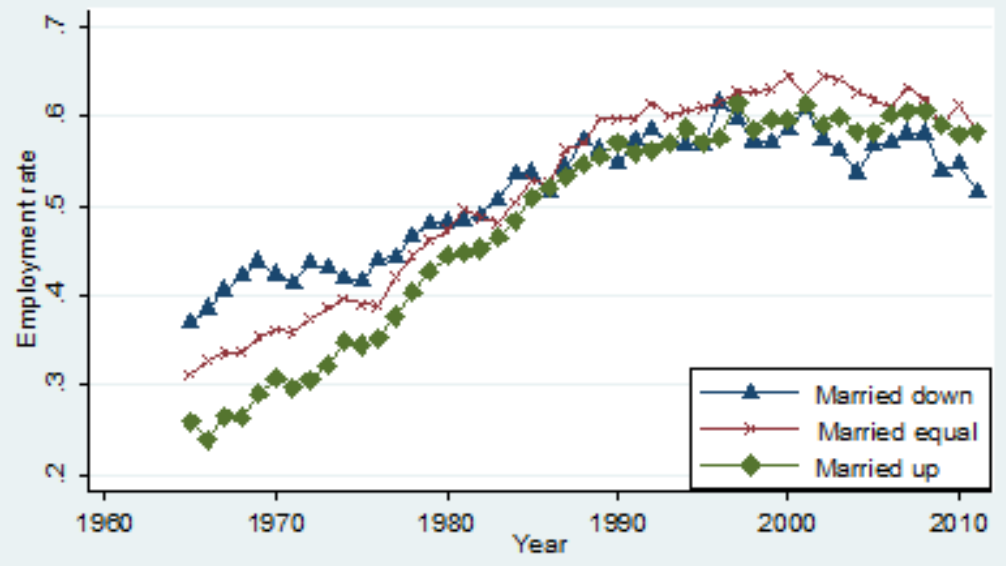

Source - March CPS 1965 - 2011.

Notes - White females, ages 25 - 55. Proportion working at least 20 weekly hours. 


\section{Appendix B}

Table B1: Men's Employment by Women and Men Education Group

\begin{tabular}{lcccc}
\hline \hline & \multicolumn{4}{c}{ Men Education Group } \\
Women Education Group & HSG & SC & CG & PC \\
\cline { 2 - 5 } & & & & \\
High School Dropout (HSD) & $\mathbf{8 4 . 6 3}$ & $\mathbf{8 4 . 1 2}$ & $\mathbf{8 7 . 5 2}$ & $\mathbf{8 7 . 3 4}$ \\
High School Graduate (HS) & 87.8 & $\mathbf{8 8 . 9 3}$ & $\mathbf{9 2 . 5 1}$ & $\mathbf{9 2 . 9 7}$ \\
Some College (SC) & 87.29 & 89.06 & $\mathbf{9 2 . 7 8}$ & $\mathbf{9 3 . 3 4}$ \\
College Graduate (CG) & 88.48 & 88.54 & 92.28 & $\mathbf{9 3 . 2}$ \\
Post College Degree (PC) & 85.8 & 85.88 & 89.54 & 92.02 \\
\hline \hline
\end{tabular}

Notes - * - small sample size. Proportion working at least 20 weekly hours. In bold: men marrying down.

Table B2: Women Employment Rate by Women and Men Education Group

(1)

Husband at the top $10 \%$ of income distribution

Men Education Group
High School Dropout (HSD)
High School Graduate (HS)
Some College (SC)
College Graduate (CG)
Post College Degree (PC)

Source - March CPS 1965 - 2011.

Women Education Group

HSG $\quad \mathrm{SC} \quad \mathrm{CG} \quad \mathrm{PC}$

$\begin{array}{rrrr}34.99 & 40.64 & 63.19 & 60\end{array}$

$\begin{array}{llll}37.11 & \mathbf{4 6 . 0 5} & \mathbf{5 2 . 4 3} & \mathbf{7 0 . 2 4}\end{array}$

$\begin{array}{llll}36.55 & 44.88 & \mathbf{5 3 . 2 4} & \mathbf{6 5 . 3 5}\end{array}$

$\begin{array}{llll}32.81 & 35.86 & 42.68 & \mathbf{5 9 . 4 4}\end{array}$

$\begin{array}{llll}33.2 & 36.02 & 39.18 & 58.33\end{array}$
Husband at median income (45-55\% of income distribution)

\begin{tabular}{lcccc}
\hline & \multicolumn{4}{c}{ Women Education Group } \\
Men Education Group & HSG & SC & CG & PC \\
HSD & $\mathbf{5 4 . 2 8}$ & $\mathbf{6 3 . 6 4}$ & $\mathbf{6 8 . 8 5}$ & $\mathbf{7 5 . 3 8}$ \\
HSG & 59.86 & $\mathbf{6 8 . 6 6}$ & $\mathbf{7 8 . 2 5}$ & $\mathbf{8 3 . 6 1}$ \\
SC & 59.95 & 68.43 & $\mathbf{7 5 . 2 6}$ & $\mathbf{8 3 . 3 6}$ \\
CG & 60.17 & 62.06 & 71.1 & $\mathbf{8 0 . 3 2}$ \\
PC & 48.33 & 54.22 & 56.86 & 73.52 \\
& & & &
\end{tabular}

Notes - Married white women, ages 25 - 55. Proportion working at least 20 weekly hours. In bold: women marrying down. 


\section{Table B3: Women's Employment Rate by Women and Men Education Group}

(1)

Husband between the $80-90 \%$ of income distribution

\begin{tabular}{lcccc}
\hline & \multicolumn{4}{c}{ Women Education Group } \\
Men Education Group & HSG & SC & CG & PC \\
High School Dropout (HSD) & $\mathbf{3 8 . 5 3}$ & $\mathbf{5 2 . 3 3}$ & $\mathbf{6 6 . 8 3}$ & $\mathbf{6 5 . 5 2}$ \\
High School Graduate (HS) & 43.88 & $\mathbf{5 4 . 3 2}$ & $\mathbf{6 5 . 9 7}$ & $\mathbf{7 9 . 0 9}$ \\
Some College (SC) & 46.14 & 55.44 & $\mathbf{6 3 . 1 6}$ & $\mathbf{7 8 . 8}$ \\
College Graduate (CG) & 41.64 & 49.61 & 57.3 & $\mathbf{7 0 . 7 9}$ \\
Post College Degree (PC) & 44.86 & 49.7 & 52.77 & 70.4
\end{tabular}

(2)

Husband between the $70-80 \%$ of income distribution

\begin{tabular}{lcccc}
\hline & \multicolumn{4}{c}{ Women Education Group } \\
Men Education Group & HSG & SC & CG & PC \\
High School Dropout (HSD) & $\mathbf{4 4 . 6 9}$ & $\mathbf{5 8 . 3 3}$ & $\mathbf{6 6 . 3 9}$ & $\mathbf{8 4 . 7 8}$ \\
High School Graduate (HS) & 50.73 & $\mathbf{6 1 . 3 2}$ & $\mathbf{7 2 . 0 2}$ & $\mathbf{8 0 . 5 9}$ \\
Some College (SC) & 51.46 & 61.49 & $\mathbf{6 8 . 2 6}$ & $\mathbf{8 0 . 7 4}$ \\
College Graduate (CG) & 49.54 & 56.56 & 64.06 & $\mathbf{7 5 . 8 3}$ \\
Post College Degree (PC) & 52 & 54.11 & 58.99 & 72.86
\end{tabular}

(3)

Husband between the $60-70 \%$ of income distribution

\begin{tabular}{lcccc}
\hline & \multicolumn{4}{c}{ Women Education Group } \\
Men Education Group & HSG & SC & CG & PC \\
High School Dropout (HSD) & $\mathbf{4 8 . 8 7}$ & $\mathbf{5 7 . 0 1}$ & $\mathbf{6 8 . 4 2}$ & $\mathbf{6 6 . 6 7}$ \\
High School Graduate (HS) & 54.82 & $\mathbf{6 5 . 8 6}$ & $\mathbf{7 4 . 3 8}$ & $\mathbf{8 3 . 3 9}$ \\
Some College (SC) & 55.89 & 64.76 & $\mathbf{7 3 . 1 4}$ & $\mathbf{8 2 . 7 2}$ \\
College Graduate (CG) & 52.36 & 58.43 & 68.14 & $\mathbf{8 0 . 0 1}$ \\
Post College Degree (PC) & 50.07 & 56.64 & 60.39 & 74.55
\end{tabular}

(4)

Husband between the 50-60\% of income distribution

\begin{tabular}{lcccc}
\hline & \multicolumn{4}{c}{ Women Education Group } \\
Men Education Group & HSG & SC & CG & PC \\
High School Dropout (HSD) & $\mathbf{5 2 . 7 4}$ & $\mathbf{6 1 . 8 9}$ & $\mathbf{6 6 . 7 7}$ & $\mathbf{7 2 . 0 6}$ \\
High School Graduate (HS) & 58.66 & $\mathbf{6 8 . 5 6}$ & $\mathbf{7 7 . 4 2}$ & $\mathbf{8 6 . 0 6}$ \\
Some College (SC) & 59.69 & 67.09 & $\mathbf{7 5 . 0 7}$ & $\mathbf{8 4 . 9 4}$ \\
College Graduate (CG) & 58.65 & 61.6 & 71.25 & $\mathbf{8 0 . 6 3}$ \\
Post College Degree (PC) & 53.61 & 54.92 & 57.83 & 74.64
\end{tabular}

Husband between the $40-50 \%$ of income distribution

\begin{tabular}{lcccc} 
& \multicolumn{4}{c}{ Women Education Group } \\
Men Education Group & HSG & SC & CG & PC \\
HSD & $\mathbf{5 5 . 8 3}$ & $\mathbf{6 2 . 6 2}$ & $\mathbf{7 1 . 2 5}$ & $\mathbf{7 5 . 7 1}$ \\
HSG & 59.52 & $\mathbf{6 7 . 6 7}$ & $\mathbf{7 7 . 8 1}$ & $\mathbf{8 4 . 6 5}$ \\
SC & 59.84 & 68.43 & $\mathbf{7 6 . 0 4}$ & $\mathbf{8 3 . 3 9}$ \\
CG & 58.36 & 62.94 & 70.25 & $\mathbf{8 1 . 1 8}$ \\
PC & 51.94 & 51.85 & 56.51 & 72.49
\end{tabular}

(6)

Husband between the $30-40 \%$ of income distribution

\begin{tabular}{lcccc} 
& \multicolumn{4}{c}{ Women Education Group } \\
Men Education Group & HSG & SC & CG & PC \\
HSD & $\mathbf{5 3 . 8 5}$ & $\mathbf{5 8 . 5 9}$ & $\mathbf{7 1 . 4 7}$ & $\mathbf{7 2 . 4 6}$ \\
HSG & 57.26 & $\mathbf{6 5 . 6 5}$ & $\mathbf{7 5 . 8 4}$ & $\mathbf{8 1}$ \\
SC & 58.49 & 64.63 & $\mathbf{7 5 . 3 9}$ & $\mathbf{8 3 . 0 4}$ \\
CG & 56.72 & 58.8 & 66.78 & $\mathbf{8 0 . 5}$ \\
PC & 54.3 & 53.86 & 57.38 & 72.94
\end{tabular}

(7)

Husband between the 20-30\% of income distribution

Women Education Group

Men Education Group HSG SC CG PC

$\begin{array}{lllll}\text { HSD } & 48.48 & 53.5 & \mathbf{7 3 . 3 3} & \mathbf{9 0 . 4 8}\end{array}$

HSG $\quad \begin{array}{lllll}51.61 & \mathbf{6 3 . 4 4} & \mathbf{7 4 . 8 6} & \mathbf{8 7 . 3 4}\end{array}$

$\begin{array}{lllll}\mathrm{SC} & 55.98 & 60.27 & \mathbf{7 3 . 1 4} & \mathbf{8 0 . 4 5}\end{array}$

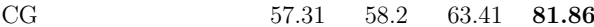

$\begin{array}{lllll}\mathrm{PC} & 46.46 & 48.08 & 53.69 & 70.24\end{array}$

Notes - Married white women, ages 25 - 55. Proportion working at least 20 weekly hours. In bold: women marrying down. 


\section{Appendix C}

\section{Appendix C.1 CPS Data}

Data were taken from the Annual Demographic Survey (March CPS supplement) conducted by the Bureau of Labor Statistics and the Bureau of the Census. A detailed description of the survey can be found at www.bls.census.gov/cps/ads/adsmain.htm. The data was extracted using the Unicon CPS utilities.

The sample is restricted to civilian adults, thus excluding the armed forces and children. We divided the sample into five education groups: high school dropouts (HSD), high school graduates (HSG), individuals with some college education (SC), college graduates (CG), and post-college degree holders (PC). In order to construct the education variable, until 1991 we used the years of schooling completed and added 0.5 years if the individual did not complete the highest grade attended; from 1992 onward we simply used years of schooling completed.

Weekly wages were constructed by taking the previous year's wage and salary income and dividing it by the number of weeks worked in the previous year. Hourly wages are defined as the weekly wage divided by the number of hours worked in the previous week in all jobs, while annual (annualized) wages are defined as the weekly wage multiplied by 52 . Wages are multiplied by 1.75 for top-coded observations until 1995. Nominal wages are deflated using the Personal Consumption Expenditure (PCE) index from the National Income and Product Account (NIPA). Since wages refer to the previous year, we use the PCE for year $X-1$ for observations in year $X$ and therefore all wages are expressed in constant 2010 dollars.

Information on number of children under six for the period 1968-1975, which is missing from the survey data, was imputed where possible using the distributions of this variable in 1967 and 1976 for each gender, marital status, and cohort separately. The imputed information can be used to construct an aggregate trend, though not to identify the number of children for a specific individual.

In order to construct a couple, we kept only heads of households and spouses (i.e., house- 
holds with two families were dropped) and dropped households with more than one male or more than one female. We then merged women and men based on year and household identification, and dropped problematic couples such as those with two heads or two spouses, more than one family, and inconsistent marital status or number of children. To create the sample, we drew from the data all married white females aged 25-55. Individuals are considered employed if they reported working at least 20 hours weekly.

\section{Appendix C.2 NLSY Data}

Data was taken from the National Longitudinal Survey of Youth 1979 (NLSY79), a nationally representative sample of 12,686 men and women who were 14-22 years old at the time of the initial 1979 survey. We focused on the white female members of this sample, a group of 2,477 young women who are meant to be representative of the non-institutionalized civilian segment of the United States population in that age group. Members of this sample were re-interviewed annually from 1979-1994 and bi-annually since then, with the most recent interview being done in 2008 when members of the sample were aged 43-52. The NLSY contains information on marital status, schooling, labor force status (in the past calendar year), income (in the past calendar year) and other socioeconomic indicators, as well as the age, sex, education, labor force status, and income of each co-resident family member, including the spouse.

In the sample, 2,230 (90\%) respondents were or had been married while 247 had never been married. For the purpose of the analysis, the data set was transformed into a panel with multiple observations for each individual. A respondent was considered employed if she reported working at least 25 weeks and 20 hours per week in the past calendar year.

We only included couples who had married during the sample period excluding those married previously, so that we are able to follow a couple from the beginning of the marriage onwards until they get divorced or until observations are right-censored. Of the 2,230 married women, 2,142 got married for the first time during the sample period. Of these, 864 got 
divorced during the sample period. The duration of marriage ranges from 0 to 29 years.

At the time of the woman's first marriage, we calculated the information on variables that remained fixed as long as the respondent remains in the marriage (e.g., age and education of the woman and her husband at the time of marriage). Respondents for whom age and/or education information was missing at the time of marriage for them or their spouse were dropped (29 respondents). We then created a series of observations, one for each completed interview, beginning with the first year of marriage. This series of observations ends either in the year of divorce or in 2008 for women who remained married until then. In addition to the fixed variables, each observation includes employment status and income for both spouses. The final sample of 2,142 women contains a total of 23,622 observations in the panel. Divorce occurrence is captured by a dummy variable that takes the value of one if the respondent divorced during the subsequent interview year. 


\section{Utility Function}

Utility from children - single female $\alpha_{2 W}$

$0.018 \quad(0.000)$

Utility from children - married female $\alpha_{3 W}$

$0.005 \quad(0.005)$

Utility from children - married male $\alpha_{3 H}$

$0.080 \quad(0.080)$

Intertemporal elasticity of substitution $\chi$

$-0.792(0.057)$

\section{Home Production}

Productivity shift from young children in housework $\gamma_{1,0-5} \quad 0.180 \quad(0.034)$

Productivity shift from older children in housework $\gamma_{1,6-18} \quad 0.165 \quad(0.003)$

Productivity shift from young children in market goods $\gamma_{2,0-5} \quad 0.821 \quad(0.022)$

Productivity shift from older children in market goods $\gamma_{2,6-18} \quad 0.831 \quad(0.035)$

Productivity of housework labor $\delta_{W} \quad 4.379 \quad(0.360)$

Elasticity of substitution between housework labor $\quad 0.834 \quad(0.014)$ and market goods $\varsigma$

\section{Fertility Process}

$\begin{array}{lll}\text { Being married } \lambda_{2} & 0.830 & (0.012)\end{array}$

Age interacted with HSG attainment $\lambda_{3}^{H S G} \quad-0.086 \quad(0.007)$

Age interacted with SC attainment $\lambda_{3}^{S C} \quad-0.088 \quad(0.008)$

Age interacted with CG attainment $\lambda_{3}^{C G} \quad-0.093 \quad(0.008)$

Age interacted with PC attainment $\lambda_{3}^{P C} \quad-0.061 \quad(0.001)$

Age squared interacted with HSG attainment $\lambda_{4}^{H S G} \quad 0.000 \quad(0.000)$

Age squared interacted with SC attainment $\lambda_{4}^{S C} \quad 0.001 \quad(0.007)$

Age squared interacted with CG attainment $\lambda_{4}^{C G} \quad 0.001 \quad(0.000)$ 
Table C1 - continued from previous page

\begin{tabular}{|c|c|c|}
\hline Age squared interacted with $\mathrm{PC}$ attainment $\lambda_{4}^{P C}$ & 0.000 & $(0.000)$ \\
\hline Husband's education $\lambda_{5}$ & 0.114 & $(0.034)$ \\
\hline Number of children in the household $\lambda_{6}$ & -0.042 & $(0.001)$ \\
\hline \multicolumn{3}{|l|}{ Wage Process, Female } \\
\hline Returns to experience $\varphi_{2 W}$ & 0.054 & $(0.006)$ \\
\hline Returns to squared experience $\varphi_{3 W}$ & -0.001 & $(0.000)$ \\
\hline HSG returns $\varphi_{4 W}^{H S G}$ & 9.481 & $(0.830)$ \\
\hline $\mathrm{SC}$ returns $\varphi_{4 W}^{S C}$ & 9.636 & $(0.620)$ \\
\hline $\mathrm{CG}$ returns $\varphi_{4 W}^{C G}$ & 10.056 & $(0.278)$ \\
\hline $\mathrm{PC}$ returns $\varphi_{4 W}^{P C}$ & 10.445 & $(0.172)$ \\
\hline Variance of wage shock $\sigma_{\epsilon_{W}}^{2}$ & 0.434 & $(0.010)$ \\
\hline Variance of ability $\sigma_{\varphi_{1 W}}^{2}$ & 0.670 & $(0.012)$ \\
\hline \multicolumn{3}{|l|}{ Wage Process, Male } \\
\hline Returns to experience $\varphi_{2 H}$ & 0.064 & $(0.003)$ \\
\hline Returns to squared experience $\varphi_{3 H}$ & -0.001 & $(0.000)$ \\
\hline HSD returns $\varphi_{4 H}^{H S D}$ & 9.454 & $(0.406)$ \\
\hline HSG returns $\varphi_{4 H}^{H S G}$ & 9.637 & $(0.226)$ \\
\hline $\mathrm{SC}$ returns $\varphi_{4 H}^{S C}$ & 9.805 & $(0.999)$ \\
\hline $\mathrm{CG}$ returns $\varphi_{4 H}^{C G}$ & 10.137 & $(0.512)$ \\
\hline $\mathrm{PC}$ returns $\varphi_{4 H}^{P C}$ & 10.391 & $(0.151)$ \\
\hline Variance of wage shock $\sigma_{\epsilon_{H}}^{2}$ & 0.609 & $(0.039)$ \\
\hline Variance of ability $\sigma_{\varphi_{1 H}}^{2}$ & 0.575 & $(0.008)$ \\
\hline
\end{tabular}




\section{Table C1 - continued from previous page}

\begin{tabular}{|c|c|c|}
\hline \multicolumn{3}{|l|}{ Job Offer, Female } \\
\hline Working previous period $\rho_{1 W}$ & 2.743 & $(0.101)$ \\
\hline HSG $\rho_{2 W}^{H S G}$ & 0.958 & $(0.019)$ \\
\hline $\mathrm{SC} \rho_{2 W}^{S C}$ & 0.051 & $(0.002)$ \\
\hline $\mathrm{CG} \rho_{2 W}^{C G}$ & 0.103 & $(0.006)$ \\
\hline $\mathrm{PC} \rho_{2 W}^{P C}$ & 0.355 & $(0.017)$ \\
\hline Accumulated experience $\rho_{3 W}$ & 0.001 & $(0.000)$ \\
\hline \multicolumn{3}{|l|}{ Match Quality } \\
\hline Probability of meeting a partner $p$ & 0.303 & $(0.008)$ \\
\hline Variance of starting bliss shock $\sigma_{Q}^{2}$ & 1.048 & $(0.125)$ \\
\hline Compatibility benefit - HSG $\theta^{H S G}$ & 1.743 & $(0.117)$ \\
\hline Compatibility benefit - SC $\theta^{S C}$ & 0.080 & $(0.002)$ \\
\hline Compatibility benefit - CG $\theta^{C G}$ & 4.267 & $(0.770)$ \\
\hline Compatibility benefit - PC $\theta^{P C}$ & 4.539 & $(0.109)$ \\
\hline Probability of a positive bliss shock $P_{Q}^{+}$ & 0.233 & $(0.008)$ \\
\hline Probability of a negative bliss shock $P_{Q}^{-}$ & 0.241 & $(0.009)$ \\
\hline
\end{tabular}

Notes - Standard errors in parentheses. Men always work so some male parameters are not estimated. 


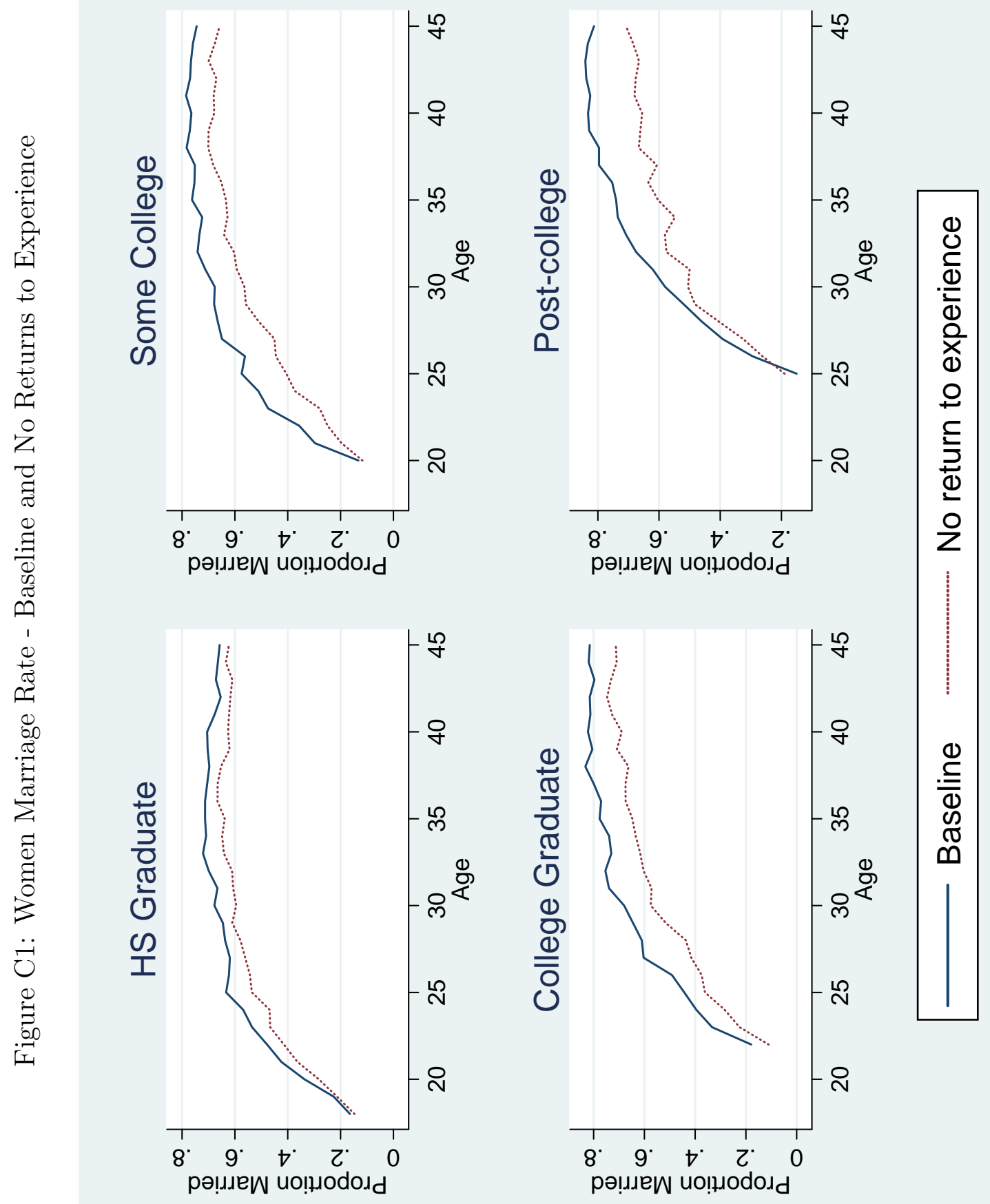




\section{Appendix D Alternative Explanations}

\section{Appendix D.1 Schooling and Non-Market Productivity}

Pencavel (1998) suggests that in more educated couples, the woman tends to work less in order to stay at home with the children. He argues that schooling yields nonmarket as well as market benefits, or more specifically, more schooling indicates higher nonmarket productivity, which is suggested by the advantages conferred on the children of better-educated parents. He estimates a model in which the dependent variable is work hours rather than employment, and includes only the spouse's education rather than the wife's education relative to the husband. The result suggest that in a more educated couple, the husband will work more while the wife will work less, investing more of her leisure time in the couple's (young) children. He also notes that the effect of the spouse's schooling on the individual's labor supply is stronger for couples with young children. This suggests that one should consider interactive effects between the wife's relative level of education and the presence of young children, in addition to the effects already controlled (see Table 3). If a wife's relative level of education is associated with her non-market productivity in the early childrearing years, interaction effects should explain the observed correlation between a wife's relative level of education and her labor supply behavior.

We therefore re-estimated the basic model of female employment, adding an interaction term between the two indicator dummies for the relative education position and the presence of young child children. ${ }^{40}$ Comparing column (1) with column (2) in Table D1, we see that the effect of marrying down or up was slightly reduced but remained sizeable (marginal effect 3.2 and 1.5 percentage points, respectively). The effects are more pronounced for those with young children, particularly in the case of women who married up. The estimates of the interaction terms indicate that a married-up woman might choose to work less in order to invest more time in her children (marginal effect of 3 percentage points). In contrast,

\footnotetext{
${ }^{40} \mathrm{We}$ also estimated the basic model separately for couples with and without children aged 0-6 and obtained similar results.
} 
the effect of young children is not substantial married-down women (marginal effect of 1 percentage point). In conclusion, although children (particularly young ones) play a role in the employment decision of married-up relative to married-down women, the non-market productivity hypothesis is unable to explain the differences in employment rates, suggesting there is room for other explanations. ${ }^{41}$

\section{Appendix D.2 The Unemployment Risk Hypothesis}

Another possible explanation derives from the correlation between the husband's unemployment risk and his education level. We already know that women married to a lesseducated man will choose to work more regardless of his income. However, it may be the case that the woman makes her employment based on the long-term income of the husband rather than his income in the previous period. In this case, if less education is associated with higher employment instability, a woman married to a less-educated man might choose to work more as insurance against the possibility her husband being laid off which is known in the literature as the Added Worker Effect (AWE). In order to test this hypothesis, we created five unemployment indexes to capture the probability of a specific individual being unemployed in a specific year according to the individual's characteristics (occupation, education, age, and industry ${ }^{42}$. The estimated marginal effects of our two main variables of interest when including each of these indexes separately (Table D2, columns (2) through (6)) do not differ significantly from the base model results (column (1)) and the marginal effects of the unemployment indexes are trivial and insignificant. We can conclude that the unemployment risk effect has no marked impact in the static framework, which is in line with

\footnotetext{
${ }^{41}$ Beck and González-Sancho (2009) find a positive impact for marital homogamy on child outcomes. Enhanced levels of parental agreement about the organization of family life and symmetry in the allocation of time to child care emerge as the intervening mechanisms behind this association. In our model, the asymmetry between the behaviour of married-up and married-down women is particularly strong and the comparison between homogamous and heterogamous couples is unable to provide an explanation for the phenomenon.

${ }^{42}$ The unemployment index is defined as the proportion of unemployed individuals in a specific group, e.g., the percentage of unemployed individuals in occupation $x$ in year $y$ will be the probability of becoming unemployed for an individual in occupation $x$ in year $y$.
} 
results in the AWE literature. Empirical studies have generally been unable to uncover a significant magnitude for the AWE (Heckman and MaCurdy, 1980; Lundberg, 1985; Cullen and Gruber, 2000). Heckman and MaCurdy (1980) showed that in a life-cycle context the AWE should be relatively small since the wives of husbands facing greater risk of unemployment will generally work more hours, not necessarily only when their husbands are unemployed. This holds as long as the income loss from a short spell of unemployment is small relative to the husband's lifetime earnings.

\section{Appendix D.3 The Divorce Risk Hypothesis}

Previous research has shown that couples are more likely to divorce when they do not share the same educational background, particularly when it is the wife who has more education. These negative effects appear to have remained unchanged over time and, by some estimates, may have even increased (Heaton, 2002; Teachman, 2002). Given the steady rise in the number of marriages in which wives have more education than their husbands (see 1), one would expect divorce rates to have increased as a result. However, divorce rates have gradually declined after increasing in the late 1970s (Stevenson and Wolfers, 2007). Nevertheless, we decided to test whether the negative coefficient of the education gap perhaps captures a higher probability of divorce. In other words, we wish to test a "precautionary working" hypothesis, according to which married-down women work more in order to increase their experience and therefore their potential earnings in the case of marriage dissolution (Becker et al., 1977). ${ }^{43}$

\section{Data $^{44}$}

We were unable to use the CPS to test this hypothesis, since it does not provide the ex-spouse's education once the individual is divorced. In order to capture the pre-divorce

\footnotetext{
${ }^{43}$ Fernandez and Wong (2011) argue that the increase in the probability of divorce can explain a large proportion of the observed differences in female LFP between the 1935 and 1955 cohorts.

${ }^{44}$ For further details about the data and variable coding, see Appendix C.2
} 
characteristics of the couple, we created a panel from the National Longitudinal Survey of Youth 1979 (NLSY79), a nationally representative sample of 12,686 men and women who were 14-22 years old at the time of the initial 1979 survey. We focus on white female members of the cross-sectional sample which constitute a group a group of 2,477 young women who are meant to be representative of the non-institutionalized civilian segment of the United States population in that age group. Members of this sample were re-interviewed annually from 1979 to 1994 and bi-annually after that, with the most recent available interview conducted in 2008, when members of the sample were aged 43-52. For each interview, the NLSY contains information on marital status, schooling, labor force status (during the past calendar year), income (during the past calendar year) and other socioeconomic variables, as well as the age, sex, education, labor force status, and income of each co-resident family member, including the spouse. A respondent is considered employed if she reported working at least 25 weeks and 20 hours per week in the past calendar year. Of the 2,230 married women in the sample, $864(39 \%)$ became divorced during 1979-2008. The duration of marriage in the sample ranges from 0 to 29 years.

\section{Educational Matching}

Table D4 illustrates the frequencies and percentages of the marriage matching distribution by educational attainment categories at the time of marriage. It can be seen that educational homogamy is most common (49\% - sum of the diagonal). In about $25 \%$ of the couples, the wife is better educated. Extreme differences in education are uncommon: only 9 couples consist of a wife who is three education categories above her husband's (CG wife/ HSD husband and PC wife/ HSD or HSG husband); and 13 couples consist of a husband who is three education categories above his wife's (CG husband/ HSD wife and PC husband/ HSG wife). 


\section{Wife's Employment and Educational Disparity Between the Spouses}

We now wish to determine whether the employment phenomenon observed in the CPS are also found in the NLSY. As in the case of the CPS, we consider white married ${ }^{45}$ women aged 25-55. By age 25, $90 \%$ of them are no longer enrolled in any college/university. We estimate the preferred model specification in Table 3 using the NLSY sample by regressing the wife's employment status on the two dummy variables for whether the female married down or married up and on a set of control variables (standard errors are clustered at the individual level). The results are shown in column (1) of TableD3, and confirm our earlier results. Women that marry down have a higher probability of being employed, even after controlling for husband's income, and the results are highly significant. The estimated logit coefficients indicate that marrying down vs marrying up has an average marginal effect of 6 percentage points, ${ }^{46}$ which implies an increase of about 10 percent in wives' employment rate. ${ }^{47}$ The estimated coefficients of the other independent variables are properly signed and significant: The probability of being employed increases with education and age; the likelihood of employment declines with the husband's annual earnings, the presence of young children, and number of children.

\section{Wife's Relative Educational Position and Divorce Risk}

Table D5 shows the rate at which first marriages dissolve during the sample period for each educational match. The figures indicate that respondents with higher educational attainment tend to have more stable marriages. This is true for both husbands and wives and is strongest for couples in which both members are highly educated (note the pattern

\footnotetext{
${ }^{45}$ We exclude 11 couples that married before the first interview so that the education gap will be at the time of marriage for all couples.

${ }^{46}$ Applying the same sample restrictions, the logit model for married females' employment yielded a remarkably similar marginal effect for married down vs married up of roughly 7 percentage points for the CPS 1960-1965 birth cohorts data (the NLSY79 birth cohorts).

${ }^{47} \mathrm{~A}$ similarly specified regression for male respondents in the panel produces small and statistically insignificant results for the effect of educational disparities between the spouses on the husband's employment status.
} 
along the diagonal). However, the influence of educational disparity is small if it exists at all. The divorce rate for couples in which the wife is more educated than the husband is $38 \%$, compared to $39 \%$ for couples in which the husband is more educated than the wife and $42 \%$ for homogamous couples.

We estimated the probability of divorce in period $t$ given the explanatory variables in $t-1$ using a complementary log-log (cloglog) regression model. ${ }^{48}$ We assumed a non-parametric baseline and created duration-specific dummy variables, one for each spell year at risk. The analysis focuses on the effects of the wife's relative educational position on the risk of divorce. We defined, as above, two dummy variables for whether the husband is more educated than the wife or vice versa (couples with same level of education are the control group). We further included a set of variables to control for various other factors that may influence the risk of divorce: Indicators for the wife's and the husband's education; wife's age; both spouses' income deciles; age gap at marriage (husband's - wife's); the number of children; and the presence of young children.

Table D6 presents the results. The standard errors reported in the table allow for arbitrary correlation between the disturbance terms within a couple (cluster). The impact of educational disparities between the spouses on the risk of divorce has a negligible and insignificant effect. The effects of the other control variables are consistent with the literature that discusses the possible causes for marital instability (Becker et al., 1977). Getting married later (for the first time) is stability-enhancing (Rotz, 2011), since women who get married later tend to have spent more time searching for the best matches and/or have gathered more information about their future spouses. This group of women should experience less post-marriage shocks and therefore have lower chance of getting divorced. The age gap between the spouses has a positive but insignificant effect. The presence of children reduces the probability of divorce since it implies the accumulation of marriage-specific capital, which would be worth less in any other marriage or when divorced. As expected,

\footnotetext{
${ }^{48}$ Results do not differ qualitatively for a logit model.
} 
own and spouse's education level have a negative effect on divorce risk. A higher level of education is a predictor of a partner's high levels of market and non-market skills. Thus, higher-educated couples gain more from marriage relatively to the less-educated couples and their risk of divorce is therefore lower.

The results using the NLSY indicate that the wife's relative education level does not affect the risk of divorce, and therefore, the divorce risk hypothesis is not confirmed.

\section{Appendix D.4 Selection}

We now attempt to determine whether a couple's pre-marriage characteristics (ability, expectations or attitudes) can explain observed behavior patterns. In this section, we will try to address the question of whether there is selection into marriage: assume two types of women: women who derive utility from consumption only and women who derive utility from consumption and work both. ${ }^{49}$ The latter type of women may choose to marry a lesseducated husband in order to be the main breadwinner in the household. On the other hand, we can also assume two types of men in the population: One preferring to more-educated women and the other preferring less-educated women. It is impossible, of course, to test those assumptions directly since the type of the individual is unobserved. Therefore, we will use observed pre-marriage characteristics of the couple that might be correlated with the unobserved type of the individual. Comparing the characteristics of the married-up women with those of the married-down women will help us decide whether selection into marriage exists. In this exercise, we will use both the CPS and NLSY data used in the previous chapters (which are described in detail in Appendix C).

\section{Pre-marriage Characteristics of the Women}

In order to test female selection into marriage, we examined pre-marriage variables that may be correlated with the unobserved work preferences of the women. We start with the

\footnotetext{
${ }^{49}$ The difference between the two types can be in preferences toward work, children, leisure and so on.
} 
age of marriage, assuming that a woman who married later might have more experience and therefore higher earning power and a higher probability of being employed. Overall, the data show that although higher-educated women married later, there was no significant difference in age between married-up and married-down women at marriage (see Table D7). The average age of marriage for HS dropouts was below 20 as compared to an average of above 31 for post-graduates, however, at each education level, married-down women got married a year earlier than married-up women. In addition, we observe that women marrying down married younger husbands (a year and a half younger relative to the married-up group).

We then wish to determine whether the reason married-down women work more is because of their higher unobserved ability. We used the average score on the AFQT, as a measure of underlying ability. As shown in Table D8, it turns out that married-down women have lower average scores married-up women. In each education group, the women with higher scores married more educated husbands relative to women with lower scores, which is not a surprising. Nevertheless, it fails to explain why women with lower scores will have higher employment rates.

We next determine whether there is a difference in the preference for children between the two "types" of women, namely, whether a woman who plans a big family might choose a more educated husband, thus enabling her to work less. The NLSY79 survey contained a direct fertility expectation question in several interviews. ${ }^{50}$ Respondents were asked how many children they actually expected to have, which is considered a good predictor of future fertility outcomes. As shown in Table D9, conditional on the female's education category, there are no significant differences in mean expected number of children across the three match types (married up, equal, and down). These data are drawn for the survey year closest to the year in which the respondent was $21 .^{51}$ We then looked at differences in actual number of children at age of 40 (Table D10) by which time most women had finished

\footnotetext{
${ }^{50}$ The survey question read: "Altogether, how many (more) children do you expect to have?" For those women who already had children, the (total) expected number of children is given by expected number of children plus the number of children already born.

${ }^{51}$ The respondent may be as young as 19 or as old as 23 .
} 
childbearing. No significant variation was found in the average number of children in the household. We also carried out this analysis using the CPS sample and reached the same conclusion.

A concern arises that this is a classic case of selection on women's attitudes towards their role in the household. The NLSY survey elicits the individual's opinion towards a woman's role in homemaking and in the labor market. In the 1979, 1982, 1987 and 2004 interviews, respondents are asked whether they strongly disagree (1), disagree (2), agree (3) or strongly agree (4) with various statements on this subject. Among them, the most straightforward statement was the following: "A woman's place is in the home, not in the office or shop". Table D11 displays the mean response according to the woman's relative educational position and her education level based on the survey closest to the year in which the respondent was 21 (as above). The table reveals no substantial variation in opinion across the categories of married-up, equal or down, given their respective education level. The responses also indicate that a lower education level is associated with "more traditional" views, i.e., women should specialise in home production and men in market production. ${ }^{52}$

Finally, a probit model (Table D12) for each female education group was estimated for an indicator of being married-down in order to test the relevance of various attributes. In addition to AFQT, number of expected children and attitude towards a woman's role, we added a measure of physical attractiveness (proxied by BMI ${ }^{53}$ ). The results are consistent with previous results: AFQT is negatively and significantly correlated with marrying down while attitudes and expected number of children are not relevant. There is some evidence among women with some college education and women who are college graduates that married-down women are more likely to be overweight or obese. However, BMI had no significant effect in the employment equation.

\footnotetext{
${ }^{52}$ Responses to other similar statements revealed similar patterns.

${ }^{53}$ Height and weight measures were used to calculate body mass index (BMI), which was then categorized as underweight $(<18.5)$, normal weight $(>=18.5$ and $<25)$, overweight $(>=25$ and $<30)$, and obese $(>=30)$. The data used were drawn from the survey year closest to the year in which the respondent was 21.
} 


\section{Pre-marriage Characteristics of Men}

We wish to determine whether more educated husbands have different characteristics, which lead to their wives working less. We are interested in whether the male marriage premium differs for men that marry up compared to those that marry equally or down. Although we have already ruled out the husband's income as playing a large role, if any, in the wife's employment decision, we nonetheless estimate a log wage regression for the husband while controlling for the type of woman he married. Virtually all studies find that married men tend to earn significantly more than single men, with estimates of the marriage premium usually exceeding 10 percent, depending on the time period, sample, and model specification (Goldin, 1990; Gray, 1997). Using the CPS data for only married men we estimated the coefficient of a dummy variable indicating for "married-up" in a log wage regression. Marriage is coded into three separate categories (married up, down and equal) and the comparison is made between those who married equal and those who married down. ${ }^{54}$ As shown in Table D14, the results indicate that husbands married to a more educated wife earn $5 \%$ more per hour, with homogamous marriages as the reference group. This is consistent with the mean AFQT scores (Table D13) for male respondents in the NLSY sample. Notice the higher mean score among men marrying up (females marrying down) conditional on educational attainment, while the average score increases monotonically with education level. This suggests that the male marriage premium mirrors the marriage selection pattern. Thus, an educated woman might choose to marry a less-educated man if his level of ability is higher than other man in the same education group. While this finding can help us to rationalize the match, it can't explain why those women are working more. Put together, Tables D8 and D13 indicate the positive assortative mating on AFQT since those with the relative lower (higher) ability within an education group are matching with their "equals",

\footnotetext{
${ }^{54}$ Control variables include education, a full-time full-year indicator, and potential experience (ageeducation-6) quartic. The presence of children is controlled for by including two dummy variables: a child younger than 6 in the family and the total number of children in the family. Other controls include dummy variables for the survey year and MSA fixed effects.
} 
i.e., those from a lower (higher) education group yet with the higher (lower) relative ability within their group. 
Table D1: Estimated Effects Including Interactions

\begin{tabular}{|c|c|c|}
\hline VARIABLES & (1) & $(2)$ \\
\hline Female married down (d) & $\begin{array}{c}0.037 * * * \\
(0.003)\end{array}$ & $\begin{array}{c}0.032 * * * \\
(0.003)\end{array}$ \\
\hline Female married up (d) & $\begin{array}{c}-0.023^{* * *} \\
(0.003)\end{array}$ & $\begin{array}{c}-0.015^{* * *} \\
(0.003)\end{array}$ \\
\hline F married down $X$ presence of child $0-6$ & & $\begin{array}{c}0.012^{* * *} \\
(0.004)\end{array}$ \\
\hline F marriedup $\mathrm{X}$ presence of child $0-6$ & & $\begin{array}{c}-0.032^{* * *} \\
(0.004)\end{array}$ \\
\hline Female post graduate (d) & $\begin{array}{c}0.293 * * * \\
(0.006)\end{array}$ & $\begin{array}{c}0.297^{* * *} \\
(0.006)\end{array}$ \\
\hline Female college graduate $(\mathrm{d})$ & $\begin{array}{c}0.204^{* * *} \\
(0.006)\end{array}$ & $\begin{array}{c}0.209^{* * *} \\
(0.006)\end{array}$ \\
\hline Female some college $(d)$ & $\begin{array}{c}0.162^{* * *} \\
(0.005)\end{array}$ & $\begin{array}{c}0.167^{* * *} \\
(0.005)\end{array}$ \\
\hline Female high school graduate (d) & $\begin{array}{c}0.111^{* * *} \\
(0.004)\end{array}$ & $\begin{array}{c}0.114^{* * *} \\
(0.004)\end{array}$ \\
\hline Age & $\begin{array}{l}-0.003^{*} \\
(0.002)\end{array}$ & $\begin{array}{r}-0.003^{*} \\
(0.002)\end{array}$ \\
\hline Age gap & $\begin{array}{l}-0.001 \\
(0.000)\end{array}$ & $\begin{array}{l}-0.001^{*} \\
(0.000)\end{array}$ \\
\hline Number of children in the $\mathrm{HH}$ & $\begin{array}{l}-0.043^{*} \\
(0.025)\end{array}$ & $\begin{array}{c}-0.043^{*} \\
(0.025)\end{array}$ \\
\hline Presence of a child $0-6$ & $\begin{array}{c}-0.233^{* * *} \\
(0.002)\end{array}$ & $\begin{array}{c}-0.228^{* * *} \\
(0.002)\end{array}$ \\
\hline Male post graduate $(\mathrm{d})$ & $\begin{array}{c}0.029^{* * *} \\
(0.008)\end{array}$ & $\begin{array}{c}0.023^{* * *} \\
(0.008)\end{array}$ \\
\hline Male college graduate $(\mathrm{d})$ & $\begin{array}{c}0.059^{* * *} \\
(0.006)\end{array}$ & $\begin{array}{c}0.053^{* * *} \\
(0.007)\end{array}$ \\
\hline Male some college (d) & $\begin{array}{c}0.096^{* * *} \\
(0.005)\end{array}$ & $\begin{array}{c}0.090^{* * *} \\
(0.005)\end{array}$ \\
\hline Male high school graduate (d) & $\begin{array}{c}0.059^{* * *} \\
(0.004)\end{array}$ & $\begin{array}{c}0.055^{* * *} \\
(0.004)\end{array}$ \\
\hline $\begin{array}{l}\text { Dummies for the deciles of } \\
\text { Husband's annual income }\end{array}$ & YES & YES \\
\hline Time dummies & YES & YES \\
\hline MSA fixed effects & YES & YES \\
\hline Observations & 681,503 & 681,503 \\
\hline
\end{tabular}

Notes - Married white women, ages 25 - 55. Employment indicator is one when working at least 20 weekly hours. Marginal effects (instead of logit coefficients) are reported. ${ }^{* * *} \mathrm{p}<0.01,{ }^{* *} \mathrm{p}<0.05,{ }^{*} \mathrm{p}<0.1$. (d) for dummy variable. Reference education group: HSD. Column (1) is identical to column (6) in table 3 (the preferred specification) and is reproduced here to facilitate comparison. 
Table D2: Estimated Effects Including Unemployment Indexes

\begin{tabular}{|c|c|c|c|c|c|c|}
\hline VARIABLES & (1) & $(2)$ & (3) & (4) & (5) & (6) \\
\hline Female married down $(\mathrm{d})$ & $\begin{array}{c}0.037^{* * *} \\
(0.003)\end{array}$ & $\begin{array}{c}0.040^{* * *} \\
(0.003)\end{array}$ & $\begin{array}{c}0.040^{* * *} \\
(0.003)\end{array}$ & $\begin{array}{c}0.041^{* * *} \\
(0.003)\end{array}$ & $\begin{array}{c}0.040^{* * *} \\
(0.003)\end{array}$ & $\begin{array}{c}0.040^{* * *} \\
(0.003)\end{array}$ \\
\hline Female married up (d) & $\begin{array}{c}-0.023^{* * *} \\
(0.003)\end{array}$ & $\begin{array}{c}-0.025 * * * \\
(0.003)\end{array}$ & $\begin{array}{c}-0.024^{* * *} \\
(0.003)\end{array}$ & $\begin{array}{c}-0.024^{* * *} \\
(0.003)\end{array}$ & $\begin{array}{c}-0.024^{* * * *} \\
(0.003)\end{array}$ & $\begin{array}{c}-0.024 * * * \\
(0.003)\end{array}$ \\
\hline Occupation unempl index & & $\begin{array}{l}-0.003 \\
(0.002)\end{array}$ & & & & \\
\hline Industry-Occupation unempl index & & & $\begin{array}{l}-0.001 \\
(0.000)\end{array}$ & & & \\
\hline Industry unempl index & & & & $\begin{array}{c}-0.003 \\
(0.002)\end{array}$ & & \\
\hline Occupation-Age-Education unempl index & & & & & $\begin{array}{l}-0.000 \\
(0.000)\end{array}$ & \\
\hline Age-Education unempl index & & & & & & $\begin{array}{l}-0.001 \\
(0.001)\end{array}$ \\
\hline $\begin{array}{l}\text { Dummies for the deciles of } \\
\text { Husband's annual income }\end{array}$ & YES & YES & YES & YES & YES & YES \\
\hline Time dummies & YES & YES & YES & YES & YES & YES \\
\hline MSA fixed effects & YES & YES & YES & YES & YES & YES \\
\hline Observations & 681,503 & 681,503 & 681,503 & 681,503 & 681,503 & 681,503 \\
\hline
\end{tabular}

Notes - Married white women, ages 25 - 55. Employment indicator is one when working at least 20 weekly hours. Marginal effects (instead of logit coefficients) are reported. All models include indicators for own and spouse education, own age, age gap, number of children in the $\mathrm{HH}$ and an indicator for the presence of a child $0-6 .{ }^{* * *} \mathrm{p}<0.01,{ }^{* *} \mathrm{p}<0.05,{ }^{*} \mathrm{p}<0.1$. (d) for dummy variable. Reference education group: HSD. Column (1) is identical to column (6) in table 3 (the preferred specification) and is reproduced here to facilitate comparison. 
Table D3: NLSY - Logit Regression on Employment for Married Age 25-55

\begin{tabular}{|c|c|}
\hline VARIABLES & $\begin{array}{c}(1) \\
\text { Married } \\
\text { Females }\end{array}$ \\
\hline Female married down (d) & $\begin{array}{c}0.357^{* *} \\
(0.180)\end{array}$ \\
\hline Female married up (d) & $\begin{array}{c}-0.081 \\
(0.175)\end{array}$ \\
\hline Female post graduate $(\mathrm{d})$ & $\begin{array}{l}1.010^{*} \\
(0.528)\end{array}$ \\
\hline Female college graduate $(\mathrm{d})$ & $\begin{array}{c}1.084^{* * *} \\
(0.382)\end{array}$ \\
\hline Female some college $(\mathrm{d})$ & $\begin{array}{c}0.860 * * * \\
(0.298)\end{array}$ \\
\hline Female high school graduate $(d)$ & $\begin{array}{c}0.707 * * * \\
(0.192)\end{array}$ \\
\hline Age & $\begin{array}{l}-0.011 \\
(0.018)\end{array}$ \\
\hline Age gap & $\begin{array}{l}-0.006 \\
(0.010)\end{array}$ \\
\hline Number of children in the $\mathrm{HH}$ & $\begin{array}{c}-0.400^{* * *} \\
(0.035)\end{array}$ \\
\hline Presence of a child $0-6$ & $\begin{array}{c}-0.874^{* * *} \\
(0.062)\end{array}$ \\
\hline Male post graduate $(\mathrm{d})$ & $\begin{array}{c}0.043 \\
(0.499)\end{array}$ \\
\hline Male college graduate $(d)$ & $\begin{array}{c}0.079 \\
(0.391)\end{array}$ \\
\hline Male some college $(\mathrm{d})$ & $\begin{array}{l}-0.004 \\
(0.304)\end{array}$ \\
\hline Male high school graduate (d) & $\begin{array}{c}0.004 \\
(0.194)\end{array}$ \\
\hline $\begin{array}{l}\text { Dummies for the deciles of } \\
\text { spouse's annual income }\end{array}$ & YES \\
\hline Time dummies & YES \\
\hline Observations & 18,460 \\
\hline
\end{tabular}

Notes - Standard errors are corrected for clustering within individual - 1,823. ${ }^{* * *} \mathrm{p}<0.01,{ }^{* *} \mathrm{p}<0.05,{ }^{*} \mathrm{p}<0.1$. (d) for dummy variable. Reference groups: High school dropouts; Females married homogamously. 
Table D4: NLSY - Distribution of Marital Matching by Education

\begin{tabular}{lccccc|c}
\hline \hline Wife's & \multicolumn{7}{c}{ Husband's Education } \\
Education & HSD & HSG & SC & CG & PC & Total \\
& & & & & & \\
\hline \multirow{2}{*}{ High School Dropout (HSD) } & 130 & 131 & 20 & 4 & 0 & 285 \\
& 6.07 & 6.12 & 0.93 & 0.19 & 0.00 & 13.31 \\
High School Graduate (HS) & 150 & 571 & 160 & 53 & 9 & 943 \\
& 7.00 & 26.66 & 7.47 & 2.47 & 0.42 & 44.02 \\
Some College (SC) & 25 & 173 & 135 & 97 & 24 & 454 \\
& 1.17 & 8.08 & 6.30 & 4.53 & 1.12 & 21.20 \\
College Graduate (CG) & 4 & 63 & 72 & 178 & 62 & 379 \\
& 0.19 & 2.94 & 3.36 & 8.31 & 2.89 & 17.69 \\
Post College Degree (PC) & 1 & 5 & 15 & 27 & 33 & 81 \\
& 0.05 & 0.23 & 0.70 & 1.26 & 1.54 & 3.78 \\
& & & & & & \\
\hline \multirow{2}{*}{ Total } & 310 & 943 & 402 & 359 & 128 & 2142 \\
& 14.47 & 44.02 & 18.77 & 16.76 & 5.98 & 100.00 \\
\hline \hline
\end{tabular}

Notes - First row reports the number of observations. Second row shows the cell percentage 
Table D5: NLSY - Proportion of Marriages that Dissolve by Educational Matching

\begin{tabular}{lccccc|c}
\hline \hline Wife's & \multicolumn{7}{c}{ Husband's Education } \\
Education & HSD & HSG & SC & CG & PC & Total \\
& & & & & & \\
\hline High School Dropout (HSD) & $\mathbf{0 . 6 8}$ & 0.54 & 0.65 & 0.75 &. & 0.61 \\
& 130 & 131 & 20 & 4 & 0 & 285 \\
High School Graduate (HS) & 0.57 & $\mathbf{0 . 4 4}$ & 0.43 & 0.30 & 0.22 & 0.45 \\
& 150 & 571 & 160 & 53 & 9 & 943 \\
Some College (SC) & 0.40 & 0.38 & $\mathbf{0 . 4 3}$ & 0.30 & 0.17 & 0.37 \\
& 25 & 173 & 135 & 97 & 24 & 454 \\
College Graduate (CG) & 0.25 & 0.25 & 0.22 & $\mathbf{0 . 2 2}$ & 0.16 & 0.22 \\
& 4 & 63 & 72 & 178 & 62 & 379 \\
College Graduate (CG) & 1.00 & 0.00 & 0.40 & 0.15 & $\mathbf{0 . 0 9}$ & 0.17 \\
& 1 & 5 & 15 & 27 & 33 & 81 \\
\hline \multirow{2}{*}{ Total } & & & & & & \\
& & & & & & \\
& 310 & 943 & 402 & 359 & 128 & 2142 \\
\hline \hline
\end{tabular}

Notes - In each cell, first row shows the probability of marriage termination for first marriages. Second row reports the number of observations. 
Table D6: NLSY - Cloglog Estimates on Probability of Divorce, First Marriages Only

\begin{tabular}{|c|c|c|c|}
\hline VARIABLES & (1) & (2) & (3) \\
\hline Female married down (d) & $\begin{array}{l}0.183^{*} \\
(0.093)\end{array}$ & $\begin{array}{l}-0.056 \\
(0.179)\end{array}$ & \\
\hline Female married up (d) & $\begin{array}{l}-0.158^{*} \\
(0.091)\end{array}$ & $\begin{array}{c}0.004 \\
(0.180)\end{array}$ & \\
\hline Female post graduate (d) & $\begin{array}{c}-0.937^{* * *} \\
(0.309)\end{array}$ & $\begin{array}{l}-0.321 \\
(0.589)\end{array}$ & $\begin{array}{l}-0.408 \\
(0.325)\end{array}$ \\
\hline Female college graduate $(\mathrm{d})$ & $\begin{array}{c}-1.086^{* * *} \\
(0.160)\end{array}$ & $\begin{array}{l}-0.637 \\
(0.411)\end{array}$ & $\begin{array}{c}-0.702^{* * *} \\
(0.168)\end{array}$ \\
\hline Female some college (d) & $\begin{array}{c}-0.598^{* * *} \\
(0.134)\end{array}$ & $\begin{array}{l}-0.269 \\
(0.303)\end{array}$ & $\begin{array}{c}-0.321^{* *} \\
(0.133)\end{array}$ \\
\hline Female high school graduate (d) & $\begin{array}{c}-0.368^{* * *} \\
(0.104)\end{array}$ & $\begin{array}{l}-0.160 \\
(0.180)\end{array}$ & $\begin{array}{c}-0.184^{*} \\
(0.103)\end{array}$ \\
\hline Age at marriage & $\begin{array}{c}-0.037^{* * *} \\
(0.011)\end{array}$ & $\begin{array}{c}-0.040^{* * *} \\
(0.011)\end{array}$ & $\begin{array}{c}-0.040^{* * *} \\
(0.011)\end{array}$ \\
\hline Age gap & $\begin{array}{c}0.010 \\
(0.008)\end{array}$ & $\begin{array}{c}0.009 \\
(0.008)\end{array}$ & $\begin{array}{c}0.009 \\
(0.008)\end{array}$ \\
\hline Number of children in the $\mathrm{HH}$ & $\begin{array}{c}-0.153^{* * *} \\
(0.049)\end{array}$ & $\begin{array}{c}-0.133^{* * *} \\
(0.049)\end{array}$ & $\begin{array}{c}-0.133^{* * *} \\
(0.049)\end{array}$ \\
\hline Presence of a child $0-6$ & $\begin{array}{l}-0.063 \\
(0.093)\end{array}$ & $\begin{array}{l}-0.009 \\
(0.093)\end{array}$ & $\begin{array}{l}-0.010 \\
(0.093)\end{array}$ \\
\hline Male PC (d) & & $\begin{array}{l}-0.840 \\
(0.544)\end{array}$ & $\begin{array}{c}-0.759^{* * *} \\
(0.271)\end{array}$ \\
\hline Male CG (d) & & $\begin{array}{l}-0.510 \\
(0.406)\end{array}$ & $\begin{array}{c}-0.443^{* * *} \\
(0.157)\end{array}$ \\
\hline Male SC (d) & & $\begin{array}{l}-0.190 \\
(0.299)\end{array}$ & $\begin{array}{l}-0.142 \\
(0.124)\end{array}$ \\
\hline Male HSG (d) & & $\begin{array}{c}-0.326^{*} \\
(0.176)\end{array}$ & $\begin{array}{c}-0.296^{* * *} \\
(0.098)\end{array}$ \\
\hline $\begin{array}{l}\text { Dummies for the deciles of } \\
\text { spouse's annual income }\end{array}$ & NO & YES & YES \\
\hline $\begin{array}{l}\text { Dummies for the deciles of } \\
\text { wife's annual income }\end{array}$ & NO & YES & YES \\
\hline Marriage duration dummies & YES & YES & YES \\
\hline Observations & 23,622 & 23,622 & 23,622 \\
\hline Clusters & 2,142 & 2,142 & 2,142 \\
\hline
\end{tabular}

Notes - Standard errors are corrected for clustering within couples; ${ }^{* *} \mathrm{p}<0.01,{ }^{* *} \mathrm{p}<0.05,{ }^{*} \mathrm{p}<0.1$. (d) for dummy variable. Reference groups: High school dropouts; Females married homogamously. 


\section{Table D7: NLSY - Mean Age at Marriage}

\begin{tabular}{lccc|c}
\hline \hline & \multicolumn{4}{c}{ Relative Position in Education } \\
$\begin{array}{l}\text { Wife's } \\
\text { Education }\end{array}$ & Married down & Married equal & Married up & Total \\
\hline HS dropout & NA & 19.13 & 20.18 & 19.70 \\
HS graduate & 22.19 & 22.41 & 23.80 & 22.70 \\
Some college & 24.20 & 23.87 & 26.07 & 24.60 \\
College graduate & 26.76 & 26.10 & 28.23 & 26.69 \\
Post-graduate & 31.04 & 31.85 & $\mathrm{NA}$ & 31.37 \\
\hline Total & 24.92 & 23.12 & 23.78 & 23.74 \\
\hline \hline
\end{tabular}

Notes -

Table D8: NLSY - Mean Wives' AFQT Score

\begin{tabular}{lccc|c}
\hline \hline & \multicolumn{4}{c}{ Relative Position in Education } \\
$\begin{array}{l}\text { Wife's } \\
\text { Education }\end{array}$ & Married down & Married equal & Married up & Total \\
\hline HS dropout & NA & 28,487 & 30,396 & 29,517 \\
HS graduate & 40,505 & 46,850 & 49,642 & 46,514 \\
Some college & 61,935 & 64,233 & 67,135 & 63,986 \\
College graduate & 76,438 & 78,569 & 82,348 & 78,408 \\
Post-graduate & 82,022 & 82,863 & NA & 82,369 \\
\hline \hline
\end{tabular}

Notes - 
Table D9: NLSY - Mean Expected Number of Children

\begin{tabular}{lccc|c}
\hline \hline & \multicolumn{3}{c}{ Relative Position in Education } \\
$\begin{array}{l}\text { Wife's } \\
\text { Education }\end{array}$ & Married down & Married equal & Married up & Total \\
\hline HS dropout & NA & 1.20 & 1.27 & 1.24 \\
HS graduate & 1.95 & 2.02 & 2.11 & 2.03 \\
Some college & 2.04 & 2.27 & 2.49 & 2.23 \\
College graduate & 2.34 & 2.65 & 2.50 & 2.51 \\
Post-graduate & 2.27 & 2.24 & NA & 2.26 \\
\hline Total & & & & \\
\hline \hline
\end{tabular}

Notes -

Table D10: NLSY - Mean Actual Number of Children

\begin{tabular}{lccc|c}
\hline \hline & \multicolumn{3}{c}{ Relative Position in Education } \\
$\begin{array}{l}\text { Wife's } \\
\text { Education }\end{array}$ & Married down & Married equal & Married up & Total \\
\hline HS dropout & NA & 1.04 & 1.20 & 1.14 \\
HS graduate & 1.47 & 1.65 & 1.86 & 1.68 \\
Some college & 1.74 & 2.00 & 1.92 & 1.86 \\
College graduate & 1.94 & 2.13 & 2.05 & 2.05 \\
Post-graduate & 1.33 & 1.61 & NA & 1.45 \\
\hline Total & 1.71 & & & \\
\hline \hline
\end{tabular}

Notes - In 2004, when the youngest women in the sample completed their 40th birthday, most women were with completed fertility. The oldest female in that survey year was 47 years of age. 
Table D11: NLSY - Gender Role Attitudes Mean Score at Age 21

\begin{tabular}{lccc|c}
\hline \hline & \multicolumn{4}{c}{ Relative Position in Education } \\
$\begin{array}{l}\text { Wife's } \\
\text { Education }\end{array}$ & Married down & Married equal & Married up & Total \\
\hline HS dropout & $\mathrm{NA}$ & 1.86 & 1.85 & 1.85 \\
HS graduate & 1.84 & 1.79 & 1.66 & 1.77 \\
Some college & 1.59 & 1.77 & 1.53 & 1.62 \\
College graduate & 1.45 & 1.46 & 1.44 & 1.45 \\
Post-graduate & 1.29 & 1.28 & $\mathrm{NA}$ & 1.29 \\
\hline \hline
\end{tabular}

Notes -

Table D12: Probit Estimates by Education Group (Dependent Variable: Marrying Down)

\begin{tabular}{|c|c|c|c|c|}
\hline VARIABLES & $\begin{array}{c}(1) \\
\text { High School } \\
\text { Graduate }\end{array}$ & $\begin{array}{c}(2) \\
\text { Some } \\
\text { College }\end{array}$ & $\begin{array}{c}(3) \\
\text { College } \\
\text { Graduate }\end{array}$ & $\begin{array}{c}(4) \\
\text { Post- } \\
\text { Graduate }\end{array}$ \\
\hline AFQT (in thousands) & $\begin{array}{c}-0.006^{* *} \\
(0.002)\end{array}$ & $\begin{array}{c}-0.006^{* *} \\
(0.003)\end{array}$ & $\begin{array}{c}-0.007^{*} \\
(0.004)\end{array}$ & $\begin{array}{c}0.005 \\
(0.010)\end{array}$ \\
\hline Gender role Attitudes & $\begin{array}{c}0.094 \\
(0.070)\end{array}$ & $\begin{array}{l}-0.109 \\
(0.086)\end{array}$ & $\begin{array}{l}-0.007 \\
(0.117)\end{array}$ & $\begin{array}{c}0.175 \\
(0.314)\end{array}$ \\
\hline Children expectations & $\begin{array}{l}-0.012 \\
(0.042)\end{array}$ & $\begin{array}{c}-0.099^{* *} \\
(0.049)\end{array}$ & $\begin{array}{l}-0.078 \\
(0.051)\end{array}$ & $\begin{array}{c}0.004 \\
(0.117)\end{array}$ \\
\hline Underweight & $\begin{array}{l}-0.028 \\
(0.180)\end{array}$ & $\begin{array}{l}-0.187 \\
(0.197)\end{array}$ & $\begin{array}{c}-0.498^{*} \\
(0.276)\end{array}$ & $\begin{array}{c}0.438 \\
(0.452)\end{array}$ \\
\hline Overweight & $\begin{array}{c}0.197 \\
(0.151)\end{array}$ & $\begin{array}{c}0.416^{* *} \\
(0.204)\end{array}$ & $\begin{array}{c}0.725 * * \\
(0.290)\end{array}$ & \\
\hline Obese & $\begin{array}{c}0.364 \\
(0.230)\end{array}$ & $\begin{array}{c}0.507 \\
(0.495)\end{array}$ & $\begin{array}{c}1.021^{* *} \\
(0.511)\end{array}$ & \\
\hline Observations & 873 & 423 & 354 & 72 \\
\hline
\end{tabular}

Notes - Married white women, first marriages. ${ }^{* * *} \mathrm{p}<0.01,{ }^{* *} \mathrm{p}<0.05,{ }^{*} \mathrm{p}<0.1$. 


\section{Table D13: NLSY - Mean Husbands' AFQT Score}

\begin{tabular}{lccc|c}
\hline \hline & \multicolumn{4}{c}{ Relative Position in Education } \\
$\begin{array}{l}\text { Husband's } \\
\text { Education }\end{array}$ & Married down & Married equal & Married up & Total \\
\hline HS dropout & $\mathrm{NA}$ & 17,988 & 23,782 & 21,286 \\
HS graduate & 40,184 & 43,915 & 49,500 & 44,740 \\
Some college & 60,114 & 63,532 & 66,001 & 62,552 \\
College graduate & 74,462 & 79,375 & 85,830 & 77,874 \\
Post-graduate & 82,604 & 92,123 & NA & 85,079 \\
\hline \hline
\end{tabular}

Notes - Married respondents men in the sample. Men who marry down (up) are men that marry women of lower (higher) education level than themselves. A male marrying down means that the female marry up, and vice versa.

Table D14: CPS - Log Hourly Wage for Married Men

\begin{tabular}{lc}
\hline \hline & $(1)$ \\
VARIABLES & \\
& \\
\hline Male married up (d) & $\mathbf{0 . 0 4 7 * * *}$ \\
& $(\mathbf{0 . 0 0 2})$ \\
Male married down (d) & $\mathbf{- 0 . 0 5 7 ^ { * * * }}$ \\
& $\mathbf{( 0 . 0 0 2 )}$ \\
Male post graduate (d) & $0.896^{* * *}$ \\
& $(0.005)$ \\
Male college graduate (d) & $0.772^{* * *}$ \\
& $(0.004)$ \\
Male some college (d) & $0.509^{* * *}$ \\
& $(0.004)$ \\
Male high school graduate (d) & $0.303^{* * *}$ \\
& $(0.004)$ \\
Time dummies & YES \\
MSA fixed effects & YES \\
Observations & 551,505 \\
\hline \hline
\end{tabular}

Notes - ${ }^{* * *} \mathrm{p}<0.01,{ }^{* *} \mathrm{p}<0.05,{ }^{*} \mathrm{p}<0.1$. (d) for dummy variable. Sample consists of husbands married to white females aged 25-55. Reference groups: High school dropouts; Males married homogamously. Model includes: education category indicators, full time full year indicator, and potential experience (age-education-6) quartic. The presence of children is controlled with two dummy variables: a child younger than 6 in the family and the number of children in the family. 